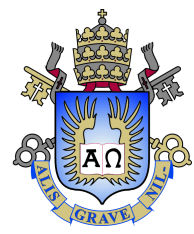

Henrique Rodrigues da Mota

Mobile broadband expansion and tasks: Evidence from Brazilian formal labor markets

Thesis presented to the Programa de Pós-graduação em Economia, do Departamento de Economia da PUC-Rio in partial fulfillment of the requirements for the degree of Mestre em Economia.

Advisor : Prof. Gustavo Gonzaga

Co-advisor: Francisco Cavalcanti 


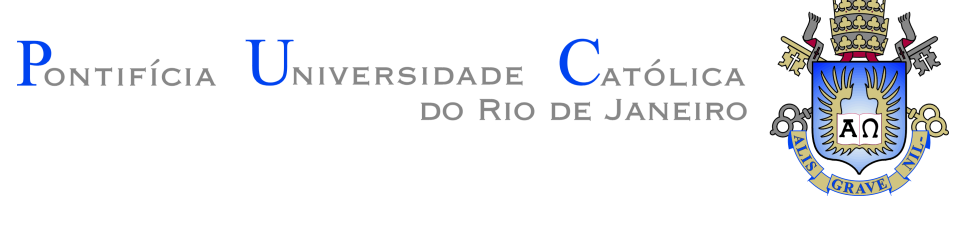

Henrique Rodrigues da Mota

\section{Mobile broadband expansion and tasks: Evidence from Brazilian formal labor markets}

Thesis presented to the Programa de Pós-graduação em Economia da PUC-Rio in partial fulfillment of the requirements for the degree of Mestre em Economia. Approved by the Examination Committee:

Prof. Gustavo Gonzaga

Advisor

Departamento de Economia - PUC-Rio

Francisco Cavalcanti

Co-advisor

Pontifícia Universidade Católica do Rio de Janeiro - PUC-Rio

Rita K. Almeida World Bank

Prof. Gabriel Ulyssea

UCL

Rio de Janeiro, April the 26th, 2021 
All rights reserved.

\section{Henrique Rodrigues da Mota}

B.A. in Economics, Pontifícia Universidade Católica do Rio de Janeiro (PUC-Rio), 2018.

Bibliographic data

Mota, Henrique Rodrigues da

Mobile broadband expansion and tasks: Evidence from Brazilian formal labor markets / Henrique Rodrigues da Mota; advisor: Gustavo Gonzaga; co-advisor: Francisco Cavalcanti. $-2021$.

107 f: il. color. ; $30 \mathrm{~cm}$

Dissertação (mestrado) - Pontifícia Universidade Católica do Rio de Janeiro, Departamento de Economia, 2021.

Inclui bibliografia

1. Economia do trabalho - Teses. 2. Banda-larga Móvel. 3. Tarefas. 4. Mudança tecnológica em favor de habilidades.

5. Rotineirização.

I. Gonzaga, Gustavo. II. Cavalcanti, Francisco. III. Pontifícia Universidade Católica do Rio de Janeiro. Departamento de Economia. IV. Título. 
To my parents, for always helping me to pursue my dreams. 


\section{Acknowledgments}

I thank my advisor Gustavo Gonzaga for his valuable contributions to this dissertation and for the opportunities he has given me through the entire course of my academic life.

I thank my co-advisor Francisco Cavalcanti for his advice, attention, and careful look to the details.

I thank professors Claudio Ferraz, Juliano Assunção, and Rogério Werneck for the research assistance experience, their classes, and their advice in graduate and undergraduate courses at PUC.

I thank Rita Almeida and Gabriel Ulyssea for their suggestions and comments to this dissertation. I also thank professor Ulyssea for the research assistance opportunity and his classes.

I thank my parents, Erica and Marcelo, for their limitless support and love. They are my North.

I am thankful to my younger sister, Helena, my best friend.

I thank my grandparents for their care and for teaching me the value of honesty, faith, good work, and persistence.

I am grateful to all my friends. In particular, I thank Marina, Cezar, and Maria, for being always there when I needed them and for all the good moments of joy and happiness that we shared.

My experience in PUC would have been certainly more stressful, less enjoyable, and less engaging without Mateus, Luiz Guilherme, João, Luiz Claudio, Lisa, Otavio, and Roberta. I'm thankful for their company.

I am thankful to the Economics Department of PUC-Rio for their support and for all the great professors that I had while in my undergraduate and graduate course.

This work was done with the support of the Coordenação de Aperfeiçoamento de Pessoal de Nível Superior - Brasil (CAPES) - Financing Code 001. 


\section{Abstract}

Mota, Henrique Rodrigues da; Gonzaga, Gustavo (Advisor); Cavalcanti, Francisco (Co-Advisor). Mobile broadband expansion and tasks: Evidence from Brazilian formal labor markets. Rio de Janeiro, 2021. 107p. Dissertação de Mestrado - Departamento de Economia, Pontifícia Universidade Católica do Rio de Janeiro.

The rise of computerization and fixed and mobile broadband has been an important factor for changes in the labor market of rich countries. However, as the world of tech rapidly evolves and even faster mobile internet emerges, there is still little evidence about the impact of current mobile technologies in developing countries. Brazil, in particular, during the last decade, has seen a remarkable increase in mobile internet access. In this dissertation, I explore this rapid expansion of $4 \mathrm{G}$ coverage to estimate the causal effects of fast mobile internet in formal local labor markets in Brazil. Since 4G technologies are not rolled out randomly, provision commitments in contracts between $4 \mathrm{G}$ national operators and Brazilian regulatory agency of telecommunications (ANATEL) work as an instrumental variable to internet presence. The average increase of mobile operators observed in sample is responsible for a reduction of $8 \%$ in formal employment contracts (about $40 \%$ of the variation in period). This reduction is explained by (i) reduced turnover and by (ii) displacement effects. Consistent with the routinization hypothesis, $4 \mathrm{G}$ expansion shifts labor demand away from manual and routine tasks. This, in turn, has benefited more high-skilled workers, increasing the share of college-graduates in the labor force and the average skill level index of local labor markets. Effects are driven by the extremes of the distribution of technological intensity but there are no changes in the industry-composition of labor markets. I also show suggestive evidence that mobile broadband is associated with job polarization.

\section{Keywords}

Mobile broadband; Tasks; Skill-biased technological change; Routinizatio. 


\section{Resumo}

Mota, Henrique Rodrigues da; Gonzaga, Gustavo; Cavalcanti, Francisco. Expansão de intenet móvel e tarefas: Evidências do mercado de trabalho formal no Brasil. Rio de Janeiro, 2021. 107p. Dissertação de Mestrado - Departamento de Economia, Pontifícia Universidade Católica do Rio de Janeiro.

A ascenção dos computadores e da banda-larga móvel e fixa são fatores importantes nas mudanças observadas no mercado de trabalho dos países ricos. Conforme o mundo tecnológico rapidamente evolui e cada vez mais rápida conectividade surge, há pouca evidência dos impactos das atuais tecnologias nos países em desenvolvimento. O Brasil, em particular, durante a última década, observou uma notória expansão do acesso à internet móvel. Nesta dissertação, explora-se o rápido avanço da cobertura de 4G para estimar os efeitos causais de internet móvel rápida para mercados locais de trabalho formal no Brasil. Como as tecnologias de $4 \mathrm{G}$ não são instaladas randomicamente, compromissos de abrangência, presentes nos contratos entre operadores nacionais da banda de $4 \mathrm{G}$ e a agência nacional de telecomunicações (ANATEL), servem como variável instrumental para presença de internet. O crescimento médio observado na amostra de número de operadores presente em cada mercado local é responsável por uma redução de $8 \%$ nos contratos formais de trabalho (40\% da variação no período). Esta redução é causada por (i) redução de rotatividade e por (ii) efeitos de desemprego. Consistentes com a hipótese de rotineirização, o $4 \mathrm{G}$ reduz a demanda de trabalho para tarefas rotineiras e manuais. Com isso, há um aumento da proporção de trabalhadores com ensino superior e em ocupações que exigem maior qualificação. Os efeitos são concentrados no extremo da distribuição dos setores em termos de uso de tecnologias, mas não houve efeitos na composição das indústrias. Identifica-se evidência sugestiva de que banda-larga móvel está associada à polarização nos empregos.

\section{Palavras-chave}

Banda-larga Móvel; Tarefas; Mudança tecnológica em favor de habilidades; Rotineirização;. 


\section{Table of contents}

1 Introduction $\quad 14$

$\begin{array}{lll}1.1 & \text { Related literature: } & 18\end{array}$

1.1.1 Computerization and routinization 18

1.1.2 Labor market effects of ICTs, internet, and broadband 20

$\begin{array}{lll}1.1 .3 & \text { Contributions } & 22\end{array}$

2 Mobile broadband institutional context and trends in the labor market $\quad 25$

2.1 The mobile broadband and ANATEL's regulations 25

2.2 The demand for tasks and skills - recent trends in local labor markets 30

$\begin{array}{lll}3 & \text { Data } & 36\end{array}$

3.1 Mobile broadband data 36

$\begin{array}{lll}3.2 & \text { Formal labor market } & 37\end{array}$

$\begin{array}{lll}3.3 \text { Tasks } & 37\end{array}$

$\begin{array}{lll}3.4 & \text { Skill level variable } & 39\end{array}$

$\begin{array}{lll}3.5 & \text { Local labor market } & 39\end{array}$

$\begin{array}{lll}3.6 & \text { Additional variables } & 40\end{array}$

$\begin{array}{lll}3.7 & \text { Descriptive Statistics } & 40\end{array}$

$4 \quad$ Identification strategy $\quad 43$

4.1 OLS estimates - limitations 43

4.2 Instrumental Variable 44

$5 \quad$ Main results: aggregate effects in local labor markets 48

5.1 First Stage 48

5.2 Pre-trends and instrument exogeneity 52

$\begin{array}{lll}5.3 & \text { Main results } & 56\end{array}$

5.4 Understanding the drop in formal employment contracts 62

6 Robustness $\quad 66$

$\begin{array}{lll}6.1 & \text { More restricted sample } & 66\end{array}$

$\begin{array}{lll}6.2 & \text { Controlling for pre-trends } & 67\end{array}$

6.3 Previous 3G trends 69

6.4 Shifts in tasks and quality of RAIS-task-content matching 72

$\begin{array}{lll}7 & \text { Composition effects and potential mechanisms } & 77\end{array}$

7.1 Effects within educational groups and increased demand for college $\begin{array}{ll}\text { graduates } & 77\end{array}$

7.2 Heterogeneity from industrial tech-intensity 83

$\begin{array}{lll}7.3 & \text { Effects on the distribution of skills } & 87\end{array}$

$\begin{array}{lll}7.4 \text { Mechanisms } & 90\end{array}$

$\begin{array}{lll}8 & \text { Conclusion } & 93\end{array}$ 
$\begin{array}{lll}\text { A Appendix } & 99\end{array}$

A.1 Occupational matching $\quad 99$

A.2 First-Stage: other outcomes 102

A.3 Extra robustness checks 103 


\section{List of figures}

Figure 2.1 Most advanced technology by municipality-year 26

Figure 2.2 Mobile subscriptions (Monthly level and shares by technology)

Figure 2.3 Supply of mobile broadband services

Figure 2.4 Task-content in formal local labor markets (2006-2017) 31

Figure 2.5 Average skill index by year (Observed data vs trend before 2014)

Figure 2.6 Smoothed changes in employment by skill percentile (2013-2017)

Figure 2.7 Share of tasks in the skill percentiles 34

Figure 2.8 Share of workers by educational groups and wage premiums 35

Figure 4.1 Two hypothetical labor markets with same population and number of municipalities

Figure 5.1 Correlation between number of 4G Operators and ANATEL's average years of compliance

Figure 5.2 Local labor markets of Minas Gerais - Years for compliance and number of $4 \mathrm{G}$ Operators

Figure 5.3 Correlation between $4 \mathrm{G}$ access per capita and ANATEL's average years of compliance

Figure 5.4 Pre-trend analysis of reduced form effects of ANATEL's average years of compliance on local labor market outcomes. (95\% Confidence Interval)

Figure 6.1 Pre-trends of $3 \mathrm{G}$ number of varieties.

Figure 6.2 4G Effects on local labor markets - Main results (controlling or not for trend-effects of $3 \mathrm{G}$ presence in 2013)

Figure 6.3 Share of workers that is matched with the task-content dataset

Figure 6.4 4G Effects on local labor markets - Main results (controlling or not for share of workers matched with task-content data)

Figure 7.1 4G effects on labor market outcomes by tech-intensity of industries

Figure 7.2 4G effects on the demand of tasks by tech-intensity of industries

Figure 7.3 Mobile broadband exposure by groups of local labor markets according to their years for compliance of mobile operators as defined by ANATEL

Figure 7.4 Smoothed employment changes in skill distribution by groups of local labor markets according to their years for compliance of mobile operators as defined by ANATEL (2013-2017) 
Figure A.1 Average wage by sample groups (RAIS subsample matched with task-content vs RAIS subsample unmatched)

Figure A.2 Share of employment in December, $31^{\text {st }}$ (RAIS subsample matched with task-content vs RAIS subsample unmatched)

Figure A.3 (Separation + Hires)-Contracts Ratio (RAIS subsample matched with task-content vs RAIS subsample unmatched) 101

Figure A.4 Share of temporary contracts (RAIS subsample matched with task-content vs RAIS subsample unmatched)

Figure A.5 Pre-trend analysis of reduced-form effects of ANATEL's average years for compliance on local labor market outcomes. (95\% Confidence Interval) 


\section{List of tables}

Table 3.1 Categories of task and its correspondences in the CBO 38

Table 3.2 Descriptive Statistics 42

Table 5.1 Effects of ANATEL rules $\quad 51$

Table 5.2 Pre-trend analysis $\quad 55$

Table 5.3 Effects of 4G operators on contracts 57

Table 5.4 Effects of 4G operators on average routine index 58

Table 5.5 Effects of $4 \mathrm{G}$ operators on average manual index $\quad 59$

Table 5.6 Effects of 4G operators on share of tasks (\%) 60

Table 5.7 Effects of $4 \mathrm{G}$ operators on average wages 61

Table 5.8 Effects of 4G operators on average skill index 62

Table 5.9 Effects of 4G operators on local labor markets 63

Table 5.10 Effects of 4G Operators on MEI 65

Table 6.1 Effects of 4G (Excluding labor markets with municipalities of more than 500,000 inhabitants) 66

Table 6.2 Effects of 4G (Controlling for previous educational trends) 68

Table 6.3 Effects of 4G (Controlling for 3G coverage trends) 71

Table 6.4 Placebo test: effects of $4 \mathrm{G}$ in the share of matched workers 73

Table 6.5 Effects of 4G (Controlling for compatibility trends) $\quad 74$

Table 6.6 Effects of 4G (Controlling for compatibility) 75

Table 7.1 $\quad$ Effects of 4G operators on schooling 80

Table 7.2 Effects of $4 \mathrm{G}$ on labor market outcomes (by educational groups) 81

Table 7.3 Effects of 4G Operators on the share of tasks (\%) 82

Table 7.4 Descriptive statistics of industries by tech-intensity 83

Table A.1 Effects of ANATEL Rules on 4G connectivity 102

Table A.2 Effects of 4G (Controlling for previous routine trends) 103

Table A.3 Effects of 4G (Controlling for previous manual trends) 104

Table A.4 Pre-Trend Analysis (excluding local labor markets with municipalities with above 500,00 inhabitants) 105

Table A.5 Effects of $4 \mathrm{G}$ Operators on contracts (Including noncompatible) 
Engineers cannot program a computer to simulate a process that they (or the scientific community at large) do not explicitly understand. This constraint is more binding than one might initially surmise because there are many tasks that we understand tacitly and accomplish effortlessly for which we do not know the explicit "rules" or procedures. I refer to this constraint as Polanyi's paradox, following Michael Polanyi's (1966) observation that, "We know more than we can tell." When we break an egg over the edge of a mixing bowl, identify a distinct species of birds based only on a fleeting glimpse, write a persuasive paragraph, or develop a hypothesis to explain a poorly understood phenomenon, we are engaging in tasks that we only tacitly understand how to perform.

David Autor, Polanyi's Paradox and the Shape of Employment Growth. 


\section{Introduction}

The complementarity of computers and automation to skilled work and the demand for non-routine tasks for the developed world is well established in the literature. ${ }^{1}$ We know much less about the impacts of mobile technologies and broadband internet in the demand for tasks, for skilled workers, and in employment levels. The potential effects of recent developments of information and communication technologies (ICT), such as faster and smarter smartphones, are often met with skepticism. Gordon (2014) attributes the recent slowdown of productivity growth in the US economy to the digital innovation that has been very consequential for the cultural industry and for leisure but had little impact on production processes. Growing but still scarce evidence, however, shows that mobiles and the internet may have relevant effects on the living standards both of people in developed countries (Atasoy, 2013; Akerman et al., 2015; Zuo, 2019; Bhuller et al., 2020) and developing countries (Corseuil et al., 2018; Hjort \& Poulsen, 2019; Bahia et al., 2020).

In this dissertation, I analyze the effects of the expansion of fast mobile broadband services in the task composition and employment in formal labor markets in Brazil. From 2013 to 2017, this emerging economy has observed a rapid increase of $4 \mathrm{G}$ coverage. Mobile internet is the main driver of increased connectivity in Brazil and, unlike rich countries, 4G internet can often be faster than fixed internet. I combine data from Brazilian telecommunications regulatory agency (Agência Nacional de Telecomunicações, ANATEL) and formal labor market data from the universe of all formal workers (Relação Anual de Informações Sociais, RAIS). RAIS data offers detailed information of each worker, including their occupation, industry, wage level, hire and separation dates, and schooling. Moreover, I also match formal workers' data with occupational task intensity as calculated by Funchal \& Soares (2013). This allows me to analyze the heterogeneous effects of mobile broadband in different segments of the formal workforce in terms of employment level and

\footnotetext{
${ }^{1}$ As some of the most relevant examples of this literature, check Autor et al. (2003, 2008), Black \& Spitz-Oener (2010), Autor \& Price (2013), and Autor \& Dorn (2013). Acemoglu \& Autor (2011) provide an extensive summary of many of these papers and recent trends in job and wage polarization. They also provide a theoretical framework to rationalize the results in the literature.
} 
task composition.

It is a big empirical challenge to identify the effects of mobile broadband in labor markets. As with many infrastructure projects, fast mobile internet presence is not a result of randomization. Installation and operation of mobile antennas face large fixed costs and demand for this sort of technology tends to be correlated with increased incomes and population density (Granja, 2021). Therefore, traditional two-way fixed effects OLS estimates are likely biased since the timing of entry of mobile operators in certain localities is likely correlated with unobserved characteristics from local labor markets. To avoid the endogeneity of internet presence, I use an instrumental variables (IV) approach.

As an instrument for broadband presence, I consider ANATEL rules available on its contracts with national operators of mobile broadband services. In the authorization contracts, there are provision commitments that aim to guarantee broadband access to less populous regions (which are likely poorer and distant from big urban centers). These provision commitments are based on population thresholds and, for each sub-group of municipalities, there are deadlines for internet coverage. Mobile operators must get to these regions, otherwise, they may face sanctions. Since local labor markets vary in terms of the composition of their municipalities, they will differ in terms of the average waiting years until operators must reach broadband coverage. I argue that (controlling for trend effects of population size and the number of municipalities of local labor markets) variation in the average years for compliance is potentially exogenous. I find that the instrument is highly correlated to mobile internet presence, both in terms of the probability of being covered by at least one company (intensive margin), by the number of $4 \mathrm{G}$ firms that provide the service (extensive margin), as well as the number of subscribers of $4 \mathrm{G}$ services.

Mobile broadband services caused a severe decrease in the level of formal employment contracts in Brazilian local labor markets. Considering the average increase of the presence of $4 \mathrm{G}$ operators in the labor market (from 0 operators in 2013 to 2 in 2017), mobile broadband caused a reduction of formal employment contracts by $8 \%$. Considering that the fall from 2013 to 2017 in labor market contracts is about 20\%, the expansion of broadband services is likely to be responsible for $40 \%$ of the fall in the period. This effect can be decomposed into two factors: displacement effects, reducing the number of individuals that were employed from one year to another, and reduced turnover. In terms of displacement, the average growth in national operators observed in data causes a reduction of $6.8 \%$ of workers employed in the whole 
year and a reduction of $5.8 \%$ of the workers employed in the 31 st of December of each year. The same variation reduces hires as close to $-13.8 \%$ but firings also reduced in $-9.1 \%$, as a result, increased mobile operator's presence reduced gross turnover (firings + hires/employed in December 31st) in 5.9 p.p., about $30 \%$ of the variation observed in data from 2013 to 2014. There are no effects, however, for wages.

I also observe that mobile broadband causes a shift in the task composition of workers, increasing the demand for skilled workers. Expanded $4 \mathrm{G}$ significantly reduced routine and manual intensity of work, these effects are consistent with the reported impact of automation and computerization widely reviewed in Acemoglu \& Autor (2011). Computers tend to substitute easily codifiable and repetitive routine tasks while complementing non-routine work. Mobile expansion in Brazil seems to have similar effects.

Results are consistent with the hypothesis that mobile broadband expansion is complementary to computers and automated machines. Increased fast mobile internet fosters the substitution between computers and labor, as evidenced by displacement effects. The shift in favor of machines disproportionately affects workers that execute routine and manual tasks, while complementing non-routine activities. Taking a closer look, the shift seems to be related to a decrease in the share of routine manual tasks (e.g., operating, distributing, transporting, equipping, and assembling) in favor of non-routine interactive tasks (e.g., negotiating, coordinating, leading people, marketing, teaching, training, and marketing). As a result of that, we also observe an increased demand for occupations requiring a higher skill level.

After a battery of successful robustness checks that address potential concerns of pre-trend effects of our instruments and our sample definitions, I then proceed to answer if the shifts on formal contracts, demand for skills, and of tasks are due to composition or within-group changes. I find robust evidence that increased $4 \mathrm{G}$ presence is responsible for a higher share of collegeeducated individuals relative to high school educated workers. Since collegeeducated workers tend to work less in routine and manual tasks and be part of occupations with higher skill levels, part of the $4 \mathrm{G}$ effects seen in data can be explained by the shift in favor of the college-educated. In terms of within groups effects, there was a large drop in the demand for manual tasks among high school dropouts. Nonetheless, it seems that workers that completed high school are the key driver of results. Within this group, there is an increase in the demand for skilled workers, a drop in routine intensity of activities, and reduce demand for manual work.

I also use data from Corseuil et al. (2018) regarding the tech intensity of 
sectors based on the share of workers that report using computers. This data matches the United States' Current Population Survey (CPS) with Brazilian industry codes present in RAIS. Using this data, I can consider if mobile broadband effects are based on the decrease of non-tech-intensive sectors in favor of tech-intensive industries. This does not seem to be the case. However, mobile broadband had heterogeneous effects among different parts of the distribution of tech intensity.

Dividing the sample of workers of each local labor market into quintiles of computer use, there are remarkable differences in terms of effects. General results in the labor market seem to be driven mainly by extremes of the distribution, while sectors in the middle of the distribution are less sensible to the $4 \mathrm{G}$ expansion shock. More in line with the routinization hypothesis, in more digitally advanced quintiles of industries, mobile expansion reduces routine work in favor of increased non-routine cognitive tasks (also commonly referred to as abstract tasks, which involve analytical or interactive skills). This, in turn, leads to an increased demand for occupations associated with more skilled work. On the other hand, in the bottom of the distribution of computer use, in the lowest quintile, mobile broadband is responsible not only for a shift from routine manual tasks to non-routine interactive tasks, but there is also an increase in routine cognitive tasks. Interestingly, however, the increase in the share of college-educated workers is driven both in the less technological sector and in the more tech-intensive sectors.

While the effects in routine cognitive tests may be counter-intuitive at first, there are reasons to believe that this is consistent with a more nuanced version of the routinization hypothesis. Industries at the bottom of the computer technology distribution in a developing country as Brazil are way behind the technological frontier of the world. Fonseca et al. (2018) analyzing the routinization hypothesis in Portugal, notice that, in the period between 1986 to 2007, there was only modest evidence of employment reduction among routine-cognitive tasks and wage premiums increased for this occupation, even though computerization and automation increased. As one of the reasons for that, the authors cite the low presence of computer capital and low educational attainment of one of the poorest countries in Western Europe. It is not difficult to imagine that industries at the bottom of the distribution of computer use in Brazil face similar constraints.

This pattern of non-response in the middle of the distribution, in particular the second and the third quintile, is consistent with a model of technology adoption where firms have different optimal production function technologies, depending on relative computer prices. Mobile broadband may be interpreted 
as complementary to computers and its expansion can be read as a reduction in costs of computer-related tasks. The possible reduction of computer costs brought by the $4 \mathrm{G}$ shock may have been enough for low-tech industries to become more similar to mid-tech industries (with fewer manual tasks and more routine cognitive and interactive tasks), while high-tech industries were able to adopt even better production technologies. Mid-tech industries may have had the chance to adopt new technologies, but switching to a new production technology may not have been profitable enough.

Finally, I consider the potential effects of mobile broadband on polarization in Brazil. I divide the sample of formal workers into three different groups, based on the regulated timing of entry of mobile operators in their local labor markets. For each of those groups, I perform an analysis of employment changes of each of the percentiles of the skill distribution, similarly to the procedure done in Acemoglu \& Autor (2011). Then, I compare this variation in the employment share of percentiles between the early and middle third of receivers of mobile broad with the late receivers. Compared to late receivers, the other groups of workers show a clear pattern of stronger demand for the top percentiles of the skill distribution. For the early receivers, there is also an increased demand for the occupations in the lower percentiles. Therefore, there is some evidence that mobile operators cause some job polarization, but this is concentrated in local labor markets that are early receivers.

\section{1}

\section{Related literature:}

\subsection{1}

\section{Computerization and routinization}

This dissertation is deeply related to the literature on computerization, skill-biased technological change (SBTC), and routinization. The third industrial revolution and the further development of computerization and automation in the labor market starting in the 1970s caused tectonic shifts in the demand for skills and the rise of college premiums. Looking at the United States, Katz \& Murphy (1992) attributed this pattern to the SBTC hypothesis. Computerization raised the relative productivity of skilled workers, causing displacement effects for low-skill workers and wage reduction. Growing college premium would have been a result of that.

Nonetheless, SBTC models had some explanatory limitations. Autor et al. (2008) note that these models would imply a deceleration of college premium growth premium right in the 1990s when technologies were growing 
rapidly. The 1990s were also known for increased job polarization: occupations in the extremes of the skill distribution increased in terms of their share of employment, while displacement effects were significant in the middle of the skill distribution. Building on the work of Autor et al. (2003), they elaborate a more refined version of the SBTC model, considering that information technology (i) complemented abstract activities (a similar definition to nonroutine cognitive work), which was performed by college-educated individuals but (ii) substituted work for routine tasks, concentrated between high school workers. This can be described as the routinization hypothesis or sometimes routine-biased technological change (RBTC).

Since then, the routinization hypothesis has been extremely relevant to analyze most of the phenomena of wages and job polarization in the United States and other developed world regions. Autor \& Dorn (2013) complement this analysis unifying the phenomena of increased job and wage polarization in the United States and of the rise of the low-skill services sector between 1980 and 2005. Local labor markets specialized in routine tasks, who experienced a stronger process of computerization, also faced stronger increases in the share of workers in low-skill service industries.

Evidence of the routinization hypothesis is not circumscribed to the United States. Black \& Spitz-Oener (2010) relates tasks with the dynamics in the female labor force participation and gender wage gap in West Germany. Moreover, Goos et al. (2014) find significant evidence of polarization caused by offshoring and routinization in 16 European countries.

In emerging economies, evidence is more mixed in terms of the potential effects of computerization. Bulla (2014), analyzing data in Mexico, Brazil, and Colombia, associating the routinization hypothesis to within-industry technical change, argues that decreases in the demand of routine cognitive tasks are deeply connected to RBTC, but the same cannot be said of the fall in routine manual tasks. Maloney \& Molina (2016), analyzing several regions, show that developing countries do not have a clear pattern for polarization, except for Indonesia, Mexico, and Brazil. Interestingly, Böhm (2020), combining the Roy Model with tasks, notice, however, that polarization is not a necessary outcome of RBTC, shifts in the distribution of overall wage depend on the initial distribution of tasks across skill-level.

In Brazil, there is growing evidence that computerization contributed to RBTC. Riva (2016) finds causal effects of trade liberalization in the personal computer sector in Brazil. This has caused a shift in labor demand from routine cognitive tasks towards non-routine manual tasks. The author does not find clear evidence of job and wage polarization, but this may be explained 
by the fact that routine tasks do not follow an inverted U-shape form in the skill distribution. Based on the skill distribution in 1988, the middle of the distribution and the low part of the distribution execute a similar level of routine tasks. Using RAIS data, and comparing individual fixed-effects estimates of task prices from a panel of 2002-2004 to individuals from 20122014, Sulzbach (2020) find evidence of "task-price polarization" with reduced prices for routine tasks and increases for (non-routine) cognitive and manual tasks.

\subsection{2}

\section{Labor market effects of ICTs, internet, and broadband}

This dissertation also contributes to the literature of the effects of (broadband) internet in local labor markets. Developed countries have seen a remarkable expansion of mobile and fixed broadband internet, especially in the 1990s and the early 2000s. This expansion had important implications in terms of employment and demand for skills. Atasoy (2013) uses a two-way fixed effects estimator to consider the effects of a county getting a broadband connection. She finds increased employment effects driven by an increased scale of firms and by higher labor force participation, these gains are concentrated among college graduates. Akerman et al. (2015) use the staggered roll-out of fixed broadband as an instrument for firm access to internet services. They find substitution effects of broadband adoption and unskilled work (as defined by workers without a college), reducing their marginal productivity. They also found important complementary effects for skilled work (college graduates) driven by increased demand for non-routine skilled work. The effects of routinization and increased demand for college graduates observed in their work are very similar to the ones observed in this dissertation. Moreover, I also don't find that ICT effects are driven by changing composition of sectors: there is no evidence of decreased or increased participation of these sectors in terms of employment share.

There are some relevant effects of ICTs in developing countries in varied socioeconomic aspects. Broadband raises female labor participation and employment (Chun \& Tang, 2018; Viollaz \& Winkler, 2020) and it impacts in welfare gains in consumption (Bahia et al., 2020). The Internet seems to have relevant effects increasing firm productivity (Paunov \& Rollo, 2016). In fact, in China, internet connection is associated with trade integration: connectivity increases manufacturing exports and improves firm performance (Fernandes et al., 2019).

Closer to the purpose of this paper, Hjort \& Poulsen (2019) exploit 
the gradual roll-out of connection of African labor markets to submarine cables that improved broadband access. There is an increase in skilled jobs, but there is unemployment reduction across all the educational attainment spectrum. These effects are driven by net firm entry and increased firm productivity. Unlike this dissertation, they find relevant positive effects in terms of employment while mobile broadband in Brazil seems to be associated with reduced levels of formal employment contracts.

Looking directly at the impact of the internet on the demand of tasks in Brazil, Poliquin (2020) analyze the adoption of fixed broadband by firms. Using a differences-in-differences approach and combining survey data with RAIS data, he finds consistent evidence of the routinization hypothesis. Broadband adoption increases wages, but gains are concentrated non-routine cognitive tasks, while losses occur for routine cognitive tasks. The author also identifies that the effects are concentrated on jobs associated with computer or internet use and managerial position and there are increases in firm wage inequality because gains are heavily skewed to the top of the wage distribution. Employment gains are also noticeable, but these are firm-level panel data estimates.

Another important paper on the impacts of fixed internet on the demand of tasks is Corseuil et al. (2018). Authors use a triple differences approach, comparing tech-intensive sectors relative to non-tech-intensive industries between municipalities that got internet connection first and those who did not get access. Like this dissertation, they found notable complementarities between internet connectivity and non-routine and cognitive tasks. Among routine tasks, there is a shift from routine manual tasks to routine cognitive tasks. Effects are mediated by the strength of labor regulations. Although labor laws are set to protect more vulnerable workers, they increased the impact of this technological shock. Costly labor regulation provides further incentives for adopting labor-saving technologies that reduce the demand for routine and manual tasks.

This dissertation focuses on the interaction of mobile broadband and changes in the task and skill composition of the formal workforce. As a result, the ICT expansion is mostly considered as a complement to processes already in motion in terms of computerization and automation, reducing the relative prices of adopting productivity-enhancing technologies. Other than the direct production function effects, that lead to increased productivity and the potential increased relative demand for skilled workers, Dutz et al. (2018) note that there many possible potential mechanisms through which ICTs could affect the workforce. ICTs can increase firms' market access. These effects are concentrated in small firms which can gather new revenue sources with 
the Internet. Another potential mechanism is through reduced cross-regional and cross-sectoral mobility costs. Internet connectivity can help workers make more well-informed moving decisions, while it may also help firms reach out to workers with a better fit for job offers. For example, improved labor market matching was observed during the staggered roll-out of broadband internet in Norway (Bhuller et al., 2020). In terms of cross-regional movements, information access may also be another relevant factor, Porcher (2020) note that the Internet has potentially increased families' welfare by preventing illinformed moving decisions from workers. Since this dissertation's estimates are reduced-form effects of mobile broadband on the formal labor market, this outcome could be the result of a wide variety of mechanisms that are summarized and briefly discussed in this dissertation.

\subsection{3}

\section{Contributions}

To the best of my knowledge, this is the first paper that finds a causal effect of mobile broadband on the demand of tasks in developed and developing countries. Despite this technological shock occurring in a developing country, I find that mobile broadband expansion works similarly to computerization. Increased $4 \mathrm{G}$ presence by mobile operators reduces the demand for routine work in favor of non-routine cognitive tasks, in particular for non-routine interactive work. As an effect of this technological shock, we also see increased demand for workers in skill-intensive occupations and college-educated workers. This is consistent with the routinization hypothesis. Nonetheless, some complementarity between routine cognitive work and mobile broadband (especially among sectors very far from the technological frontier) suggests a more nuanced version of the routinization hypothesis, as similarly seen in Portugal by Fonseca et al. (2018). This shows that, even in underdeveloped regions, far from the cutting-edge of technological innovation, there is growing pressure from ICTs in the demand of skills, negatively affecting workers in routine manual tasks.

This dissertation also addresses potential job polarization effects brought by routinization. I find suggestive evidence that local labor markets that would receive earlier mobile broadband access, due to ANATEL rules, experienced stronger demand for the top percentiles of the distribution. For those that were the earliest receivers, it seems that there is an increased demand for workers in the very bottom of the distribution. Therefore, at least in the earliest receivers, we see some evidence of job polarization associated with mobile broadband expansion.

Moreover, I find some evidence of substitution between high-school 
graduates (associated with the highest intensity in routine cognitive tasks) and increases in college graduates (associated with high levels of non-routine cognitive tasks) caused by the provision of $4 \mathrm{G}$ services by an additional operator. There is also an increase in the skill index within high school graduates, which is consistent with part some of these workers often associated with mid-skill levels moving towards occupations that require more human capital from its workers. Mobile broadband does not cause particular changes in general wage levels, nor does it affect (raw) college and high-school degree wage premiums.

The second contribution of this paper is methodological. This dissertation uses an innovative IV approach. Using mobile operators contractual commitments to the telecommunications regulatory agency, I am able to find exogenous variation in mobile broadband presence. This is particularly important considering that the timing of entry of mobile operators is strongly associated with the economic conditions of local labor markets. Mobile operators will strategically prefer offering services to regions with higher population density and higher incomes. Similarly, we can think that more productive firms (and those that are more intensive in skilled work) are more likely to rapidly adopt new ICT tools. Moreover, recent developments in staggered roll-out (Goodman-Bacon, 2018; Sun \& Abraham, 2018) differences in differences uncovered several new potential biases of panel TWFE estimates that are very common in both the computerization and the ICT expansion literature. The approach described in this dissertation avoids these and offers robust causal estimates of mobile expansion.

Finally, the third contribution of this dissertation relates to the aggregate effects of technological change in employment. Broadband is often hailed as a tool of promotion of development, increased opportunities, and reduced unemployment but this dissertation offers a different perspective in Brazilian labor markets. Mobile broadband caused a significant reduction of formal employment contracts. Part of this could be explained by a good reason: reduced turnover in the labor market, with better ties between workers and firms. However, most of it is associated with a reduced number of individuals working over the year. This is consistent with recent results on the literature on automation considered in Acemoglu \& Restrepo (2020), where the substitution between workers and machines are known for displacement effects, that are not being completely compensated through the creation of new tasks and productivity gains. One possible reason for this large negative effect is that the economic crisis in Brazil (2015-2017) might intensify the displacement effects, but this is still an open research question. 
This dissertation is structured as follows. Section 2 outlines the institutional context of mobile broadband expansion in Brazil and the regulatory framework from which the IV strategy builds upon. Section 3 describes the data used. Section 4 explains the methodology of the empirical strategy. Section 5 presents the main results. Section 6 offers a series of robustness checks to the identification strategy. Section 7 analyzes composition effects and detail some possible mechanisms that could explain the pattern seen in this reduced-form estimates and section 8 concludes. 


\section{Mobile broadband institutional context and trends in the labor market}

\section{1}

\section{The mobile broadband and ANATEL's regulations}

Since the late 1990s, after the privatization of the telecommunications sector, there has been not only a notorious expansion of fixed phones and internet, but also a remarkable rise in mobile use. Brazil has a large market for mobile communications and broadband access, but it is very concentrated and the four biggest national mobile operators ${ }^{1}$ (Claro, Vivo, Tim, and Oi) represent more than $90 \%$ of the mobile users' market share. These operators are tightly regulated and they must comply with several quantitative and qualitative demands from the national regulatory agency.

The Brazilian telecommunication sector is regulated by ANATEL, a special autarchy from the government. Private firms participate in auction processes to provide cable television, mobile services, and fixed and mobile broadband. Mobile network operators utilize the radio frequency spectrum to transmit data. Hence, in Brazil, as in many other developed and developing countries, the government licenses these frequency bands and allocates them through auction processes. Mobile operators that win those auction processes and get to have an authorization contract are required to achieve quality and provision goals to guarantee consumer's rights and promote State interests.

Brazil's booming economy in the mid-2000s was accompanied by a notorious expansion of mobile phone use, which has been one of the main tools for communications and internet use for many of its citizens. Brazil has three important periods of connectivity expansion. At first, there was a buildup of mobile communications through $2 \mathrm{G}$ technologies, then, secondly, there was the development of broadband services through $3 \mathrm{G}$, and, third, there was a qualitative change of access, with increased speed of mobile broadband

\footnotetext{
${ }^{1}$ There are three other operators in this dissertation's period of analysis:: Algar, Sercomtel and Nextel. Nextel was recently bought by Claro and Oi is in the process of being bought by the other big three providers: Claro, Tim, and Vivo. Despite this recent consolidation process, the mobile services sector has been very stable in terms of entry and exit. For this dissertation, I focus on the provision of the 4 major national operators.
} 
connection through $4 \mathrm{G}$ internet.

Figure 2.1 shows the geographical expansion of these technologies across municipalities, according to the most advanced technology in December of the previous year. We don't have data of mobile operators' presence before 2013 at the municipal level, that is why we cannot observe the expansion accordingly. From the period of 2013 to 2018, there was a significant increase in mobile broadband, becoming prevalent in almost all of the territory. While the expansion of $4 \mathrm{G}$ from 2015 to 2017 visually seems shy, it is important to notice that the initial expansion was more concentrated in urban centers with high urban density but small territories. Furthermore, the presence of $4 \mathrm{G}$ had potential effects in all municipalities bordering those centers.

Figure 2.1: Most advanced technology by municipality-year

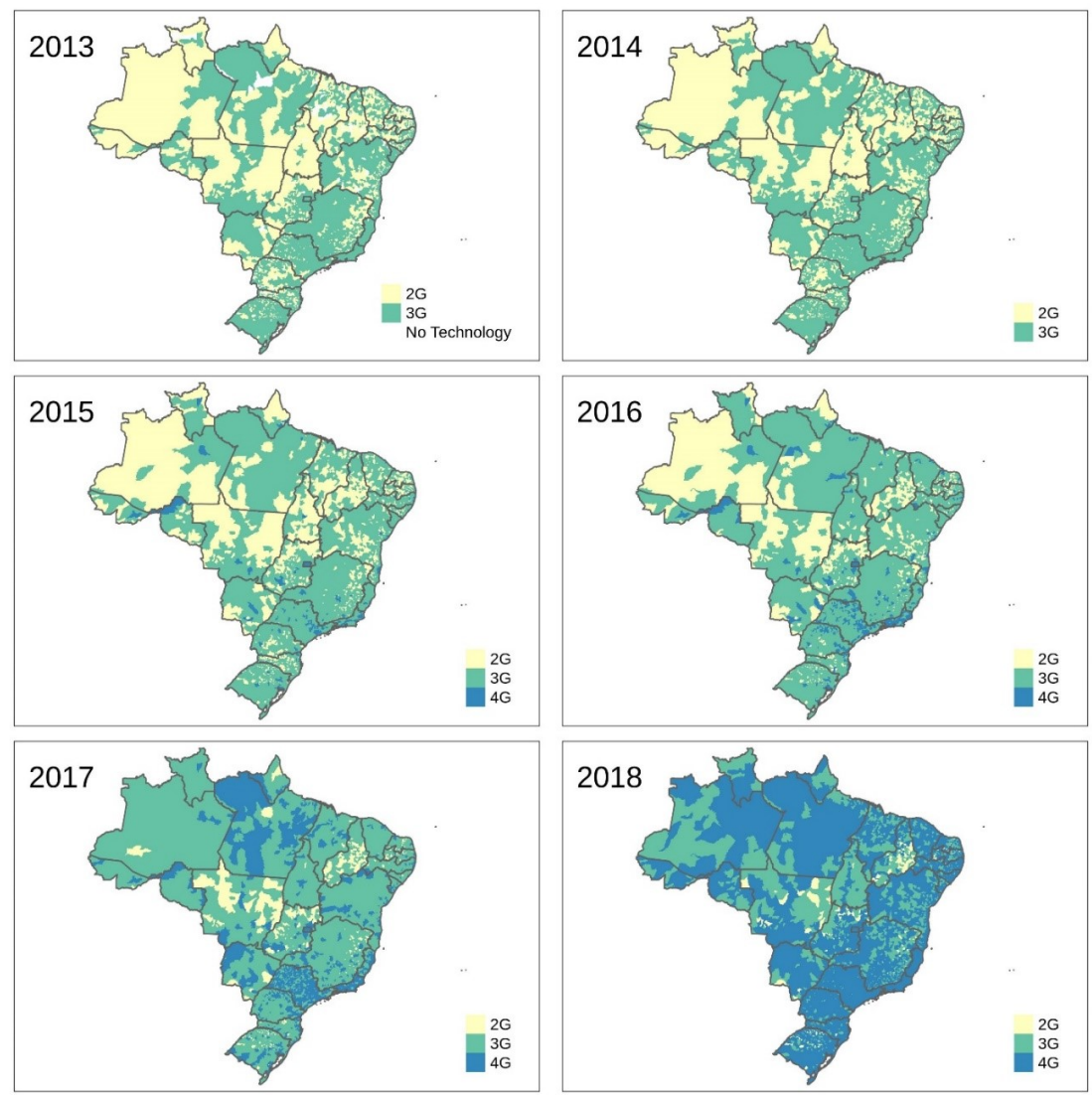

ANATEL data. The figure exhibits Brazilian municipalities and the most advanced technology across each year (considering the presence in December of the previous year). The presence is considered when at least one operator provides $4 G$ services. At this analysis, this map is considering the presence of all operators, not only the big four national operators.

In February of 2005, there were more than 67 million subscriptions of $2 \mathrm{G}$ communications in Brazil. This measure is based on subscriber identity module (SIM) cards; hence, it could be the case that one individual has more 
than one connection. In three years, this number would rise to 124 million subscriptions, about $64 \%$ of the population that year. Starting from 2008 , one year after a large auction of sub-bands for the provision of $3 \mathrm{G}$ services, there was a huge increase in connectivity in Brazil.

Figure 2.2: Mobile subscriptions (Monthly level and shares by technology)
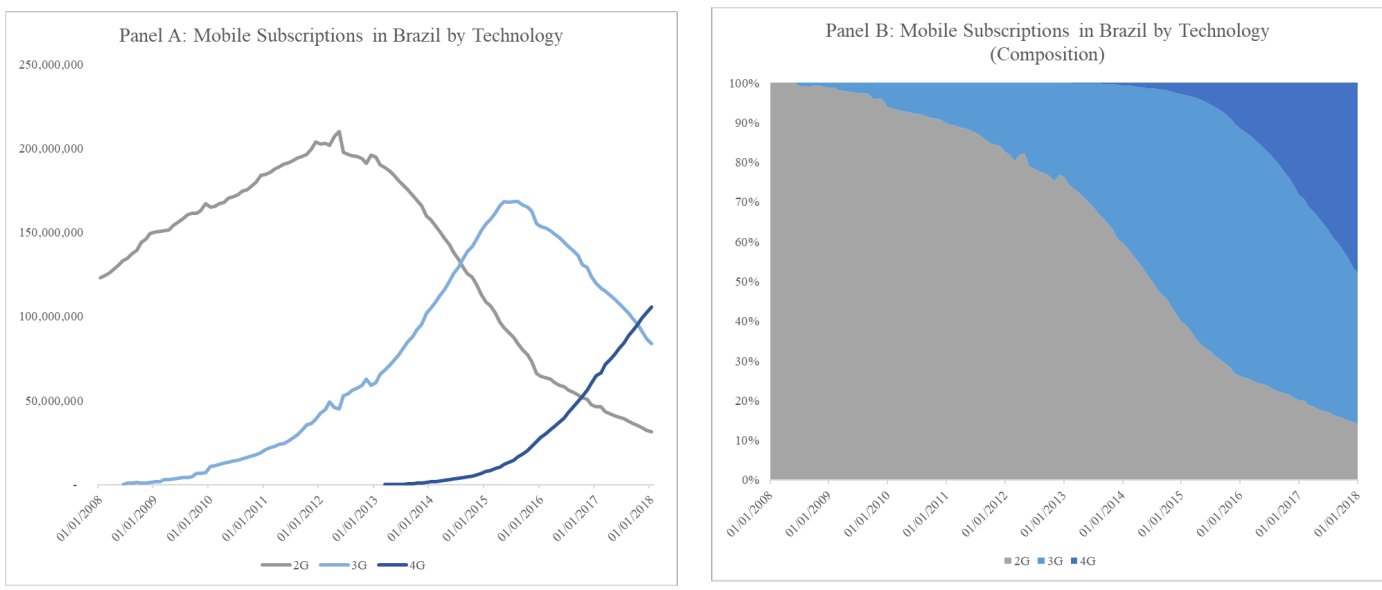

Mobile subscription data publicly provided by ANATEL. Subscriptions represent an active SIM card for each technology-operators. Technologies in blue represent mobile broadband.

Figure 2.2 plots the expansion cycle of mobile services in Brazil by groups of technology using official ANATEL data. In both panels, the x-axis represents the months between January 2008 and January 2018. The y-axis, in panel A, shows the total number of subscriptions and, in panel $\mathrm{B}$, it shows the share of each technology in the total number of subscriptions. As we can see from figure 2.2 in Panel A, since 2008, Brazil experienced a tremendous increase in mobile broadband connectivity. At first, 3G technologies had a large cycle of expansion, reaching more than 168 million users at its peak in mid-2015 (about 88.9 subscriptions per hundred people), this was the period where the total number of mobile access (with broadband connection or not) also reached its peak, with more than 273 million subscriptions, about 133 subscriptions per a hundred people.

As we can see in Panel B of figure 2.2, 3G inaugurated a period where the mobile broadband connection would gradually represent the majority of mobile subscriptions in Brazil. The share of $2 \mathrm{G}$ technologies (in grey) had steadily decreased since 2008. This just shows how widespread this sort of internet connection has become. Internet connection in Brazil has been driven mainly by $3 \mathrm{G}$ and $4 \mathrm{G}$ access. Bessone et al. (2020) noticed that, in 2014, according to the Brazilian household survey (PNAD, Pesquisa Nacional por 
Amostra de Domicílio), among households with an internet connection, 80\% reported at least one mobile internet user.

After 2015, there seems to be some consolidation of the mobile broadband market, with families gradually adopting faster technologies. Most Brazilians are now connected to the internet through mobile phones. In January 2021, there were about 97.1 mobile subscriptions per individual in Brazil, while there were only 50 fixed broadband connections per one hundred households. 4G connection, however, cannot be ignored in terms of its importance in qualitative terms, increasing the speed of mobile access.

Regulations had an important role in broadband expansion in Brazil. In 2012, the Brazilian government announced the licensing of the $2500 \mathrm{MHz}$ to 2690 bands of the spectrum to the provision of $4 \mathrm{G}$ technologies. Through an auction process, mobile broadband operators got authorization contracts of 15 years, renewable in the same time length. The design of these contracts was similar to the $3 \mathrm{G}$ contracts, auctioned in 2007. National spectrum sub-bands (W, X, V1, V2) were licensed to the four major players in the telecommunication sector.

ANATEL established provision commitments that had to be followed by mobile broadband companies. The Brazilian government was concerned that big national operators would only focus on the larger mobile markets. To ensure that this was not the case, not only ANATEL targeted connectivity on the intensive margin (at least one firm operating) but she also forced competition, which we shall call connectivity on the extensive margin (the number of operators competing in the market). Under certain specific deadlines, municipalities had to be covered by mobile operators with $3 \mathrm{G}$ or $4 \mathrm{G}$ services. A municipality was considered covered if $80 \%$ of its central district's area had access to these mobile services. According to the authorization contracts and the auction notice, those were the provision commitments that operators were mandated to comply with:

1. All of them would have to provide $4 \mathrm{G}$ services to:

(a) World Cup hosts and sub-hosts until the 31st of December, 2013.

(b) the Brazilian Federal District, state capitals, and municipalities with more than 500,000 inhabitants until the 31st of May of 2014.

(c) all municipalities with more than 200,000 inhabitants until the 31st of December, 2015.

(d) all municipalities with more than 100,000 inhabitants until the 31st of December, 2016. 
2. At least one $4 \mathrm{G}$ provider for all municipalities with population between 30,000 and 100,000 inhabitants until the 31st of December, 2017. Operators of sub-bands $\mathrm{W}$ and $\mathrm{X}$ had to cover $1 / 3$ of municipalities each, and owners of V1 and V2, had to cover $1 / 6$ each. All had to provide $3 \mathrm{G}$ technologies by this deadline (it was allowed to provide $4 \mathrm{G}$ instead).

3. All municipalities with less than 30,000 inhabitants had to be covered by $3 \mathrm{G}$ access or faster technology by December 31, 2019. Only one company needs to be present in each area. At least 30\% (60\%) of these municipalities had to have access by December, 2017 (2018).

Non-compliance to provision commitments could mean possible harsh punishments. For each deadline, mobile operators had to give guarantees in the form of cash, insurance, or bank warranty. For the national sub-bands, these guarantees represented about 1.2 billion reais. Moreover, the companies must report regularly to ANATEL. On the 1st day of October of each year, they shall report which municipalities are covered and will be covered by the end of the year. Failure of compliance could mean losing these guarantees proportionally to the number of municipalities not properly covered. Operators may face fines of up to the value of 50 million reais from the regulatory agency for each irregularity. In case of severe disrespect of regulations, mobile broadband may even lose their authorization contracts and lose their spectrum sub-bands.

Taking a look at the $3 \mathrm{G}$ coverage requirements in the 2012 auctions, Granja (2021) identifies that these ANATEL rules have accelerated 3G provision in small municipalities in one year. In section 5 , I identify that these provision commitments had significantly positive effects in the provision of $4 \mathrm{G}$ technologies. Local labor markets through which the average time of waiting to the deadline was longer had less $4 \mathrm{G}$ coverage and reduced competition between $4 \mathrm{G}$ operators. Since my focus is on the effects of $4 \mathrm{G}$ technologies, ANATEL rules will serve as an instrument for $4 \mathrm{G}$ provision.

As we can see from figure 2.2, there was a steady growth of $4 \mathrm{G}$ connectivity starting from 2015. At the end of 2017, $4 \mathrm{G}$ access represented more than half of broadband connectivity in Brazil and about $46 \%$ of all subscriptions. This movement is contemporaneous to expanded $4 \mathrm{G}$ infrastructure. Looking closely at the sample of our analysis, local labor markets, that not included state capitals or Brasília, the national capital, in figure 2.3, there has been a remarkable increase of $4 \mathrm{G}$ services supply. For the average formal worker on these markets, $3 \mathrm{G}$ supply was already offered to more than $90 \%$ of the local labor market population in 2013, no local labor market had 4G supply as described in ANATEL standards (covering $80 \%$ of the central district). In 2015, 
Figure 2.3: Supply of mobile broadband services
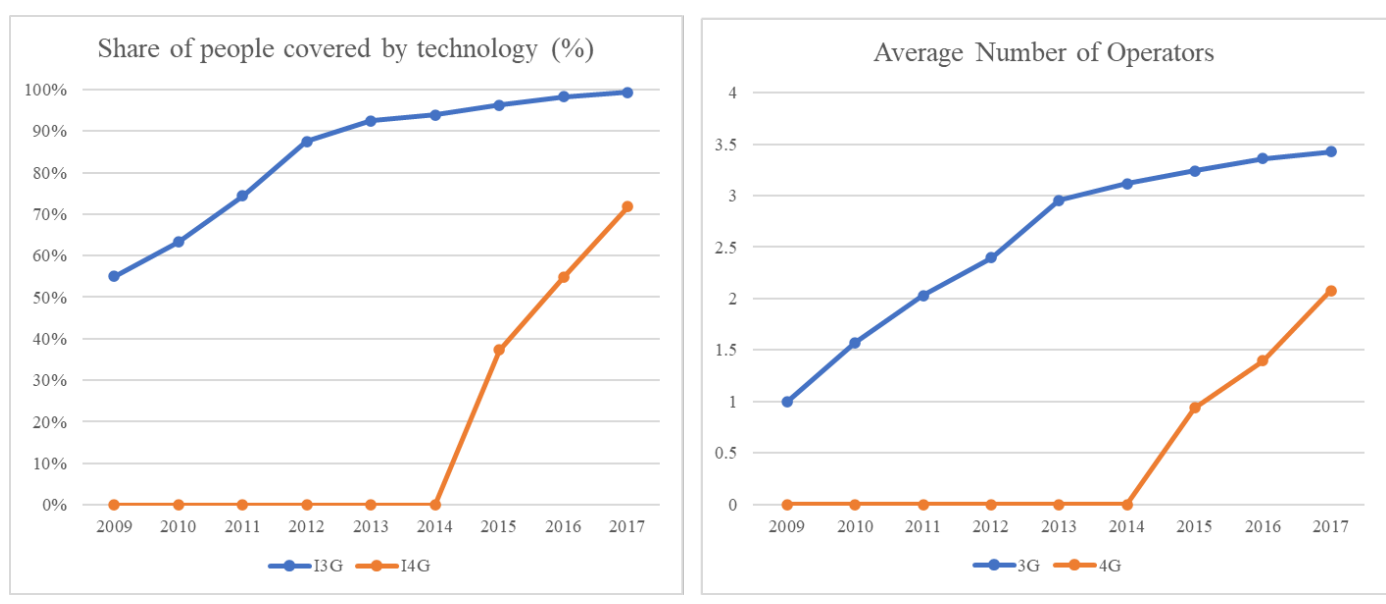

Mobile broadband data provided by ANATEL. Employment data by RAIS. Yearly-averages of the variables are employment-weighted (with the number of contracts in 2013 as weights). Intuitively, it must be read as the average statistics of connectivity of the formal worker in local labor markets in Brazil.

installed infrastructure covered more than $40 \%$ of the population, up to $72 \%$ in 2017. There has been a high increase in the average presence of $4 \mathrm{G}$ operators as well, from 0 in 2014 to close to 2 operators at the end of 2017. As we shall see, the tectonic shift in $4 \mathrm{G}$ connectivity was accompanied by relevant changes in local labor markets.

\section{2}

\section{The demand for tasks and skills - recent trends in local labor markets}

Brazil has a very routine-intensive labor market. Figure 2.4 plots task intensity of the workforce, in five different categories as defined by Funchal \& Soares (2013). The y-axis indicates the yearly employment-weighted average between each year and the $\mathrm{x}$-axis represents the year of the observations. The categories in the y-axis can be routine and non-routine. Between non-routine tasks, there are non-routine manual tasks and non-routine abstract or cognitive tasks, divided into analytical and interactive activities. Routine tasks can be defined as manual and cognitive tasks.

We will get a better understanding of these categories in the data section. For now, those routine activities shall be understood as tasks that are more easily replaceable for computers (or robots), since they follow a certain simplified set of rules and repetitive (manual or cognitive) procedures, e.g., workers in a production line or accountants. Non-routine tasks tend to be associated with more complex activities, that require sophisticated analytical capacity, human interaction, and abstract thinking. These tasks tend to be 
Figure 2.4: Task-content in formal local labor markets (2006-2017)
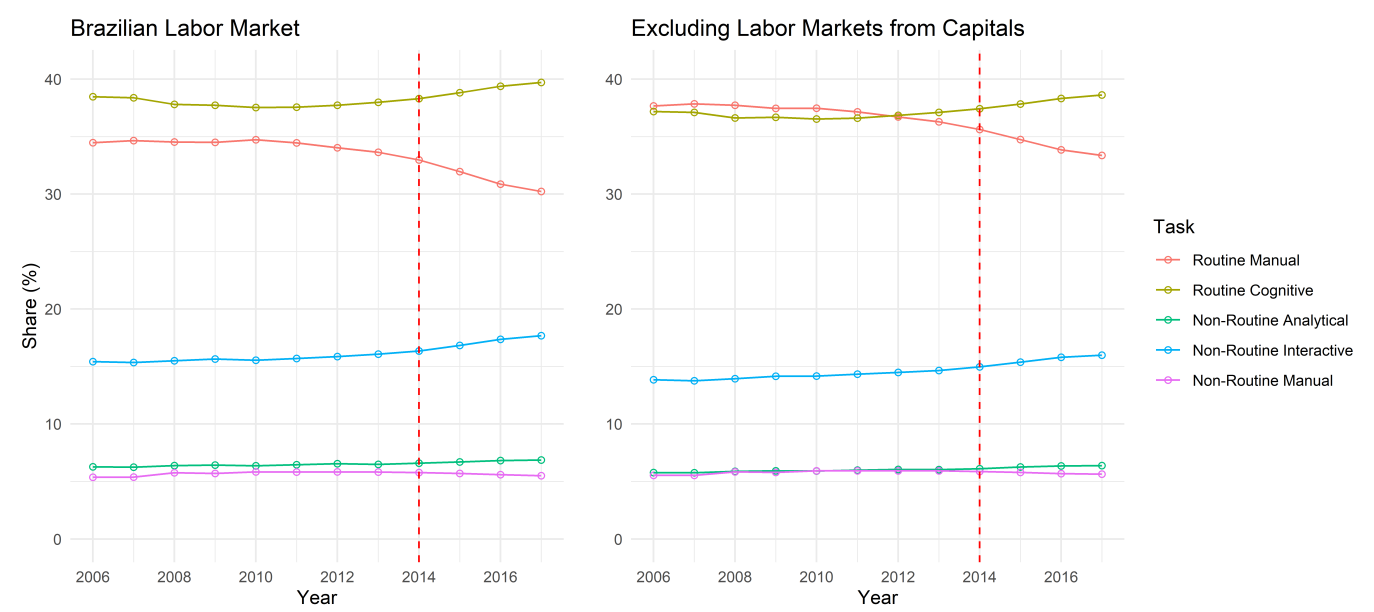

RAIS data. Task shares are yearly employment-weighted averages of a task-intensity measures as defined by Funchal and Soares (2013). RAIS data is matched through the occupational classification in Brazil (CBO) to the task-intensity measures constructed by these authors. 275 4-digit occupations had their task-intensity classified.

common in high-skill occupations. Nonetheless, certain non-routine tasks, usually that involve complex manual skills, are concentrated in low-skill work, such as personal care, cooking, and cleaning.

As we can see from figure 2.4, routine cognitive and routine manual tasks represent more than $70 \%$ of tasks executed in Brazilian local labor markets. Excluding local labor markets from national or state capitals, routine manual tasks are even more significant. Interestingly, however, there has been a noticeable shift towards cognitive and non-routine tasks since 2011, accelerating in 2013. After more widespread implementation of $4 \mathrm{G}$ technologies, these trends seem to have moved, if anything, even faster. The dashed line in figure 2.4 marks 2014 as the last year before any municipality had 4G coverage in December of the previous year. Since then, the shift towards non-routine and cognitive tasks is clear. It is also true that during that period (2015-2017), there has been a large drop in the workforce caused by a big economic crisis, a $20 \%$ drop in formal contracts, considering the full sample, but it is unclear that an economic crisis brought by political uncertainty, high interest rates, and debt crisis would be skill-biased.

In figure 2.5, I plot the average skill index of the formal labor market from 2006 to 2017. This skill index varies from 0 to 100 and it's based on the wage distribution of occupations in 2008 (before overspread mobile broadband presence). Being closer to zero means that it is an occupation very close to the minimum mean wage across occupations and closer to one hundred means that 
Figure 2.5: Average skill index by year (Observed data vs trend before 2014)

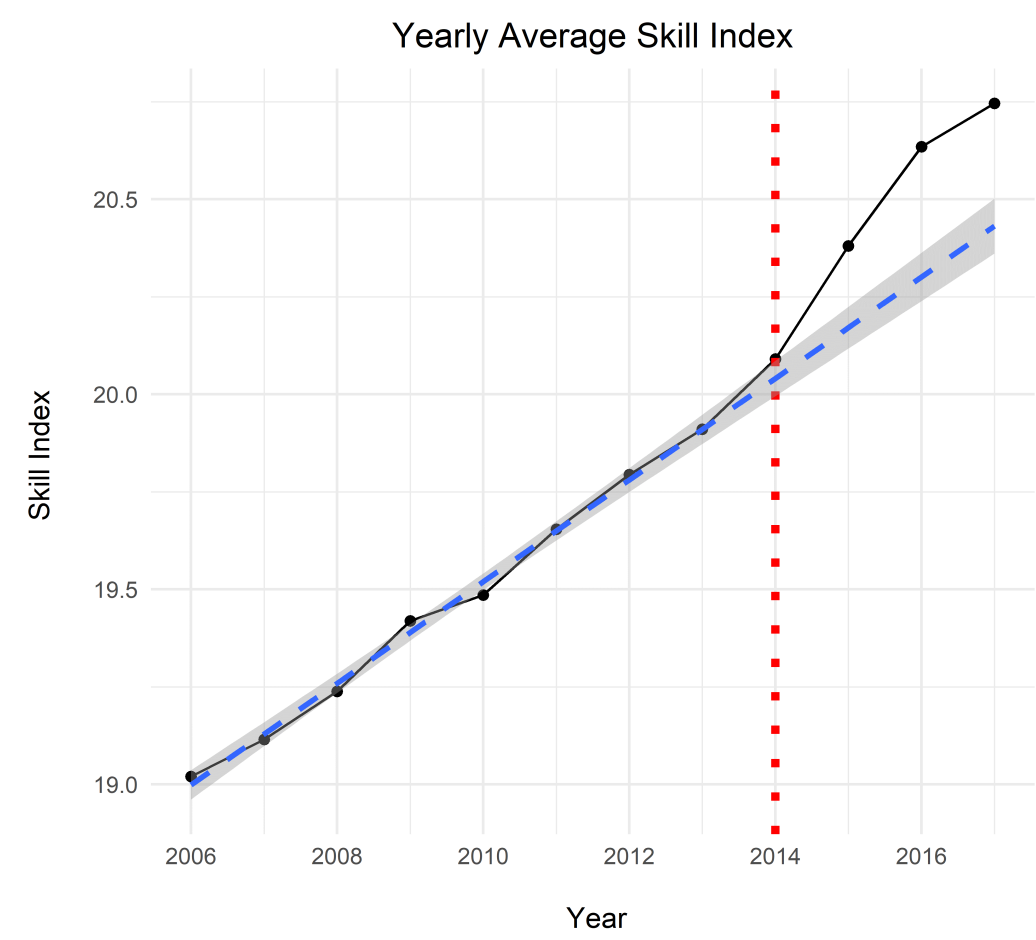

RAIS data. Figure plots the yearly average of a skill index based on the occupation's position in the distribution of wages.

it is an occupation very close to the maximum mean wage across occupations. The details of the construction of this index are given later on in the data section. What is relevant of this figure is the break after 2014, with an apparent increase in the shift towards skilled labor. The blue line exhibits the predicted values for 2014 and beyond considering the 2006-2013 trend. Aggregate effects like this, however, are consistent with many possible channels: a shift from low-skilled workers to mid-skilled occupations or an increase centered only at the top of the distribution. Even job polarization could be driving the results if the increase in the top is stronger than in the bottom of the distribution.

Following closely to Acemoglu \& Autor (2011), I examine the employment changes across the distribution of skills. I use data of 275 occupations and rank them across the monthly wage distribution. From that, I build employmentweighted hundredths of skill level. In particular, I analyze the variation between 2013 and 2017. The figure 2.6 plots changes in the employment share multiplied by a hundred in the $\mathrm{y}$-axis of each percentile and the $\mathrm{x}$-axis represent each percentile (more precisely, each hundredth) of the skill distribution of 2008 . Variation is exhibited with a locally weighted smoothing regression.

As we can see, during this period, there have been very skewed gains of 
Figure 2.6: Smoothed changes in employment by skill percentile (2013-2017)

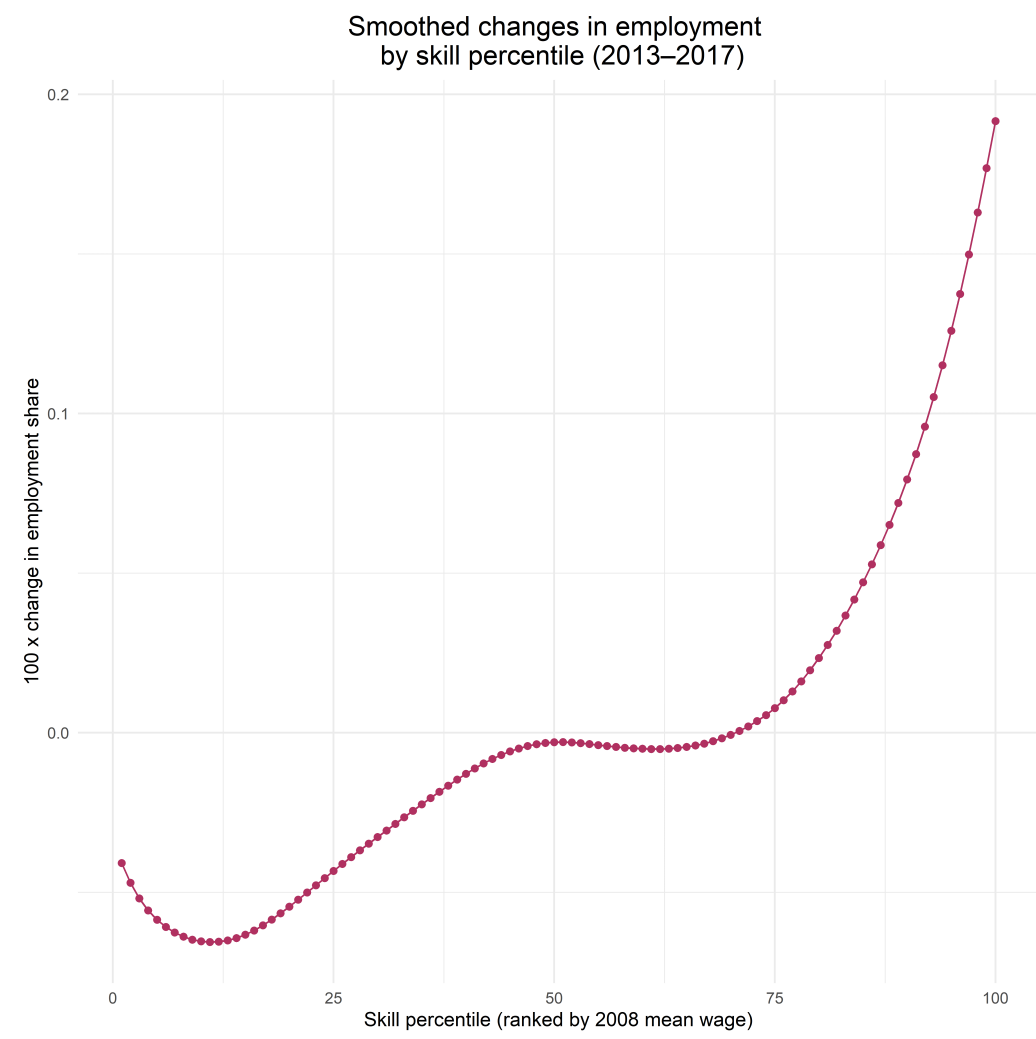

RAIS data. Figure plots changes in employment shares by hundredths of the 2008 skill distribution. Percentiles are employment-weighted and variation in the $y$-axis is represented by the output of a locally weighted smoothing regression (using Stata command lowess, bandwidth 0.8 and 100 observations, following closely to Acemoglu \&S Autor (2011) methodology). Skill percentiles are defined based on wages and the number of contracts for each occupation. An additional step is the normalization of mean variation into zero since the sum of variation in all percentiles must be zero.

employment in the top percentiles of the skill distribution. This is consistent with skill-biased technological change that increases the demand for skilled labor. But is it possible that routinization forces are also driving the results? To consider this hypothesis, it is important to analyze the distribution of taskintensiveness across the skill distribution. In figure 2.7, there is a representation of that. In the x-axis, we can see the percentiles of the skill distribution and, in the y-axis, we can see the task-intensiveness of these percentiles exhibited through a locally weighted smoothing regression.

While developed countries tend to see an inverted U-shape of the share of routine tasks, with the middle of the distribution concentrating them, this is not the case for Brazilian formal local labor markets. Like Riva (2016), I find that routine tasks (cognitive or manual) tend to be stable from the bottom and middle percentiles of the distribution, dropping significantly after the $75 \%$ percentile. However, routine cognitive tasks do observe lesser variation in the 
top quintiles when compared with manual tasks. Gains observed in terms of employment during the 2013-2017 period are concentrated in the top 20\% of the skill distribution, with negative effects in the bottom $80 \%$ of the skill distribution. It is clear here that the increased relative demand for skills may certainly be associated with increased demand for non-routine abstract tasks and reduced demand for manual and cognitive tasks.

Figure 2.7: Share of tasks in the skill percentiles

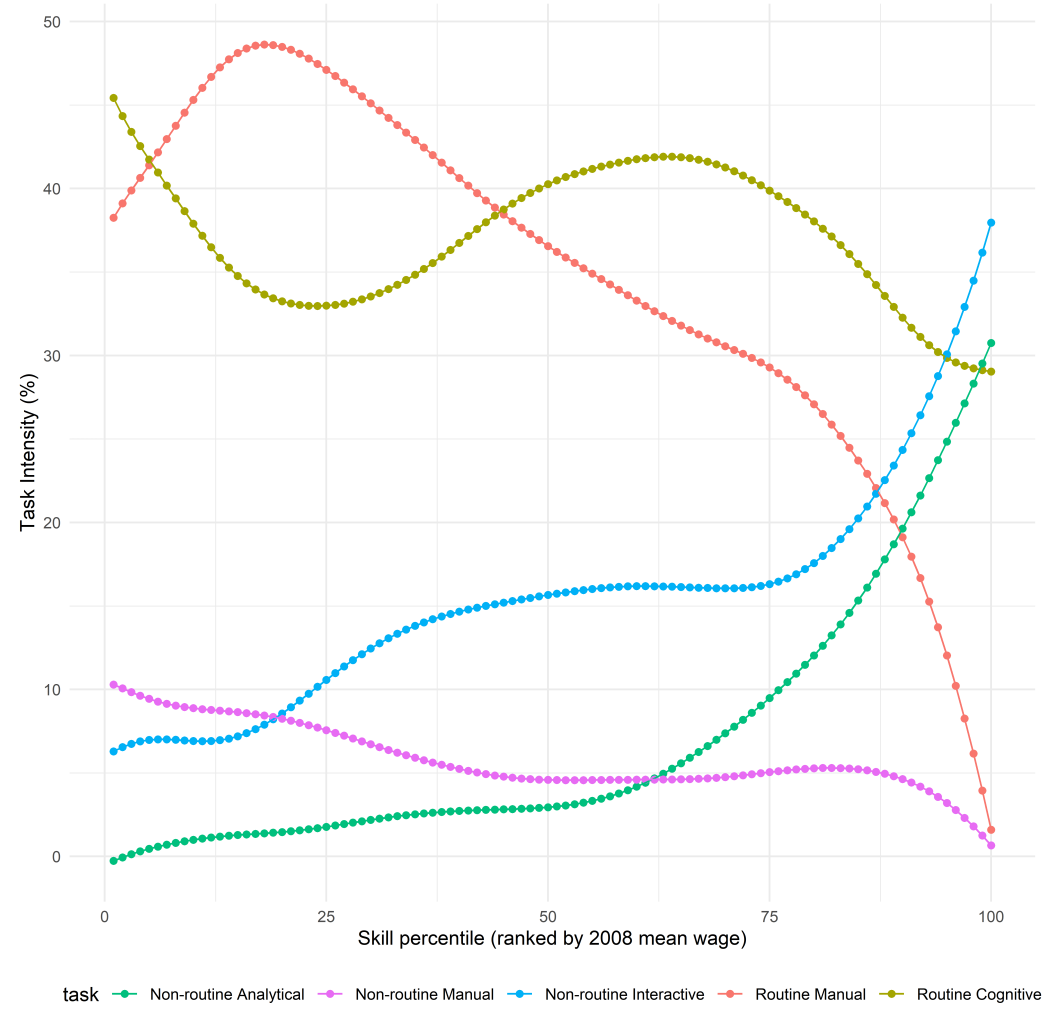

RAIS data and task-content data originally developed by Funchal $\&$ Soares (2013). Figure plots taskintensiveness shares by hundredths of the 2008 skill distribution. Percentiles are employment-weighted and the $y$-axis is represented by the output of a locally weighted smoothing regression Skill percentiles defined based on wages and the number of contracts for each occupation. Shares do not match exactly to 1 , due to the smoothing procedure.

Interestingly, these shifts in the demand for skills could be driven more by within educational groups changes rather than by increases in the share of workers with higher education. Figure 2.8 exhibit in panel A, in the y-axis, the share of the workforce among different groups of education and panel B, in the y-axis, the raw wage premium considering the log-differences between mean wages of high-school (or college) graduates and of workers that left high school (or had less attainment than that). There has been a steady increase in the supply of better-educated workers but there does not seem to be any big differences in terms of trends during the whole period. It is true, however, 
that college graduates seem to have a little more robust presence starting from 2015 (although this is not that clear in visualization) and the drop in college premiums decelerates in the same period.

Figure 2.8: Share of workers by educational groups and wage premiums
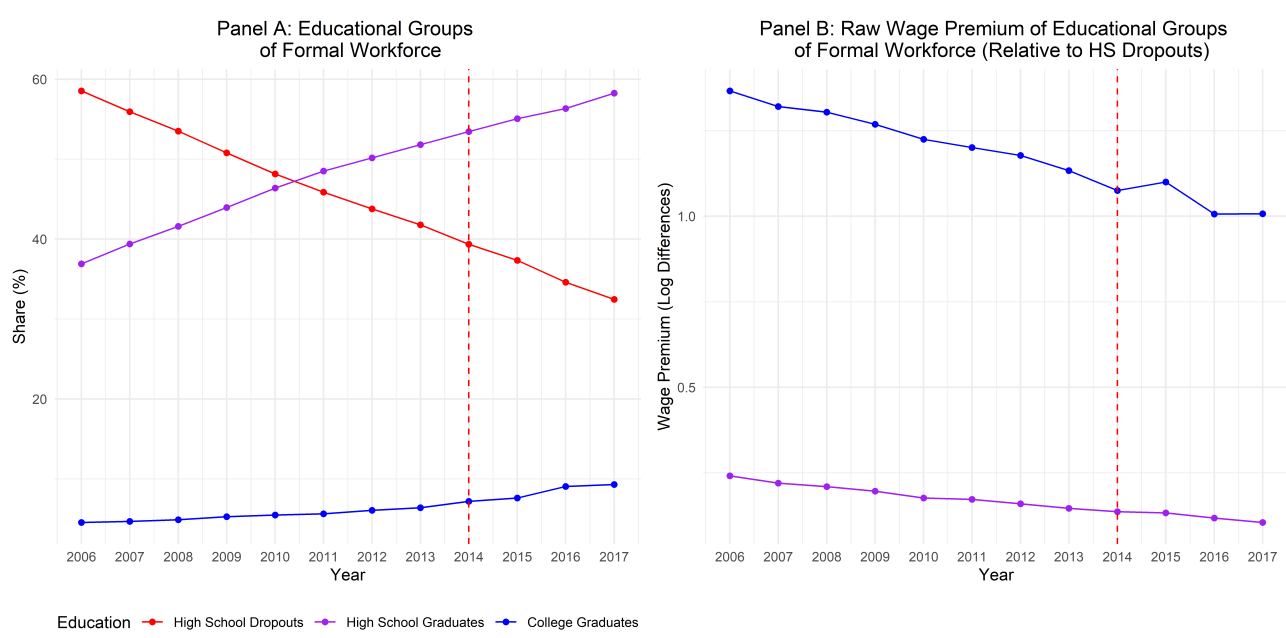

RAIS Data. Shares in Panel A represent the share of total contracts of the formal workforce through the year. High school dropouts represent workers with less than secondary education in Brazil, including those who had some high school education but have not completed it. High school graduates include workers that completed high school and those who have not fully completed college education but got some of it. College graduates are those who graduated in tertiary education or more (Master degree or Doctorate). Panel B compares the yearly log differences between the averages of these groups. Formally, this is the raw-wage premium.

Whether or not mobile broadband has played some role in the recent shifts in the demand for tasks and skills in Brazil is a relevant empirical question. In the next sections, I will use the provision commitments of ANATEL regulation as a source of exogenous variation in the presence of $4 \mathrm{G}$ internet informal labor markets in Brazil to estimate mobile broadband causal effects. 


\section{3 \\ Data}

\section{1 \\ Mobile broadband data}

ANATEL considers a municipality covered when $80 \%$ of its central district is covered by the mobile operator's infrastructure. While there is currently a publicly available dataset for connectivity, there is no public report at the municipality level for previous years. I requested through the Lei de Acesso a Informação to the government regulatory agency, which provided me with the yearly data from 2013 to 2019. ANATEL dataset includes information of each operator for each municipality, hence it is possible to determine not only the most advanced technology available $(2 \mathrm{G}, 3 \mathrm{G}$, or $4 \mathrm{G})$ but the number of operators providing it.

Through this information, it is possible to build access measures based on the share of population covered by at least one $4 \mathrm{G}$ operator or a competition measure based on the average number of operators on each municipality. This measures at the municipality level will be population weighted-averages. As the main variable for internet connection on this dissertation, I use the number of $4 \mathrm{G}$ operators, since ANATEL rules seem to have a stronger explanatory power than the share of individuals covered by at least one operator. ${ }^{1}$ Preferably, we would rather have information on the average number of subscriptions per capita at the local economy level, those are use measures. However, this variable of use is only available before 2019 at the Telephone Code (In Brazil, DDD code) Zone Area. DDD areas are smaller than states but tend to include several local economies (although for some states, this is not true and DDD borders and state borders are the same). This would significantly reduce the sample size, decreasing the statistical power of the regression analysis, therefore a measure of access rather than actual use is preferred: I use the number of mobile operators providing $4 \mathrm{G}$ in the market.

For complimentary analysis, I also use additional data for $3 \mathrm{G}$ from a consulting firm called Teleco, from 2009 to 2012, provided by Bessone et al.

${ }^{1}$ I will do a Two-Stage Least Square regression (2SLS) analysis. First stage F-stat was stronger considering the number of $4 \mathrm{G}$ mobile operators than with the share of individuals covered by at least one firm. 
(2020). The information in Teleco is very similar to the official regulatory agency dataset, especially in the extensive margin, presence of at least one firm. Considering the overlapping period between 2013 to 2016, I compare this dissertation's data and Bessone et al. (2020) original dataset (built by Teleco). When comparing $3 \mathrm{G}$ presence (a dummy that indicates at least one operator), compatibility between municipalities is higher than $92.5 \%$. When considering the number of operators, the compatibility is close to $90 \%$ in 2013 and 2014 but is close to $80 \%$ (75\%) in 2015 (2016). ANATEL's data shows a higher connectivity than Teleco's, but Brazilian national average's are very similar.

\section{2}

\section{Formal labor market}

I use RAIS, an administrative matched employee-employer annual dataset collected by the Brazilian Labor Ministry. All tax-paying companies must report in RAIS every worker with a formal employment contract during the previous calendar year. I use data from the years 2013 to 2017 in our main analysis. Additionally, I also collect information from 2006 to 2012. Firms reporting to RAIS have to provide information of workers about their tenure, age, gender, race, schooling, sector, establishment size, location of the job (municipality), as well as information of their wages and if they were hired or separated from firms. I focus on private-sector workers and remove duplicated contracts.

\section{3}

\section{Tasks}

I use an occupation-level dataset provided by Gonzaga \& Guanziroli (2019). It was originally created by Funchal \& Soares (2013). They use the Brazilian classification of occupations $(\mathrm{CBO})$ and the descriptions of these occupations. They then move on to classify each occupation based on its activities. Tasks performed by occupations are classified as routine (cognitive and manual) and non-routine (analytical, interactive, and manual). This mapping follows a task classification proposed by Spitz-Oener (2006) to classify 275 occupations in the Brazilian Occupation Code (Classificação Brasileira de Ocupações, CBO). With this, I can analyze the task composition of each occupation. On table 1, I offer the correspondences used by Funchal \& Soares (2013); it matches activities described the CBO with the classification of SpitzOener (2006).

Routine tasks are the ones that are easily codifiable and are more easily replaceable by machines. They can be manual, involving repetitive and 
Table 3.1: Categories of task and its correspondences in the CBO

\begin{tabular}{|c|c|}
\hline $\begin{array}{c}\text { As proposed by Sptiz- } \\
\text { Oener (2006) }\end{array}$ & Correspondence in CBO* \\
\hline Non-Routine Analytic & $\begin{array}{c}\text { Researching, Investigating, Analysing, } \\
\text { Examining, Studying, Evaluating, Planning, } \\
\text { Budgeting, Making diagnosis, Judging. }\end{array}$ \\
\hline Non-Routine Interactive & $\begin{array}{c}\text { Negotiating, Practising Law, Coordinating, } \\
\text { keading people, Teaching, Training, Spreading } \\
\text { knowledge, Instructing, Selling, Marketing }\end{array}$ \\
\hline Routine Cognitive & $\begin{array}{c}\text { Calculating, Programming, Transforming, } \\
\text { Bokkeping, Recording, Measuring, Verifying. }\end{array}$ \\
\hline Routine Manual & $\begin{array}{c}\text { Operating, Distributing, Transporting, Equipping } \\
\text { and Assembling. }\end{array}$ \\
\hline Non-Routine Manual & Repairing, Renovating, Serving, Accomodating, \\
Cleaning.
\end{tabular}

mechanical physical movement, or cognitive, such as simple mathematical calculations, bookkeeping, and easy accounting procedures. Non-routine tasks can be analytical, requiring important problem-solving techniques and complex thought, or they can be interactive, demanding communication abilities. There are also non-routine manual tasks, which involve activities that are not easily replaceable by machines and involve some more refined hand movements. Table 3.1 gives a brief set of examples of activities that are classified by each category.

Hence, I have the following measure for each occupation o and each category of task content $\mathrm{k}$ :

$$
\operatorname{Task}_{o}^{k}=\frac{\text { number of activities of type } \mathrm{k} \text { in o }}{\text { number of activities in } \mathrm{o}}
$$

I also create a routine-intensity index for each occupation o, that is:

$$
R_{o}=100 \times\left(\text { Task }_{o}^{\text {Routine }}-\text { Task }_{o}^{\text {Non-Routine }}\right)
$$

Where routine includes the cognitive and manual tasks and non-routine includes manual, analytical, and cognitive ones. Most of the results will be aggregated at the local labor market level. We shall have the following for each local labor market $\mathrm{m}$ :

$$
R_{m t}=\sum_{o \in \Theta} \text { Contracts }_{\text {omt }} \times R_{o}
$$

A similar measure $M_{m t}$ is built based upon the manual-content of tasks. $\Theta$ is a vector of all occupations o in the dataset. In total, there are 275 occupational codes (CBO 4-digits) with their task intensity defined, which represent about $85.1 \%$ of formal employment contracts. 


\section{4}

\section{Skill level variable}

I use two different measures of skill level. One of those is focused on schooling levels, but I also use the pre-treatment distribution of wages among workers (in 2008) and create an index from 0 to 100 for each occupation. The index is created by the following way:

$$
\text { Skill Index }{ }_{o}=100 \times \frac{\log \left(\max _{o \in \Theta}\left\{\text { wage }_{2008}\right\}\right)-\log \left(\text { wage }_{o 2008}\right)}{\log \left(\min _{o \in \Theta}\left\{\text { wage }_{2008}\right\}\right)-\log \left(\text { wage }_{o 2008}\right)}
$$

If the occupation is close to the most well payed occupation in the distribution, it gets a score close to a hundred. If it is close to the least well payed occupation, it is close to zero. The skill-level required of workers is not necessarily associated with education, this is an alternative measure of skill intensity in the local economy. As in the routine index level, for this skill index measure, changes in the demand for skills at the local labor market level will only be captured if they happen between occupations (as defined by the 4-digit occupational code). If a local economy observes an increase in the skill index, this means that there was an increase in occupations that were associated with higher wages in the pre-treatment period.

\section{5}

\section{Local labor market}

I use the same local labor market definitions as the ones of Dix-Carneiro \& Kovak (2015), Costa et al. (2016), and Dix-Carneiro et al. (2018). Microregions are groups of municipalities defined by IBGE based on local economies' characteristics. They are good approximations of commuting zones or local labor markets. I do most of my analysis at the local labor market level and, hence, I aggregate all the relevant outcomes and dependent variables from other datasets. Proceeding with a regression analysis at the local labor market presents some important advantages. When a municipality receives mobile broadband services, neighboring municipalities could have their local labor markets affected in, at least, two ways. First, through a direct connectivity channel: infrastructure from mobile networks will possibly affect bordering neighborhoods from other municipalities. Once a mobile operator installs an antenna in a certain region, the same antenna can be used to cover part of the other municipality. Network forces and gains of scale could also potentially foster connectivity in neighboring regions. Secondly, there are potential general equilibrium effects: if mobile broadband affects the demand of tasks in one of 
the municipalities of a local labor market, this could cause changes in the price of tasks in the labor market as whole.

In my analysis, I use 385 microregions (out of 413), excluding 26 local labor markets that include state capitals, one that does not exhibit formal contracts in all years, and the national capital, Brasília. I remove capitals from my analysis because, while they serve as a parameter of the rule of provision commitments, as established by ANATEL, the fact that they are capitals also mean that they receive other types of special treatment in terms of policy and government investment, leading to very different pre-trends that could potentially invalidate the intended identification strategy.

\section{6}

\section{Additional variables}

I use population estimates and population official counts (from Censuses) by IBGE extracted from SIDRA, their website for extraction of social statistics. Additionally, I use publicly available data on MEIs for Brazilian Federal Revenue System. I also use a measure of industry's technological intensity provided by Corseuil et al. (2018). They use an October 2003 supplement of the US Census Bureau's CPS. In this survey, respondents were asked to answer if they used a computer on their current job. The authors aggregate this at the industry category, calculating the share of workers who used a computer in each sector. They then match the industry category used in the US with Brazilian categories CNAE 1.0. While it is true that there will be differences in terms of the real share of computers used by Brazilian firms, it is reasonable to assume that, at least in relative terms, computer-intensive sectors in the US will probably be the computer-intensive sectors in Brazil.

\section{7 \\ Descriptive Statistics}

In table 3.2, we can see relevant labor market outcomes and connectivity measures of $3 \mathrm{G}$ and $4 \mathrm{G}$ technologies. As shown in panel $\mathrm{A}$, the average worker in the selected local labor markets had no connection of $4 \mathrm{G}$ technology and lived in a labor market where $92 \%$ of the population had at least one operator providing $3 \mathrm{G}$ services in their market. On average, $3 \mathrm{G}$ services were provided by 3 operators. In fact, $3 \mathrm{G}$ connection was very widespread in the country. As shown by the minimum number of $3 \mathrm{G}$ operators (1.55), there is no local labor market which is covered by no less than one firm (although such coverage may not be offered for all municipalities in local labor markets). 
Another important factor is the task content and the average skill index. It shows that the average worker in Brazil was overwhelmingly in low-skilled occupations (index varies from 0 to 100) and the majority of its tasks are routine tasks. Routine tasks represent $75 \%$ of the share of tasks, divided almost equally among routine cognitive and routine manual activities. These statistics are related to formal labor markets only since I'm using RAIS data.

Panel B shows a rapid expansion of $4 \mathrm{G}$ connection. The average formal worker lived in a local labor market where more than $70 \%$ of the population had a $4 \mathrm{G}$ connection and $3 \mathrm{G}$ services are almost accessible to all people (99.32\%). Nonetheless, variation is high in terms of $4 \mathrm{G}$ availability, while some local labor markets are fully covered by $4 \mathrm{G}$, others do not have this type of mobile broadband for more than $10 \%$ of the population. On average, this coverage is provided by 2 firms, but there is also a lot of variation.

Contemporaneous to the expansion of $4 \mathrm{G}$ connections, there were remarkable shifts in the number of contracts and task content. There was a significant decrease in the number of contracts, by close to $20 \%$. It is important to note, however, that Brazil has also experienced a very significant drop of economic activity due to the economic crisis of 2015-2016 and weak growth after that. The reduced employment levels were not homogenous among tasks. The share of manual tasks (routine and manual) reduced while non-routine cognitive and routine cognitive experienced increases. There was also a noticeable increase of the average skill level. 
Table 3.2: Descriptive Statistics

\begin{tabular}{|c|c|c|c|c|}
\hline \multicolumn{5}{|c|}{ Panel A: 2013} \\
\hline Statistic & Mean & SD & $\operatorname{Pctl}(10)$ & Petl(90) \\
\hline Number of Contracts & 209936 & 246335 & 21956 & 384844 \\
\hline 4G Available (\%) & 0.00 & 0.00 & 0.00 & 0.00 \\
\hline 3G Available (\%) & 92.43 & 13.91 & 74.32 & 100.00 \\
\hline Number of $4 \mathrm{G}$ firms & 0.00 & 0.00 & 0.00 & 0.00 \\
\hline Number of $3 \mathrm{G}$ firms & 2.95 & 0.97 & 1.55 & 3.96 \\
\hline Wage & 1331.75 & 319.14 & 947.98 & 1745.03 \\
\hline Skil Index $(0-100)$ & 19.91 & 2.28 & 17.29 & 22.54 \\
\hline Non-routine Analytical (\%) & 6.04 & 1.24 & 4.53 & 7.60 \\
\hline Non-routine Interactive (\%) & 14.65 & 2.24 & 12.05 & 17.52 \\
\hline Non-routine Manual (\%) & 5.93 & 0.81 & 5.22 & 6.81 \\
\hline Routine Manual & 36.28 & 4.34 & 31.34 & 42.32 \\
\hline Routine Cognitive & 37.10 & 2.51 & 34.08 & 40.38 \\
\hline \multicolumn{5}{|c|}{ Panel B: 2017} \\
\hline Statistic & Mean & SD & $\operatorname{Pctl}(10)$ & Petl(90) \\
\hline Number of Contracts & 168404 & 200978 & 18508 & 304718 \\
\hline 4G Available (\%) & 71.83 & 32.00 & 10.52 & 100.00 \\
\hline $3 \mathrm{G}$ Available (\%) & 99.32 & 3.24 & 98.86 & 100.00 \\
\hline Number of $4 \mathrm{G}$ firms & 2.08 & 1.26 & 0.11 & 3.51 \\
\hline Number of $3 \mathrm{G}$ firms & 3.43 & 0.59 & 2.64 & 3.98 \\
\hline Wage & 1394.29 & 315.60 & 1020.17 & 1815.61 \\
\hline Skil Index $(0-100)$ & 20.83 & 2.54 & 18.07 & 23.50 \\
\hline Non-routine Analytical (\%) & 6.38 & 1.40 & 4.81 & 8.04 \\
\hline Non-routine Interactive (\%) & 15.99 & 2.37 & 13.21 & 18.68 \\
\hline Non-routine Manual (\%) & 5.65 & 0.73 & 4.85 & 6.42 \\
\hline Routine Manual & 33.36 & 4.29 & 28.20 & 38.87 \\
\hline Routine Cognitive & 38.62 & 2.07 & 35.74 & 41.11 \\
\hline
\end{tabular}

Mobile broadband data from ANATEL and local labor market data from RAIS. Results are weighted by the number of contracts in 2013 on each of 385 local labor markets. The following table exhibits the descriptive statistics of observable characteristics of broadband connection and labor market outcomes. Panel A exhibits outcomes for the year of 2013 and Panel B exhibits outcomes for the year of 2017. 


\section{4 \\ Identification strategy}

\section{1}

\section{OLS estimates - limitations}

The two-way fixed effects model is a common approach in Economics to identify the causal impact of mobile broadband technologies in labor markets when using panel data. Equation (1) represents these types of models:

$$
y_{m t}=\alpha_{m}+\alpha_{t}+\beta \text { Operators of } 4 \mathrm{G}_{m t}+X_{m t}^{\prime} \gamma+\varepsilon_{m t}
$$

Where $y_{m t}$ represents the outcome of interest for labor market $m$ and year t, $\alpha_{m}$ is a labor market fixed effect, $\alpha_{t}$ is year fixed effect, $X_{m t}$ are a vector of controls, and $\varepsilon_{m t}$ is an error term. The parameter of interest is $\beta$. This parameter describes the effects of an additional $4 \mathrm{G}$ operator in local labor markets. The number of operators is a population-weighted average of the number of operators of each municipality. One of the key necessary conditions to a causal interpretation of the OLS estimate of is the following:

$$
E\left[\varepsilon_{m t} \mid \text { Operators of } 4 \mathrm{G}_{m t}, \alpha_{m}, \alpha_{t}, X_{m t}\right]=0
$$

That is, conditional on fixed effects and observable controls, entry, and variation on the extensive margin of $4 \mathrm{G}$ companies (number of operators) is exogenous and uncorrelated with the error term. There are reasons to believe, however, that this assumption is difficult to hold in most of the cases in the real world, including in our context. Mobile broadband technologies have high fixed costs of entry and, usually, operators tend to expand on regions where there is a high demand for those services. One possible approach to try to achieve causal estimates of $4 \mathrm{G}$ effects is to control for observed variables that could be related to internet expansion and also with labor market effects. Controlling for educational level and income would have been a possible path. However, it may be the case that there are unobservable factors that tend to influence $4 \mathrm{G}$ entry and that could be related to labor outcomes. Moreover, if there is a possibility of reverse causality between $4 \mathrm{G}$ technologies and labor market outcomes, then the OLS estimates will yield biased estimates of the 
real effects of mobile broadband expansion. A local labor market that has faced an adverse demand shock, for example, could have higher unemployment, and for this reason, entry of $4 \mathrm{G}$ technologies may be postponed.

\section{2}

\section{Instrumental Variable}

To avoid the problem of reverse causation between $4 \mathrm{G}$ coverage by operators and labor market outcomes and of omitted variable bias, I use an IV approach. In the Brazilian context, ANATEL's regulatory framework could be used as an instrument that generates exogenous variation in $4 \mathrm{G}$ presence. It is important to remind that ANATEL defined, during the auction procedure, deadlines for coverage by all $4 \mathrm{G}$ operators for each municipality. Deadlines were defined by population size in 2010. I use the average waiting time for compliance in the baseline year (2013) and interact it with dummies of treatment years (post-2014) Therefore, the instrument can be represented as follows:

$$
Z_{m t}=\left(\begin{array}{c}
I_{2015} \\
I_{2016} \\
I_{2017}
\end{array}\right) \times \overline{Y f C}_{m 2013}=\left(\begin{array}{c}
I_{2015} \\
I_{2016} \\
I_{2017}
\end{array}\right) \times \sum_{i \in m}\left(s_{i} \times Y f C_{i 2013}\right), \text { s.t. } s_{i}=\frac{P_{o p_{i 2010}}}{\sum_{j \in m} P_{o p} p_{j 210}}
$$

$Z_{m t}$ is a vector of instrumental variables for local labor market $m$ and year $\mathrm{t}, I_{t}$ is a dummy variable for year t, and $\overline{Y f C}_{m 2013}$ represents the average years for compliance in the local labor market in the baseline year of 2013. Note that $s_{i}$ represents the share of municipality i in local labor market m, while $Y f C_{i 2013}$ represents the number of years for compliance, as described by ANATEL's rule. Since I exclude capitals from my analysis, $Y f C_{i 2013}=f\left(P_{o p_{i 2010}}\right)$ where $\mathrm{f}($. varies discontinuously among the thresholds presented in section 2 .

With that instrumental variable, I'm able to estimate through a two-stage least square (2SLS) estimator. Formally:

$$
\begin{aligned}
& 2^{n d} \text { Stage: } y_{m t}=\alpha_{m}+\alpha_{t}+\beta \text { Operators of } 4 \mathrm{G}_{m t}+X_{m t}^{\prime} \gamma+\varepsilon_{m t} \\
& 1^{s t} \text { Stage: Operators of } 4 \mathrm{G}_{m t}=\zeta_{m}+\zeta_{t}+Z_{m t}^{\prime} \delta+X_{m t}^{\prime} \psi+u_{m t}
\end{aligned}
$$


To obtain a causal interpretation of $\hat{\beta}_{2 S L S}$, two relevant necessary conditions need to hold:

1. Conditional on the covariates, the instrument must have an effect on $4 \mathrm{G}$ presence, i.e., $\delta \neq 0$.

2. The exclusion restriction: $Z_{m t}$ has an impact on $y_{m t}$ only through the relationship described in the first stage.

For this second assumption to hold, it is necessary that $E\left[\varepsilon_{m t} \mid\right.$ Operators of $\left.4 \mathrm{G}_{m t}, \alpha_{m}, \alpha_{t}, X_{m t}\right]=0$. That is, conditional on fixed effects and controls, $\varepsilon_{m t}$ is orthogonal to $Z_{m t}$. Notice, however, that two important elements of the formula are $s_{i}$ and $Y f C_{i 2013}$. Remember that $Y f C_{i 2013}=f\left(P_{o p} p_{2010}\right)$, i.e., the years for compliance of national operators is a function of population in municipality i. Therefore, the average years for compliance is correlated with the total population of the local labor market $\sum_{j \in m} \operatorname{Pop}_{j 2010}$. Moreover, $s_{i}$ is possibly related with the degree of political fragmentation in the labor market, that, is, the average $s_{i}$ is negatively correlated with the number of municipalities in the labor market.

Larger local labor markets may be more attractive for $4 \mathrm{G}$ companies and correlated with more dynamic formal markets. Moreover, politically fragmented local labor markets may affect economic dynamism while making it more difficult for the installation of broadband technologies. Therefore, it is crucial to control for these factors. The assumption here is that, when accounting for time and local labor market fixed effects and trend effects of total population and political fragmentation, the variation caused by ANATEL rules on $4 \mathrm{G}$ coverage should be potentially exogenous. ${ }^{1}$

Figure 4.1, below, gives an intuitive hypothetical scenario: local labor markets A and B have 4 municipalities and 300,000 people in 2010. The distribution of population within local labor markets yields remarkably different results. On average, the local labor market A will wait close to one year and a half more than local labor market B to have the ANATEL rule become binding. I explore this type of heterogeneity in binding rules to capture exogenous variation in $4 \mathrm{G}$ presence.

One way to understand this IV approach is in the shift-share approach. Absent from ANATEL rules, local labor markets with the same population size and initial political fragmentation would have had the same mobile broadband

\footnotetext{
${ }^{1}$ An important detail is that I restrict my analysis to local labor markets that do not include capitals. Capitals are a priority of ANATEL rules, but they are also a priority for many other policies and laws. Even if we control for trend-effects of population size and the number of municipalities in the local labor markets, many other confounding factors may be in place for capitals.
} 
Figure 4.1: Two hypothetical labor markets with same population and number of municipalities

\begin{tabular}{|l|r|r|r|r|}
\hline Local Labor Market A & Population & YfC in 2013 \\
\hline Munic 1 & 98,000 & 5.00 \\
\hline Munic 2 & 98,000 & 5.00 \\
\hline Munic 3 & 80,000 & 5.00 \\
\hline Munic 4 & 24,000 & 7.00 \\
\hline Total $\mid$ Average & 300,000 & 5.16 \\
\hline
\end{tabular}$\quad$\begin{tabular}{|l|r|r|}
\hline Local Labor Market B & Population & YfC in 2013 \\
\hline Munic 1 & 200,001 & 3.00 \\
\hline Munic 2 & 39,997 & 5.00 \\
\hline Munic 4 & 30,001 & 5.00 \\
\hline Total $\mid$ Average & 300,000 & 5.00 \\
\hline \\
Local Labor Market A: \\
5.16 Years for Compliance
\end{tabular}

expansion after the spectrum sub-band auctions. And how does ANATEL's rule would be different among those local labor markets? Through the shares of each municipality in the labor market's total population. Local labor markets that have a higher share of its population in municipalities where ANATEL assigned them as early receivers should be more prone to get early access to mobile broadband expansion and increased competition between $4 \mathrm{G}$ firms.

Goldsmith-Pinkham et al. (2020) argue that shift-share approach is analogous to GMM estimates where initial shares are the instruments. Therefore, exogeneity of a shift-share approach is given by the exogeneity of its initial shares. In this dissertation's context, therefore, it would be necessary that, controlling for population size and political fragmentation effects, the initial share of the population in each of ANATEL's category should be exogenous to conditions of local labor market. This is plausible.

As we see from the hypothetical example in figure 4.1, getting to have an initial share of a certain municipality as an early receiver is probably correlated to have one municipality that concentrates more of the total population than another, but it is often the case where political concentration does not mean practical real-world concentration of a municipality. In fact, since I'm relying upon local labor markets as the unit of observation, this even more 
likely by construction, since local labor market are constructed to represent geographically contiguous, relatively connected, regions that share common economic dynamics and functions as a single labor market.

This theoretical plausibility will be further reinforced with empirical evidence. If initial shares are exogenous, we won't see relevant pre-treatment effects of the instrument, when controlling for the population size and political fragmentation effects. In the empirical results, we see no robust evidence of these pre-trends. Therefore, the assumption of exogeneity of initial shares seems to hold. 


\section{Main results: aggregate effects in local labor markets}

\section{1}

\section{First Stage}

Figure 5.1: Correlation between number of 4G Operators and ANATEL's average years of compliance

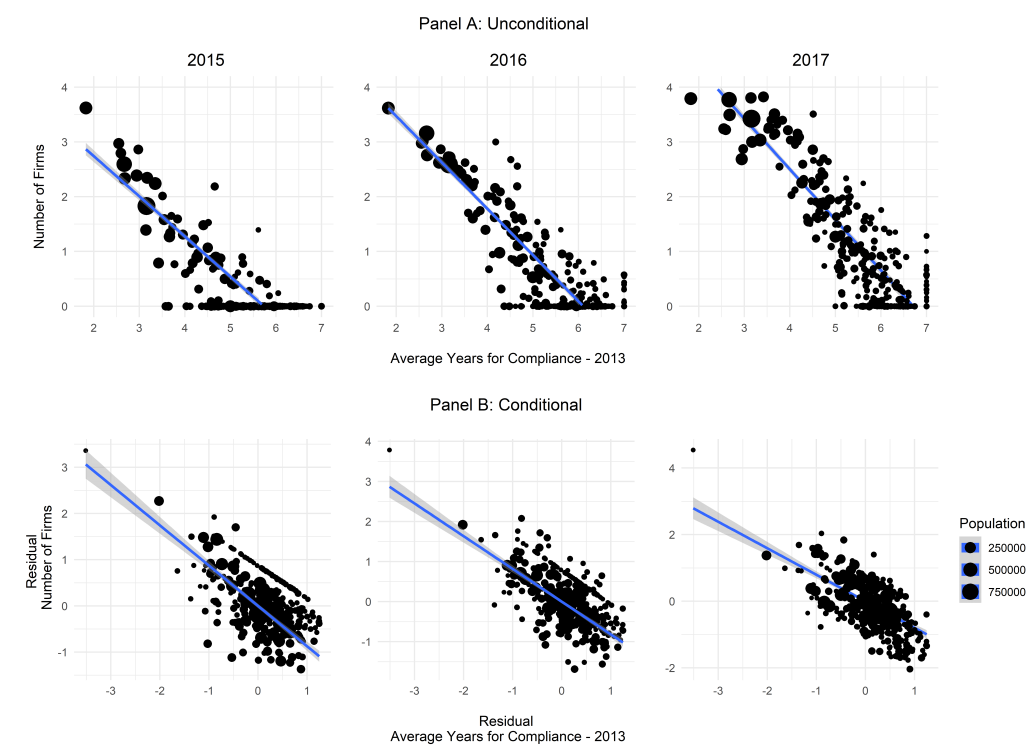

ANATEL data. Figure represents a scatter plot of the relationship between the share of the population covered by at least one $4 G$ operator and ANATEL's average waiting year so that operators will have to cover the municipalities of each local labor market. Panel A exhibits the raw correlation and Panel $B$ exhibits the conditional correlation, controlling for population size and political fragmentation of each local labor market. In blue, the linear fit. Regressions are weighted by the number of contracts of each local labor market in 2013. 385 local labor markets.

Causal identification assumptions of instrumental variables are not directly testable, but there is robust evidence that the instrument is strong. Figure 5.1 exhibits the correlation between ANATEL's deadline years for compliance and the $\%$ of population covered by at least one $4 \mathrm{G}$ operator. As expected, local labor markets with longer waiting times for mobile operators' compliance to provision commitments are the regions where $4 \mathrm{G}$ provision was lower. Strikingly, as we can see in panel B, this pattern holds when controlling for relevant factors for $4 \mathrm{G}$ expansion that are associated with ANATEL rules 
(population size and political fragmentation). Figure 5.2 exhibits two maps of the state of Minas Gerais in 2017. The first represents average years for compliance in 2017 and the second one represents the average number of $4 \mathrm{G}$ firms in each of those regions. Red regions represent local labor markets with longer waiting periods and a lower average presence of $4 \mathrm{G}$ firms.

Figure 5.2: Local labor markets of Minas Gerais - Years for compliance and number of $4 \mathrm{G}$ Operators
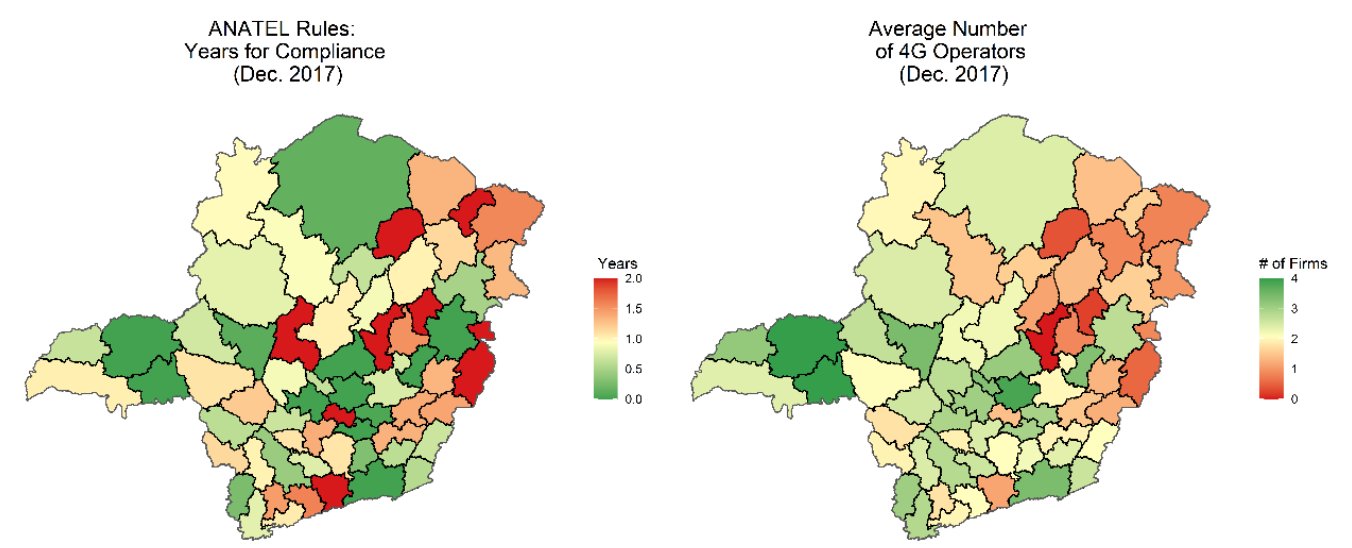

ANATEL data. The figure exhibits Brazilian local labor markets in terms of years for compliance and aveage number of operators.

While there is little doubt about this pattern of the causal impact of rules in $4 \mathrm{G}$ provision, it could be argued that government-induced supply of $4 \mathrm{G}$ services may not be met with significant adoption by population and firms. However, Figure 5.3 shows that this is not the case. Conditional on population size and political fragmentation, there is still a negative association between ANATEL's Years for Compliance and the number of active $4 \mathrm{G}$ subscriptions (SIM cards with active $4 \mathrm{G}$ connection) per capita. This suggests that not only does ANATEL's regulations increase the presence of $4 \mathrm{G}$, but it also fosters early adoption by users, possibly through a competition channel. 
Figure 5.3: Correlation between 4G access per capita and ANATEL's average years of compliance
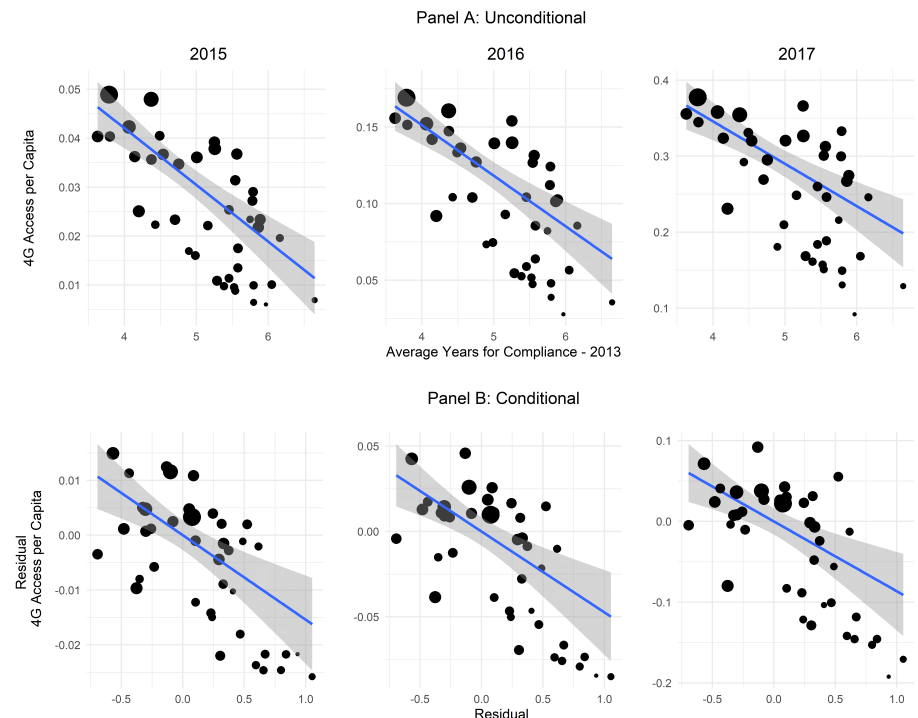

Panel B: Conditional
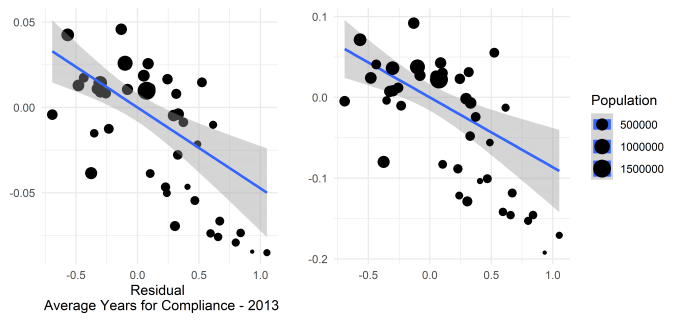

ANATEL data. Figure represents a scatter plot of the relationship between the number of $4 G$ subscriptions per capita and ANATEL's average waiting year so that operators will have to cover the municipalities of each local labor market. Panel A exhbits the raw correlation and Panel B exhibits the conditional correlation, considering the. In blue, the linear fit. Regressions are weighted by the number of contracts of each local labor market in 2013. 385 local labor markets.

The first stage equation is estimated in Table 5.1. All columns are controlling for year and labor market fixed effects. It shows that longer waiting periods for mandatory provision of $4 \mathrm{G}$ services reduce the average number of firms in local labor markets. More importantly, as column 2 shows, results are robust for two relevant controls: the population size and the number of municipalities iterated with year dummies. That is, when comparing local labor markets with a similar population size and number of municipalities, ANATEL rules has still a large and significant effect on $4 \mathrm{G}$ provision. It is important to note that, in column 3, I also control for state trends and coefficients are very similar. For column 3, on average, ceteris paribus, a local labor market with one SD more years of compliance than another local market, will have one less $4 \mathrm{G}$ operator providing broadband services in it.

In the appendix, table A.1, I also provide similar estimates for different outcomes. For regressions on the share of the population covered by at least one company, results are at the local labor market level; for the number of $4 \mathrm{G}$ access per capita, at the telephonic zone code level. Controlling for statespecific trends, I show that an extra year for compliance reduces the share of population covered by at least one firm in 20 p.p on average, and decrease users' access on average of 2015 to 2017 by about 5 users per capita, effects 
Table 5.1: Effects of ANATEL rules

\begin{tabular}{|c|c|c|c|}
\hline & \multicolumn{3}{|c|}{ Dependent variable: } \\
\hline & \multicolumn{3}{|c|}{ Number of $4 \mathrm{G}$ Firms } \\
\hline & $(1)$ & $(2)$ & $(3)$ \\
\hline $\mathrm{YfC} \times 2015$ & $\begin{array}{c}-0.733^{* * *} \\
(0.036)\end{array}$ & $\begin{array}{c}-0.872^{* * *} \\
(0.089)\end{array}$ & $\begin{array}{c}-0.855^{* * *} \\
(0.095)\end{array}$ \\
\hline YfC $\times 2016$ & $\begin{array}{c}-0.845^{* * *} \\
(0.025)\end{array}$ & $\begin{array}{c}-0.817^{* * *} \\
(0.041)\end{array}$ & $\begin{array}{c}-0.758^{* * *} \\
(0.040)\end{array}$ \\
\hline YfC $\times 2017$ & $\begin{array}{c}-0.923^{* * *} \\
(0.024)\end{array}$ & $\begin{array}{c}-0.795^{* * *} \\
(0.100)\end{array}$ & $\begin{array}{c}-0.767^{* * *} \\
(0.087)\end{array}$ \\
\hline Labor Markets FE & $\mathrm{X}$ & $\mathrm{X}$ & $\mathrm{X}$ \\
\hline Year FE & $\mathrm{X}$ & $\mathrm{X}$ & $\mathrm{X}$ \\
\hline $\log \left(\operatorname{Pop}_{2010}\right) \times Y$ & & $\mathrm{X}$ & $\mathrm{X}$ \\
\hline$\#$ Munic $\times Y$ & & $\mathrm{X}$ & $\mathrm{X}$ \\
\hline State Trends & & & $\mathrm{X}$ \\
\hline Observations & 1,925 & 1,925 & 1,925 \\
\hline Adjusted $\mathrm{R}^{2}$ & 0.918 & 0.921 & 0.936 \\
\hline
\end{tabular}

All models control for local labor markets and years fixed effects. Regressions are weighted by the level of contracts in 2013. Columns (1) to (3) are OLS estimates. Robust standard errors are clustered at the meso-region level. Numbers between parenthesis are the coefficient standard deviations. $\log \left(\mathrm{Pop}_{2010}\right) \times \mathrm{Y}$ represents the trend-effects of the log-population of 2010 (yearly dummies interacted with this variable). \# Munic $\times \mathrm{Y}$ represents the trend-effects of the number of municipalities in local labor markets (yearly dummies interacted with this variable). * represents significance at the $10 \%$ level, ${ }^{* *}$ represents significance at the $5 \%$ level, and ${ }^{* * *}$ represents significance at the $1 \%$ level.

of adoption by users, however, are stronger as time goes by: one additional year of waiting reduces in 1.5 users per capita in 2015 and 8.6 users in 2017. Therefore, the first stage is strong. 


\section{2}

\section{Pre-trends and instrument exogeneity}

One may be concerned, however, about the identification strategy and fear that the results implied by the IV estimates absorb other sorts of biases. Even when accounting for trend effects of population size and political fragmentation, the exclusion restriction of $Z_{m t}$ may not hold. There is no way to directly test this hypothesis, but at least I can check if, conditional on controls, $Z_{m t}$ is associated with divergent pre-trends.

Hence, I shall estimate the $\hat{\omega}$ of the following reduced form equation:

$$
\begin{aligned}
& y_{m t}=\tilde{\alpha}_{t}+\tilde{\alpha}_{m}+X_{m t}^{\prime} \tilde{\gamma}+\tilde{Z}_{m t}^{\prime} \omega+\eta_{m t} \\
& \text { s.t. } \tilde{Z}_{m t}^{\prime}=\left(\begin{array}{c}
I_{2015} \\
\vdots \\
I_{2017}
\end{array}\right)_{t \neq 204} \times \overline{Y f C}_{m 2013}
\end{aligned}
$$

With these estimates, we can proceed to some sort of analysis of pretrends. If $\tilde{Z}_{m t}$, conditional on controls, is not independent from labor market outcomes before 2014, this would be an indication that the exclusion restriction won't hold. After all, if $\tilde{Z}_{m t}$ is correlated with some previous pre-trend of the labor market, it may well be the case that the instrument is not as good as random and that the 2SLS estimates are biased. Figure 5.4 plots the vector $\hat{\omega}$ and $95 \%$ confidence interval (CI). It shows that there is no evidence of pretrends on any relevant labor market outcome variable. For all coefficients of years before 2014 , point estimates are close to zero and are not statistically significantly different from zero. It is true, however, that for educational level variables (such as the share of people of high school dropouts) point estimates are a little distant from zero, but, yet, these coefficients are not precise, as they are not significantly different from zero at the $5 \%$ level. Moreover, in table 5.2, I estimate the $\hat{\omega}$ for a dummy $I_{(t<2014)}$, and they are not statistically different from zero at a $5 \%$ level. However, there is some evidence that labor markets that were set to wait more for $4 \mathrm{G}$ coverage previously had a higher share of high-school dropouts. Nonetheless, the null hypothesis for pre-trend coefficients of the share of workers that did not complete and those that completed high school is only rejected at the $10 \%$ level but not at $5 \%$ level.

Since I am estimating the number of contracts in 2013 as weights, some could argue that these pre-trends results could be excessively driven by large labor markets. In the appendix, I repeat the same procedure, also excluding labor markets with municipalities with more than 500,000 inhabitants. As we can see in figure A.5, the results are qualitatively similar but a little worse. 
In some cases, some of the point estimates are far for from zero but they are rarely statistically different from zero at the $5 \%$ significance level. Table A.4 shows no clear sign of pre-trends when considering a single dummy for all the pre-trend periods, except for some educational variables that are statistically different from zero at $5 \%$ level and manual tasks at $10 \%$ level. Due to these possible concerns in differential trends in terms of educational outcomes, we will address attentively to this issue in the robustness section. I also do that for other previous trends in other observable variables. It is possible to anticipate that this dissertation's results do not seem to be driven by these trends, and they tend not to change very substantially any of the results. 
Figure 5.4: Pre-trend analysis of reduced form effects of ANATEL's average years of compliance on local labor market outcomes. (95\% Confidence Interval)
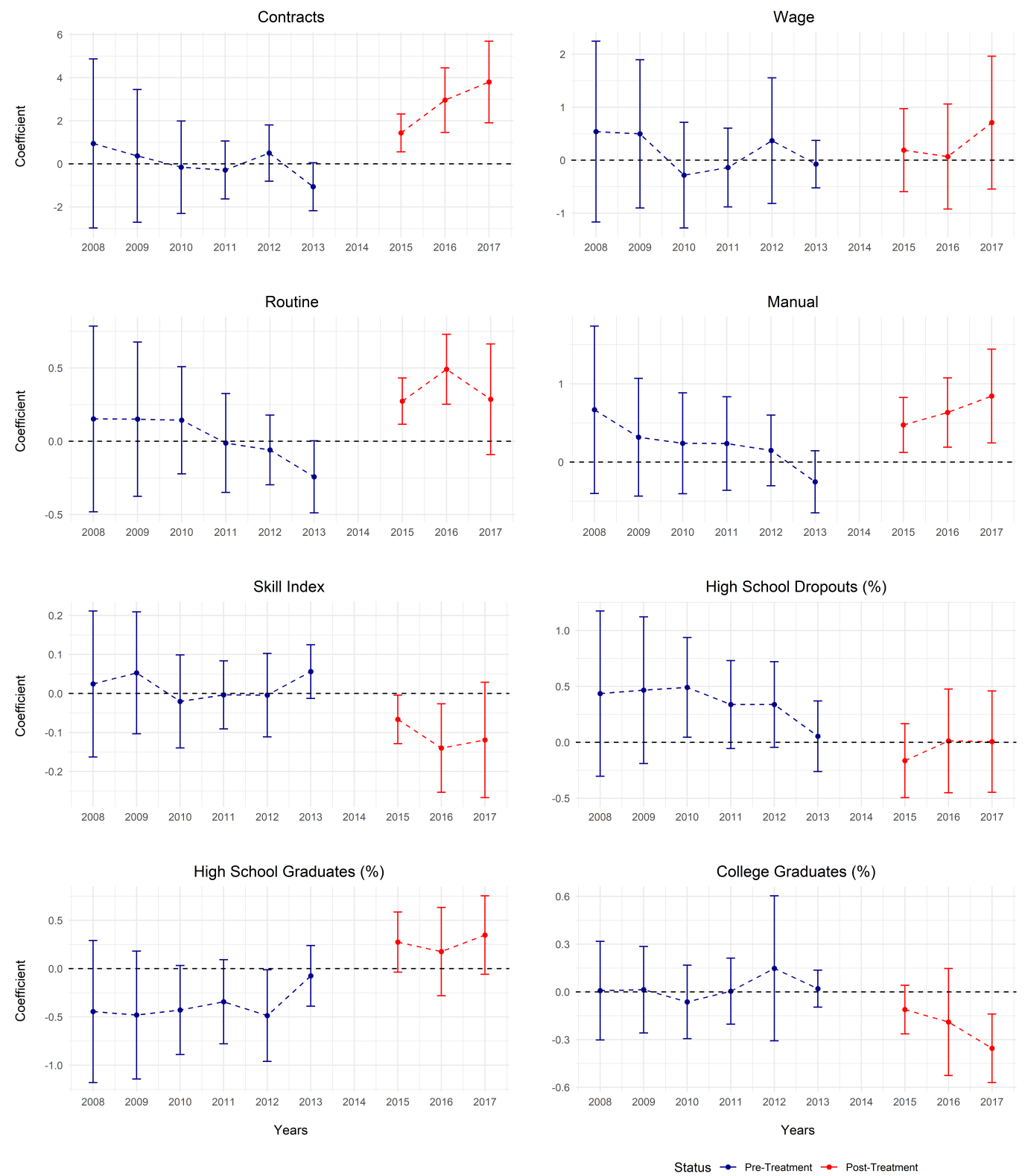

Local labor market data from RAIS. Each coefficient represents the OLS coefficients of the ANATEL rules interacted with dummies for each year. All reduced-form regressions control for trend effects of state-specific factors, population size, and political fragmentation. Error bar indicates the $95 \%$ confidence interval. Robust standard errors are clustered at the meso-region level. The sample includes 385 micro-regions. 


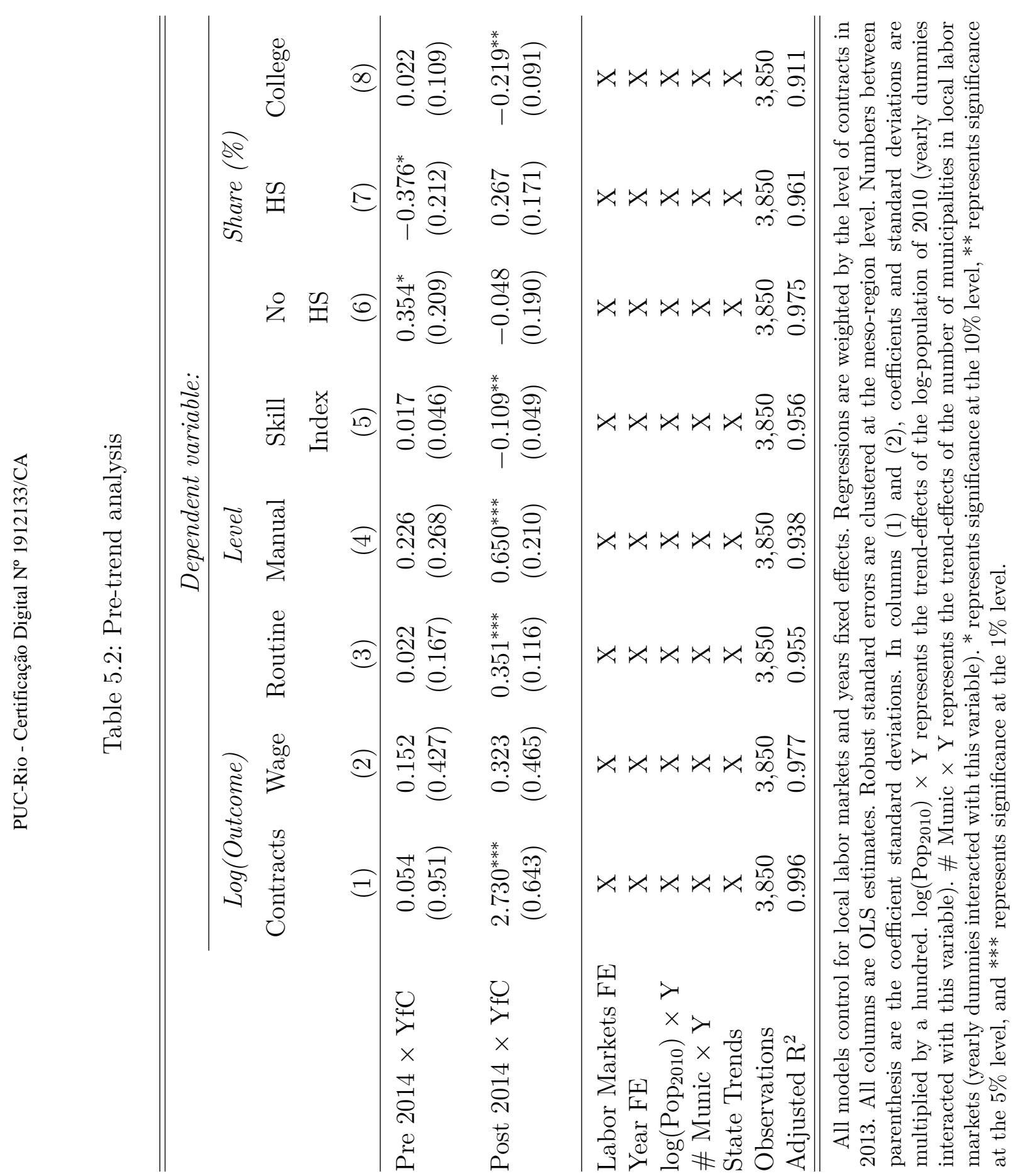




\section{3 \\ Main results}

We are interested in the impact of $4 \mathrm{G}$ presence in labor market outcomes. My preferred specification is the IV regression, controlling for local economy and year census fixed effects. Moreover, it also controls for state-specific trends and trend-effects of initial population and number of municipalities (these variables interacted with yearly dummmies). For all tables in this dissertation, results are weighted by the number of formal contracts in 2013 and standarderrors are clustered at the meso-region level. OLS estimates results may be textually reported to contrast it with IV estimates and discuss the potential omitted variable bias related with it.

Table 5.3 outlines the effects of provision of $4 \mathrm{G}$ services on the level of formal employment contracts in the labor market. Columns 1 to 3 are estimates of the linear model using OLS. I start with a very simple specification controlling only for fixed effects of year and labor market, then I control for political fragmentation and population size effects on trends in column 2, and, in column 3, I consider possible differential among state trends. This latter control is relevant because some states like Ceará and Minas Gerais had special connectivity programs that fostered $4 \mathrm{G}$ participation. OLS estimates do not vary a lot in all of these first three specifications and the effects are mild. In column 3, one additional $4 \mathrm{G}$ firm reduces formal employment contracts in $1.75 \%$. Considering the $95 \% \mathrm{CI}$, a lower bound of the effects are of $-0.8 \%$ and an upper bound is of $-2.7 \%$.

In columns 4 to 5 , the IV specification, shows much stronger displacement effects. In column 5 , one additional $4 \mathrm{G}$ provider reduces formal contracts by $4 \%$ (although it is also true that the effects are less precise). There was an average increase of 2 firms in Brazil from 2013 to 2017. This increase reduces in $8 \%$ the number of formal employment contracts. In the same time period, in labor markets excluding state capitals and the Federal District, there was a reduction of employment by $20 \%$, which could indicate that the expansion of $4 \mathrm{G}$ could be responsible for $40 \%$ of the fall in the period. Considering the $95 \%$ CI, this effect could represent as much as $58.30 \%$ of the observed variation, or at least $21.7 \%$ of it. Stronger IV effects are consistent with the endogeneity of entry of $4 \mathrm{G}$ operators. Mobile broadband services will target economically dynamic regions, hence, if the real effects of are negative, OLS estimates will imply a smaller effect in terms of magnitude. 
Table 5.3: Effects of $4 \mathrm{G}$ operators on contracts

\begin{tabular}{|c|c|c|c|c|c|}
\hline & \multicolumn{5}{|c|}{ Dependent variable: } \\
\hline & \multicolumn{5}{|c|}{$\log ($ Contracts $)$} \\
\hline & \multicolumn{3}{|c|}{$O L S$} & \multicolumn{2}{|c|}{$I V$} \\
\hline & $(1)$ & $(2)$ & $(3)$ & $(4)$ & $(5)$ \\
\hline \# of $4 \mathrm{G}$ Operators & $\begin{array}{c}-1.480^{* * *} \\
(0.362)\end{array}$ & $\begin{array}{c}-1.868^{* * *} \\
(0.494)\end{array}$ & $\begin{array}{c}-1.752^{* * *} \\
(0.476)\end{array}$ & $\begin{array}{c}-3.576^{* * *} \\
(0.891)\end{array}$ & $\begin{array}{c}-3.925^{* * *} \\
(0.915)\end{array}$ \\
\hline $\mathrm{F} 4 \mathrm{G}$ & & & & 203.59 & 178.95 \\
\hline Local Markets FE & $\mathrm{X}$ & $\mathrm{X}$ & $\mathrm{X}$ & $\mathrm{X}$ & $\mathrm{X}$ \\
\hline Year FE & $\mathrm{X}$ & $\mathrm{X}$ & $\mathrm{X}$ & $\mathrm{X}$ & $\mathrm{X}$ \\
\hline $\log \left(\operatorname{Pop}_{2010}\right) \times Y$ & & $\mathrm{X}$ & $\mathrm{X}$ & $\mathrm{X}$ & $\mathrm{X}$ \\
\hline$\#$ Munic $\times$ Y & & $\mathrm{X}$ & $\mathrm{X}$ & $\mathrm{X}$ & $\mathrm{X}$ \\
\hline State Trends & & & $\mathrm{X}$ & & $\mathrm{X}$ \\
\hline Observations & 1,925 & 1,925 & 1,925 & 1,925 & 1,925 \\
\hline Adjusted $\mathrm{R}^{2}$ & 0.998 & 0.998 & 0.998 & 0.998 & 0.998 \\
\hline
\end{tabular}

All models control for local labor markets and years fixed effects. Regressions are weighted by the level of contracts in 2013. Robust standard errors are clustered at the meso-region level. Columns (1) to (3) are OLS estimates, while Columns (4) to (5) are IV estimates. Coefficients and standard deviations are multiplied by a hundred. Numbers between parenthesis are the coefficient standard deviations. $\log \left(\mathrm{Pop}_{2010}\right) \times$ Y represents the trend-effects of the log-population of 2010 (yearly dummies interacted with this variable). \# Munic $\times$ Y represents the trend-effects of the number of municipalities in local labor markets (yearly dummies interacted with this variable). * represents significance at the $10 \%$ level, ${ }^{* *}$ represents significance at the $5 \%$ level, and ${ }^{* * *}$ represents significance at the $1 \%$ level. 
Table 5.4: Effects of $4 \mathrm{G}$ operators on average routine index

\begin{tabular}{|c|c|c|c|c|c|}
\hline & \multicolumn{5}{|c|}{ Dependent variable: } \\
\hline & \multicolumn{5}{|c|}{ Average of Routine Index } \\
\hline & \multicolumn{3}{|c|}{$O L S$} & \multicolumn{2}{|c|}{$I V$} \\
\hline & $(1)$ & $(2)$ & $(3)$ & $(4)$ & $(5)$ \\
\hline \# of $4 \mathrm{G}$ Operators & $\begin{array}{c}-0.387^{* * *} \\
(0.085)\end{array}$ & $\begin{array}{c}-0.244^{* * *} \\
(0.084)\end{array}$ & $\begin{array}{c}-0.257^{* * *} \\
(0.083)\end{array}$ & $\begin{array}{c}-0.523^{* * *} \\
(0.167)\end{array}$ & $\begin{array}{c}-0.579^{* * *} \\
(0.173)\end{array}$ \\
\hline $\begin{array}{l}\text { Mean of Variable } \\
\text { F } 4 \mathrm{G}\end{array}$ & 45.25 & 45.25 & 45.25 & $\begin{array}{c}45.25 \\
203.59\end{array}$ & $\begin{array}{c}45.25 \\
178.95 \\
\end{array}$ \\
\hline Local Markets FE & $\mathrm{X}$ & $\mathrm{X}$ & $\mathrm{X}$ & $\mathrm{X}$ & $\mathrm{X}$ \\
\hline Year FE & $\mathrm{X}$ & $\mathrm{X}$ & $\mathrm{X}$ & $\mathrm{X}$ & $\mathrm{X}$ \\
\hline $\log \left(\operatorname{Pop}_{2010}\right) \times Y$ & & $\mathrm{X}$ & $\mathrm{X}$ & $\mathrm{X}$ & $\mathrm{X}$ \\
\hline$\#$ Munic $\times$ Y & & $\mathrm{X}$ & $\mathrm{X}$ & $\mathrm{X}$ & $\mathrm{X}$ \\
\hline State Trends & & & $\mathrm{X}$ & & $\mathrm{X}$ \\
\hline Observations & 1,925 & 1,925 & 1,925 & 1,925 & 1,925 \\
\hline Adjusted $\mathrm{R}^{2}$ & 0.975 & 0.975 & 0.975 & 0.975 & 0.975 \\
\hline
\end{tabular}

All models control for local labor markets and years fixed effects. Regressions are weighted by the level of contracts in 2013. Columns (1) to (3) are OLS estimates, while Columns (4) to (5) are IV estimates. Robust standard errors are clustered at the meso-region level. Numbers between parenthesis are the coefficient standard deviations. $\log \left(\mathrm{Pop}_{2010}\right) \times$ Y represents the trend-effects of the log-population of 2010 (yearly dummies interacted with this variable). \# Munic $\times$ Y represents the trend-effects of the number of municipalities in local labor markets (yearly dummies interacted with this variable). * represents significance at the $10 \%$ level, ${ }^{* *}$ represents significance at the $5 \%$ level, and ${ }^{* * *}$ represents significance at the $1 \%$ level.

Displacement effects, however, may not be homogenous among the population. The presence of $4 \mathrm{G}$ technologies may be complementary to certain tasks, while having substituting effects in others. Table 5.4 exhibits $4 \mathrm{G}$ effects in terms of an average routine index level of the workforce. Column 1, the simple two-way FE OLS estimate, suggests a complementarity between nonroutine tasks and $4 \mathrm{G}$ technologies. This is seen in all other specifications of this table. Nonetheless, there are striking differences in terms of magnitude. When considering relevant covariates in columns 2 to 3, OLS estimates are much smaller. But those OLS estimates seem to be biased towards zero since columns 4 to 5 , considering the IV strategy, suggest even stronger effects than column 1. Column 5, my preferred specification, shows the average increase of 2 firms between 2013 to 2017 results in a drop of -1.16 points (-0.579 x 2), about $43 \%$ of the 2.8 points drop observed that same period. Considering the $95 \% \mathrm{CI}$, this could represent as much as -1.85 points (66\% of the drop) or as low as -0.46 points $(16.42 \%)$. In table 5.5 , we see a similar pattern for manual 
Table 5.5: Effects of $4 \mathrm{G}$ operators on average manual index

\begin{tabular}{|c|c|c|c|c|c|}
\hline & \multicolumn{5}{|c|}{ Dependent variable: } \\
\hline & \multicolumn{5}{|c|}{ Average of Manual Index } \\
\hline & \multicolumn{3}{|c|}{$O L S$} & \multicolumn{2}{|c|}{$I V$} \\
\hline & $(1)$ & $(2)$ & $(3)$ & $(4)$ & $(5)$ \\
\hline \# of $4 \mathrm{G}$ Operators & $\begin{array}{c}-0.329^{* *} \\
(0.140)\end{array}$ & $\begin{array}{c}-0.249^{*} \\
(0.133)\end{array}$ & $\begin{array}{c}-0.480^{* * *} \\
(0.167)\end{array}$ & $\begin{array}{c}-0.726^{* * *} \\
(0.267)\end{array}$ & $\begin{array}{c}-0.951^{* * *} \\
(0.279)\end{array}$ \\
\hline $\begin{array}{l}\text { Mean of Variable } \\
\text { F } 4 \mathrm{G}\end{array}$ & -18.9 & -18.9 & -18.9 & $\begin{array}{l}-18.9 \\
203.59 \\
\end{array}$ & $\begin{array}{l}-18.9 \\
178.95 \\
\end{array}$ \\
\hline Local Markets FE & $\mathrm{X}$ & $\mathrm{X}$ & $\mathrm{X}$ & $\mathrm{X}$ & $\mathrm{X}$ \\
\hline Year FE & $\mathrm{X}$ & $\mathrm{X}$ & $\mathrm{X}$ & $\mathrm{X}$ & $\mathrm{X}$ \\
\hline $\log \left(\operatorname{Pop}_{2010}\right) \times Y$ & & $\mathrm{X}$ & $\mathrm{X}$ & $\mathrm{X}$ & $\mathrm{X}$ \\
\hline$\#$ Munic $\times \mathrm{Y}$ & & $\mathrm{X}$ & $\mathrm{X}$ & $\mathrm{X}$ & $\mathrm{X}$ \\
\hline State Trends & & & $\mathrm{X}$ & & $\mathrm{X}$ \\
\hline Observations & 1,925 & 1,925 & 1,925 & 1,925 & 1,925 \\
\hline Adjusted $\mathrm{R}^{2}$ & 0.959 & 0.959 & 0.962 & 0.959 & 0.962 \\
\hline
\end{tabular}

All models control for loca labor markets and years fixed effects. Columns (1) to (3) are OLS estimates, while Columns (4) to (5) are IV estimates. Robust standard errors are clustered at the meso-region level. Numbers between parenthesis are the coefficient standard deviations. $\log \left(\mathrm{Pop}_{2010}\right) \times \mathrm{Y}$ represents the trend-effects of the log-population of 2010 (yearly dummies interacted with this variable). \# Munic $\times \mathrm{Y}$ represents the trend-effects of the number of municipalities in local labor markets (yearly dummies interacted with this variable). * represents significance at the $10 \%$ level, $* *$ represents significance at the $5 \%$ level, and $* * *$ represents significance at the $1 \%$ level.

tasks. In column 5 , it shows that 2 additional firms reduce the manual index by 1.9 points, about $29.7 \%$ of the drop in the period (-6.39 points). Considering the $95 \%$ CI, these effects could be as high (low) as $47 \%$ (12\%) of the drop of the manual index in the period.

In table 5.6, I estimate linear models of the share of tasks executed by the workforce on $4 \mathrm{G}$ presence through $2 \mathrm{SLS}$. The mobile broadband expansion caused a reduction in the share of routine manual tasks and an increase in nonroutine cognitive tasks. Considering the coefficients of table 5.6, it shows that the provision of $4 \mathrm{G}$ services by two operators, increases non-routine analytical in 0.14 p.p. (95\% CI: -0.02 to 0.3 p.p.) and interactive tasks in 0.52 p.p. (95\% CI: 0.22 to 0.82 p.p.), while reducing routine manual tasks in 0.86 p.p. (95\% CI: 0.36 to 1.36 p.p.). There is some suggestive evidence that $4 \mathrm{G}$ technologies could have also been complementary to routine cognitive tasks, but the positive effects are not statistically significant from zero.

The effects of $4 \mathrm{G}$ provision in non-routine cognitive (analytical and interactive) tasks are similar to the computerization effects present in literature, 
Table 5.6: Effects of $4 \mathrm{G}$ operators on share of tasks (\%)

\begin{tabular}{lccccc}
\hline \hline & \multicolumn{5}{c}{ Dependent variable: } \\
\cline { 2 - 6 } & \multicolumn{4}{c}{ Non-Routine } \\
& Analytical & Interactive & Manual & Manual & Cognitive \\
& $(1)$ & $(2)$ & $(3)$ & $(4)$ & $(5)$ \\
\hline \# of 4G Operators & $0.072^{*}$ & $0.262^{* * *}$ & -0.044 & $-0.432^{* * *}$ & 0.142 \\
& $(0.041)$ & $(0.076)$ & $(0.043)$ & $(0.125)$ & $(0.105)$ \\
& & & & & \\
Mean of Variable (\%) & 6.04 & 14.65 & 5.93 & 36.28 & 37.1 \\
F 4G & 178.95 & 178.95 & 178.95 & 178.95 & 178.95 \\
\hline Local Markets FE & $\mathrm{X}$ & $\mathrm{X}$ & $\mathrm{X}$ & $\mathrm{X}$ & $\mathrm{X}$ \\
Year FE & $\mathrm{X}$ & $\mathrm{X}$ & $\mathrm{X}$ & $\mathrm{X}$ & $\mathrm{X}$ \\
log(Pop 2010$) \times \mathrm{Y}$ & $\mathrm{X}$ & $\mathrm{X}$ & $\mathrm{X}$ & $\mathrm{X}$ & $\mathrm{X}$ \\
\# Munic $\times \mathrm{Y}$ & $\mathrm{X}$ & $\mathrm{X}$ & $\mathrm{X}$ & $\mathrm{X}$ & $\mathrm{X}$ \\
State Trends & $\mathrm{X}$ & $\mathrm{X}$ & $\mathrm{X}$ & $\mathrm{X}$ & $\mathrm{X}$ \\
Observations & 1,925 & 1,925 & 1,925 & 1,925 & 1,925 \\
Adjusted R & 0.972 & 0.972 & 0.901 & 0.966 & 0.901 \\
\hline \hline
\end{tabular}

All models control for local labor markets and years fixed effects. Regressions are weighted by the level of contracts in 2013. Columns (1) to (5) are IV estimates. Robust standard errors are clustered at the meso-region level. Coefficients and standard deviations are multiplied by a hundred. Numbers between parenthesis are the coefficient standard deviations. $\log \left(\mathrm{Pop}_{2010}\right) \times \mathrm{Y}$ represents the trend-effects of the $\log$-population of 2010 (yearly dummies interacted with this variable). \# Munic $\times$ Y represents the trend-effects of the number of municipalities in local labor markets (yearly dummies interacted with this variable). ${ }^{*}$ represents significance at the $10 \%$ level, ${ }^{* *}$ represents significance at the $5 \%$ level, and ${ }^{* * *}$ represents significance at the $1 \%$ level.

so it is the decrease in routine manual. However, Autor et al. (2003), Autor \& Price (2013), Autor \& Dorn (2013) identify that the expansion of computers has increased the demand for non-routine tasks while substituting the demand for routine cognitive works. Nonetheless, $4 \mathrm{G}$ provision does not seem to reduce the demand for routine cognitive tasks.

Another remarkable feature is that mobile broadband expansion in formal labor markets in Brazil does not seem to affect the average wages. Table 5.7 shows no significant effect in terms of wages although most specifications of OLS and all specifications of the IV suggest a slightly negative result, but it is not statistically significant.

There have also been noticeable effects in terms of the average skill of workers. With the skill level index of occupations described in section 3, I explore causal effects of $4 \mathrm{G}$ technologies. As shown by table 5.8 , there has been an increase in the average level of skill of workers caused by mobile broadband expansion. More specifically, in the preferred specification, in column 5, the 
Table 5.7: Effects of $4 \mathrm{G}$ operators on average wages

\begin{tabular}{|c|c|c|c|c|c|}
\hline & \multicolumn{5}{|c|}{ Dependent variable: } \\
\hline & \multicolumn{5}{|c|}{ log(Average Wages) } \\
\hline & \multicolumn{3}{|c|}{$O L S$} & \multicolumn{2}{|c|}{$I V$} \\
\hline & $(1)$ & $(2)$ & $(3)$ & $(4)$ & $(5)$ \\
\hline \# of $4 \mathrm{G}$ Operators & $\begin{array}{c}-0.024 \\
(0.205)\end{array}$ & $\begin{array}{c}-0.125 \\
(0.268)\end{array}$ & $\begin{array}{c}-0.250 \\
(0.236)\end{array}$ & $\begin{array}{c}-0.044 \\
(0.450)\end{array}$ & $\begin{array}{l}-0.437 \\
(0.542)\end{array}$ \\
\hline $\mathrm{F} 4 \mathrm{G}$ & & & & 203.59 & 178.95 \\
\hline Local Markets FE & $\mathrm{X}$ & $\mathrm{X}$ & $\mathrm{X}$ & $\mathrm{X}$ & $\mathrm{X}$ \\
\hline Year FE & $\mathrm{X}$ & $\mathrm{X}$ & $\mathrm{X}$ & $\mathrm{X}$ & $\mathrm{X}$ \\
\hline $\log \left(\operatorname{Pop}_{2010}\right) \times Y$ & & $\mathrm{X}$ & $\mathrm{X}$ & $\mathrm{X}$ & $\mathrm{X}$ \\
\hline$\#$ Munic $\times$ Y & & $\mathrm{X}$ & $\mathrm{X}$ & $\mathrm{X}$ & $\mathrm{X}$ \\
\hline State Trends & & & $\mathrm{X}$ & & X \\
\hline Observations & 1,925 & 1,925 & 1,925 & 1,925 & 1,925 \\
\hline Adjusted $\mathrm{R}^{2}$ & 0.985 & 0.985 & 0.987 & 0.985 & 0.987 \\
\hline
\end{tabular}

All models control for local labor markets and years fixed effects. Regressions are weighted by the level of contracts in 2013. Columns (1) to (3) are OLS estimates, while Columns (4) to (5) are IV estimates. Robust standard errors are clustered at the mesoregion level. Coefficients and standard deviations are multiplied by a hundred. Numbers between parenthesis are the coefficient standard deviations. $\log \left(\mathrm{Pop}_{2010}\right) \times \mathrm{Y}$ represents the trend-effects of the log-population of 2010 (yearly dummies interacted with this variable). \# Munic $\times \mathrm{Y}$ represents the trend-effects of the number of municipalities in local labor markets (yearly dummies interacted with this variable). ${ }^{*}$ represents significance at the $10 \%$ level, ** represents significance at the $5 \%$ level, and *** represents significance at the $1 \%$ level.

increase of 2 operators of $4 \mathrm{G}$ (equivalent to the variation between 2013 to 2017 ) increase the average skill index in 0.35 (CI: 0.07 to 0.59 ) points (about $38 \%(7.6 \%$ to $64.1 \%)$ of the shift of the index in 2013$)$.

In summary, $4 \mathrm{G}$ technological change seems to be labor-saving (in formal markets), skill-biased and complementary to non-routine tasks. The IV strategy shows that these results are even stronger than what two-way FE estimates suggest. 
Table 5.8: Effects of 4G operators on average skill index

\begin{tabular}{|c|c|c|c|c|c|}
\hline & \multicolumn{5}{|c|}{ Dependent variable: } \\
\hline & \multicolumn{5}{|c|}{ Average of Skill Index } \\
\hline & \multicolumn{3}{|c|}{$O L S$} & \multicolumn{2}{|c|}{$I V$} \\
\hline & $(1)$ & $(2)$ & $(3)$ & $(4)$ & $(5)$ \\
\hline \# of $4 \mathrm{G}$ Operators & $\begin{array}{c}0.105^{* * *} \\
(0.032)\end{array}$ & $\begin{array}{c}0.079^{* * *} \\
(0.030)\end{array}$ & $\begin{array}{l}0.057^{* *} \\
(0.025)\end{array}$ & $\begin{array}{c}0.186^{* * *} \\
(0.065)\end{array}$ & $\begin{array}{l}0.166^{* *} \\
(0.065)\end{array}$ \\
\hline $\begin{array}{l}\text { Mean of Variable } \\
\text { F } 4 \mathrm{G}\end{array}$ & 19.91 & 19.91 & 19.91 & $\begin{array}{c}19.91 \\
203.59\end{array}$ & $\begin{array}{c}19.91 \\
178.95 \\
\end{array}$ \\
\hline Local Markets FE & $\mathrm{X}$ & $\mathrm{X}$ & $\mathrm{X}$ & $\mathrm{X}$ & $\mathrm{X}$ \\
\hline Year FE & $\mathrm{X}$ & $\mathrm{X}$ & $\mathrm{X}$ & $\mathrm{X}$ & $\mathrm{X}$ \\
\hline $\log \left(\operatorname{Pop}_{2010}\right) \times Y$ & & $\mathrm{X}$ & $\mathrm{X}$ & $\mathrm{X}$ & $\mathrm{X}$ \\
\hline$\#$ Munic $\times \mathrm{Y}$ & & $\mathrm{X}$ & $\mathrm{X}$ & $\mathrm{X}$ & $\mathrm{X}$ \\
\hline State Trends & & & X & & $\mathrm{X}$ \\
\hline Observations & 1,925 & 1,925 & 1,925 & 1,925 & 1,925 \\
\hline Adjusted $\mathrm{R}^{2}$ & 0.978 & 0.979 & 0.979 & 0.978 & 0.979 \\
\hline
\end{tabular}

All models control for local labor markets and years fixed effects. Regressions are weighted by the level of contracts in 2013. Columns (1) to (3) are OLS estimates, while Columns (4) to (5) are IV estimates. Robust standard errors are clustered at the mesoregion level. Coefficients and standard deviations are multiplied by a hundred. Numbers between parenthesis are the coefficient standard deviations. $\log \left(\mathrm{Pop}_{2010}\right) \times \mathrm{Y}$ represents the trend-effects of the log-population of 2010 (yearly dummies interacted with this variable). \# Munic $\times \mathrm{Y}$ represents the trend-effects of the number of municipalities in local labor markets (yearly dummies interacted with this variable). ${ }^{*}$ represents significance at the $10 \%$ level, ${ }^{* *}$ represents significance at the $5 \%$ level, and ${ }^{* * *}$ represents significance at the $1 \%$ level.

\section{4}

\section{Understanding the drop in formal employment contracts}

The reduction of formal employment contracts seen at the level of formal contracts can be explained by two different factors: (i) there can be a reduction in the actual level of individuals that were employed at least once in the year; or, (ii) there can be a reduction of turnover, which means the workers tend to remain in one job rather than change job positions.

In table 5.9, I estimate the effects of fast mobile broadband effects in the level of the total number of individuals that have worked in the year and the number of workers employed in December, 31st. As we see in columns 1 and 2, the estimated coefficients, respectively, of $-3.43 \%$ and $-2.89 \%$ of the provision of $4 \mathrm{G}$ technologies by one additional operator is milder than the effects on formal employment contracts $(-3.95 \%)$ but they are still very relevant. This shows that, potentially, the drop of formal contracts can't be fully explained by 
a reduction in formal labor contracts but also by reduced number of contracts per individual. It also provides further evidence of potential labor-saving effects of the expansion of $4 \mathrm{G}$ technologies in formal labor markets.

Table 5.9: Effects of $4 \mathrm{G}$ operators on local labor markets

\begin{tabular}{|c|c|c|c|c|c|}
\hline & & Dep & ndent varia & ble: & \\
\hline & & $\log (\mathrm{Ou}$ & come) & & Share (\%) \\
\hline & Individuals & Employed & Firings & Hires & Gross \\
\hline & & $(12 / 31)$ & & & Turnover \\
\hline & $(1)$ & $(2)$ & $(3)$ & $(4)$ & $(5)$ \\
\hline \# of 4G Operators & $\begin{array}{c}-3.431^{* * *} \\
(0.914)\end{array}$ & $\begin{array}{c}-2.897^{* * *} \\
(0.794)\end{array}$ & $\begin{array}{c}-4.551^{* * *} \\
(1.721)\end{array}$ & $\begin{array}{c}-6.789^{* * *} \\
(1.767)\end{array}$ & $\begin{array}{c}-2.958^{* * *} \\
(0.969)\end{array}$ \\
\hline Mean of Variable & & & & & 94.49 \\
\hline $\mathrm{F} 4 \mathrm{G}$ & 178.95 & 178.95 & 178.95 & 178.95 & 178.95 \\
\hline Local Markets FE & $\mathrm{X}$ & $\mathrm{X}$ & $\mathrm{X}$ & $\mathrm{X}$ & $\mathrm{X}$ \\
\hline Year FE & $\mathrm{X}$ & $\mathrm{X}$ & $\mathrm{X}$ & $\mathrm{X}$ & $\mathrm{X}$ \\
\hline $\log \left(\right.$ Pop $\left._{2010}\right) \times Y$ & $\mathrm{X}$ & $\mathrm{X}$ & $\mathrm{X}$ & $\mathrm{X}$ & $\mathrm{X}$ \\
\hline$\#$ Munic $\times \mathrm{Y}$ & $\mathrm{X}$ & $\mathrm{X}$ & $\mathrm{X}$ & $\mathrm{X}$ & $\mathrm{X}$ \\
\hline State Trends & $\mathrm{X}$ & $\mathrm{X}$ & $\mathrm{X}$ & $\mathrm{X}$ & $\mathrm{X}$ \\
\hline Observations & 1,925 & 1,925 & 1,925 & 1,925 & 1,925 \\
\hline Adjusted $\mathrm{R}^{2}$ & 0.998 & 0.999 & 0.994 & 0.996 & 0.882 \\
\hline
\end{tabular}

All models control for local labor markets and years fixed effects. Regressions are weighted by the level of contracts in 2013. Columns (1) to (5) are IV estimates.Robust standard errors are clustered at the meso-region level. Coefficients and standard deviations are multiplied by a hundred. Numbers between parenthesis are the coefficient standard deviations. $\log \left(\mathrm{Pop}_{2010}\right) \times \mathrm{Y}$ represents the trend-effects of the log-population of 2010 (yearly dummies interacted with this variable). \# Munic $\times$ Y represents the trend-effects of the number of municipalities in local labor markets (yearly dummies interacted with this variable). ${ }^{*}$ represents significance at the $10 \%$ level, ${ }^{* *}$ represents significance at the $5 \%$ level, and ${ }^{* * *}$ represents significance at the $1 \%$ level.

In columns 3 and 4 of table 5.9, we find decreased hires and firings, but the drop in hires caused by mobile broadband expansion is less intense than firings. The provision of $4 \mathrm{G}$ by one additional mobile network operator reduce firings in $4.5 \%$ and hires in $6.8 \%$. This in turn, as expected, reduces turnover (as defined by the sum of hiring and firings divided by the number of people employed in December, 31st). The average increase of 2 operators seen from 2013 to 2017 reduce turnover in 5.9 percentage points, that is about $24.6 \%$ $(-5.9 /-24)$ of the drop observed in data. Therefore, we have now evidence that the drop on formal labor contracts is a result of labor-saving effects of mobile broadband and decreased turnover in formal markets. Decreased turnover is probably caused by a better job match between employees and its employers. 
In developed countries, expanded broadband internet improves job matching in terms of time length to return to a job position and the average time in the same job (Bhuller et al., 2020). It may be the case that the same is happening in Brazil. Mobile connectivity may have helped workers to find better jobs and have more stable connections with firms.

An important limitation of this dissertation's research setting, however, is that mobile broadband expansion in Brazil occurs in a period of macroeconomic recession. While it is true that year fixed effects control for common economic trends in the period for all local labor markets, it could be the case that mobile broadband effects in the labor market interact with the economic recession conditions If that occurs, then part of the displacement effects shall reduce in the next years, after macroeconomic conditions ameliorate. With additional RAIS data, for the next following years, we may be able to understand if that is the case. Therefore, we should have caution in terms of interpretation of disemployment effects: what could be said is that these are the causal effects of mobile broadband in a period of economic recession in a developing country.

Considering all labor markets, displacement effects could be milder if we take into consideration that part of workers may become self-employed or informal workers, rather than formal workers. In fact, it may very well be the case that increased mobile connectivity may be responsible for creating new gig economy jobs. The emergence of apps like Uber, iFood and Rappi may be responsible for an increase of self-entrepreneurs that sell food, deliver food and other products, as well as self-employed drivers. In some circumstances, it may very well be the case that workers opt out of the formal labor market to go to these services.

Informality and self-entrepreneurship in Brazil are something hard to measure in the local labor market level. Household surveys are not representative at the municipal level, while Censuses are done between decades. Additionally, informality by definition is not something properly detected in official administrative records. Nonetheless, there are some formal self-entrepreneurs that we can track in the municipal level. Those are the MEIs (Microempreendedores Individuais). MEIs are micro entrepreneurs, normally self-employed or freelancer workers, that are formally registered to the Brazilian government. The MEI firm category was originally created as a tool for formalization of the labor force and allow individual workers to pay for social security benefits and report tax receipts for the government and for consumers.

In table 5.10, I identify the causal effects of $4 \mathrm{G}$ services in MEIs. Without controls for trend effects of population size and municipal fragmentation would indicate that one additional firm increases the number of MEIs in $1.5 \%$. This 
effect, however, is not robust. OLS with additional controls and IV estimates indicate that effects are close to zero and they are not statistically significant. Therefore, we see no evidence that increased mobile broadband causes a reduction or an increase of formally registered self-entrepreneurs. Unfortunately, we cannot assess effects on informal workers or non-tax-paying self-entrepreneurs due to data limitation. If mobile broadband increases informality, then, when considering the labor markets as whole, employment reduction may be less pronounced.

Table 5.10: Effects of 4G Operators on MEI

\begin{tabular}{|c|c|c|c|c|c|}
\hline & \multicolumn{5}{|c|}{ Dependent variable: } \\
\hline & \multicolumn{5}{|c|}{$\log (\mathrm{MEI})$} \\
\hline & \multicolumn{3}{|c|}{$O L S$} & \multicolumn{2}{|c|}{$I V$} \\
\hline & $(1)$ & $(2)$ & $(3)$ & $(4)$ & $(5)$ \\
\hline \# of $4 \mathrm{G}$ Operators & $\begin{array}{c}1.495^{* * *} \\
(0.566)\end{array}$ & $\begin{array}{c}0.931 \\
(0.892)\end{array}$ & $\begin{array}{l}-0.165 \\
(0.919)\end{array}$ & $\begin{array}{c}1.585 \\
(1.328)\end{array}$ & $\begin{array}{c}0.170 \\
(1.063)\end{array}$ \\
\hline $\mathrm{F} 4 \mathrm{G}$ & & & & 203.59 & 178.95 \\
\hline Local Markets FE & $\mathrm{X}$ & $\mathrm{X}$ & $\mathrm{X}$ & $\mathrm{X}$ & $\mathrm{X}$ \\
\hline Year FE & $\mathrm{X}$ & $\mathrm{X}$ & $\mathrm{X}$ & $\mathrm{X}$ & $\mathrm{X}$ \\
\hline $\log \left(\operatorname{Pop}_{2010}\right) \times Y$ & & $\mathrm{X}$ & $\mathrm{X}$ & $\mathrm{X}$ & $\mathrm{X}$ \\
\hline$\#$ Munic $\times$ Y & & $\mathrm{X}$ & $\mathrm{X}$ & $\mathrm{X}$ & $\mathrm{X}$ \\
\hline State Trends & & & $\mathrm{X}$ & & $\mathrm{X}$ \\
\hline Observations & 1,925 & 1,925 & 1,925 & 1,925 & 1,925 \\
\hline Adjusted $\mathrm{R}^{2}$ & 0.998 & 0.998 & 0.999 & 0.998 & 0.999 \\
\hline
\end{tabular}

All models control for local labor markets and years fixed effects. Regressions are weighted by the level of contracts in 2013. Columns (1) to (3) are OLS estimates, while Columns (4) to (5) are IV estimates. Robust standard errors are clustered at the mesoregion level. Coefficients and standard deviations are multiplied by a hundred. Numbers between parenthesis are the coefficient standard deviations. $\log \left(\mathrm{Pop}_{2010}\right) \times \mathrm{Y}$ represents the trend-effects of the log-population of 2010 (yearly dummies interacted with this variable). \# Munic $\times \mathrm{Y}$ represents the trend-effects of the number of municipalities in local labor markets (yearly dummies interacted with this variable). ${ }^{*}$ represents significance at the $10 \%$ level, ** represents significance at the $5 \%$ level, and *** represents significance at the $1 \%$ level. 


\section{6}

\section{Robustness}

On this section, I perform a series of robustness checks, using different subsets of the sample, controlling for pre-trend effects and taking into consideration possible $4 \mathrm{G}$ effects. I also address the growing incompatibility between the task-intensity measures used on this analysis and the RAIS dataset.

Table 6.1: Effects of $4 \mathrm{G}$ (Excluding labor markets with municipalities of more than 500,000 inhabitants)

\begin{tabular}{lcccc}
\hline \hline & \multicolumn{4}{c}{ Dependent variable: } \\
\cline { 2 - 5 } & $\log ($ Contracts $)$ & Routine & Manual & Skill Index \\
& $(1)$ & $(2)$ & $(3)$ & $(4)$ \\
\hline \# of 4G Operators & $-6.148^{* * *}$ & $-0.630^{* * *}$ & $-1.049^{* *}$ & $0.203^{*}$ \\
& $(1.474)$ & $(0.228)$ & $(0.426)$ & $(0.112)$ \\
\hline Original Specification & -3.925 & -0.579 & -0.951 & 0.166 \\
\hline Local Markets FE & $\mathrm{X}$ & $\mathrm{X}$ & $\mathrm{X}$ & $\mathrm{X}$ \\
Year FE & $\mathrm{X}$ & $\mathrm{X}$ & $\mathrm{X}$ & $\mathrm{X}$ \\
log(Pop 2010$) \times \mathrm{Y}$ & $\mathrm{X}$ & $\mathrm{X}$ & $\mathrm{X}$ & $\mathrm{X}$ \\
\# Munic $\times \mathrm{Y}$ & $\mathrm{X}$ & $\mathrm{X}$ & $\mathrm{X}$ & $\mathrm{X}$ \\
State Trends & $\mathrm{X}$ & $\mathrm{X}$ & $\mathrm{X}$ & $\mathrm{X}$ \\
Observations & 1,870 & 1,870 & 1,870 & 1,870 \\
Adjusted $\mathrm{R}^{2}$ & 0.997 & 0.970 & 0.946 & 0.973 \\
\hline \hline
\end{tabular}

All models control for local labor markets and years fixed effects. Regressions are weighted by the level of contracts in 2013. Regressions are weighted by the level of contracts in 2013. All columns are IV estimates. Robust standard errors are clustered at the meso-region level. Numbers between parenthesis are the coefficient standard deviations. In column (1), coefficients and standard deviations are multiplied by a hundred. $\log \left(\mathrm{Pop}_{2010}\right) \times \mathrm{Y}$ represents the trend-effects of the log-population of 2010 (yearly dummies interacted with this variable). \# Munic $\times$ Y represents the trend-effects of the number of municipalities in local labor markets (yearly dummies interacted with this variable). ${ }^{*}$ represents significance at the $10 \%$ level, ${ }^{* *}$ represents significance at the $5 \%$ level, and ${ }^{* * *}$ represents significance at the $1 \%$ level.

\section{1}

\section{More restricted sample}

In table 6.1, I exhibit IV estimates when excluding the local labor markets with municipalities with more than 500,000 inhabitants. If anything, 
the estimates show much more economically significant results for the effects on task-content, formal employment contracts and average skill level. Hence, we could argue that these estimates are more conservative than a specification with a more restricted sample.

\section{2}

\section{Controlling for pre-trends}

Although the previous subsection showed that there is little if any statistically significant evidence of pre-trend effects, some could still be concerned that my IV results are being driven by previous trend effects. One way to check if pre-trends are driving the IV results is to control for previous trends directly. That is:

$$
\begin{gathered}
y_{m t}=\alpha_{m}+\alpha_{t}+\beta \text { Operators of } 4 \mathrm{G}+\left(I_{t} \times \Delta V_{m, 2006-2012}\right) \lambda+X_{m t}^{\prime} \gamma+u_{m} t \\
\text { where } I_{t}=\left(\begin{array}{c}
I_{2008} \\
\vdots \\
I_{2017}
\end{array}\right)_{t \neq 2014}
\end{gathered}
$$

$\Delta V_{m, 2006-2012}$ is the pre-trend variation in a variable $V$. Since the only more concerning pre-trend effect was the educational variable, I control for trend effects of previous variation of share of high school dropouts. In table 6.2, I exhibit the IV estimates with this additional controls and there is no evidence that previous educational trends biased the IV results. In fact, the estimates are almost unchanged. In appendix, the results are similar when controlling for effects on trend of pre-trends of routine index variation (table A.2) and manual index variation (table A.3), there are no relevant differences in estimates. 
Table 6.2: Effects of $4 \mathrm{G}$ (Controlling for previous educational trends)

\begin{tabular}{lcccc}
\hline \hline & \multicolumn{4}{c}{ Dependent variable: } \\
\cline { 2 - 5 } & $\log ($ Contracts $)$ & Routine & Manual & Skill Index \\
& $(1)$ & $(2)$ & $(3)$ & $(4)$ \\
\hline \# of 4G Operators & $-3.955^{* * *}$ & $-0.579^{* * *}$ & $-0.958^{* * *}$ & $0.165^{* *}$ \\
& $(0.908)$ & $(0.175)$ & $(0.283)$ & $(0.065)$ \\
& & & & \\
\hline Original Specification & -3.925 & -0.579 & -0.951 & 0.166 \\
\hline Local Markets FE & $\mathrm{X}$ & $\mathrm{X}$ & $\mathrm{X}$ & $\mathrm{X}$ \\
Year FE & $\mathrm{X}$ & $\mathrm{X}$ & $\mathrm{X}$ & $\mathrm{X}$ \\
$\log ($ Pop 2010$) \times \mathrm{Y}$ & $\mathrm{X}$ & $\mathrm{X}$ & $\mathrm{X}$ & $\mathrm{X}$ \\
\# Munic $\times \mathrm{Y}$ & $\mathrm{X}$ & $\mathrm{X}$ & $\mathrm{X}$ & $\mathrm{X}$ \\
State Trends & $\mathrm{X}$ & $\mathrm{X}$ & $\mathrm{X}$ & $\mathrm{X}$ \\
Observations & 1,925 & 1,925 & 1,925 & 1,925 \\
Adjusted $\mathrm{R}^{2}$ & 0.998 & 0.975 & 0.962 & 0.979 \\
\hline \hline
\end{tabular}

All models control for local labor markets and years fixed effects. Regressions are weighted by the level of contracts in 2013. All columns are IV estimates. Robust standard errors are clustered at the meso-region level. Numbers between parenthesis are the coefficient standard deviations. In column (1), coefficients and standard deviations are multiplied by a hundred. $\log \left(\mathrm{Pop}_{2010}\right) \times$ Y represents the trend-effects of the log-population of 2010 (yearly dummies interacted with this variable). \# Munic $\times$ Y represents the trend-effects of the number of municipalities in local labor markets (yearly dummies interacted with this variable). * represents significance at the $10 \%$ level, $* *$ represents significance at the $5 \%$ level, and $* * *$ represents significance at the $1 \%$ level. 


\section{3}

\section{Previous 3G trends}

Another very important concern is that ANATEL rules for $3 \mathrm{G}$ provision in the $20073 \mathrm{G}$ auctions and $20124 \mathrm{G}$ auctions are highly correlated with the ones of $4 \mathrm{G}$ provision. In fact, it is true that the provision threshold on population is almost the same for $3 \mathrm{G}$ provision. Although $3 \mathrm{G}$ provision rules are based on 2006 population and not 2010 population of the $4 \mathrm{G}$ provision rules, they are tightly correlated. Hence, we may expect that Years for Compliance of $4 \mathrm{G}$ rules are correlated with previous trends in $3 \mathrm{G}$ availability. That is true.

Figure 6.1: Pre-trends of 3G number of varieties.

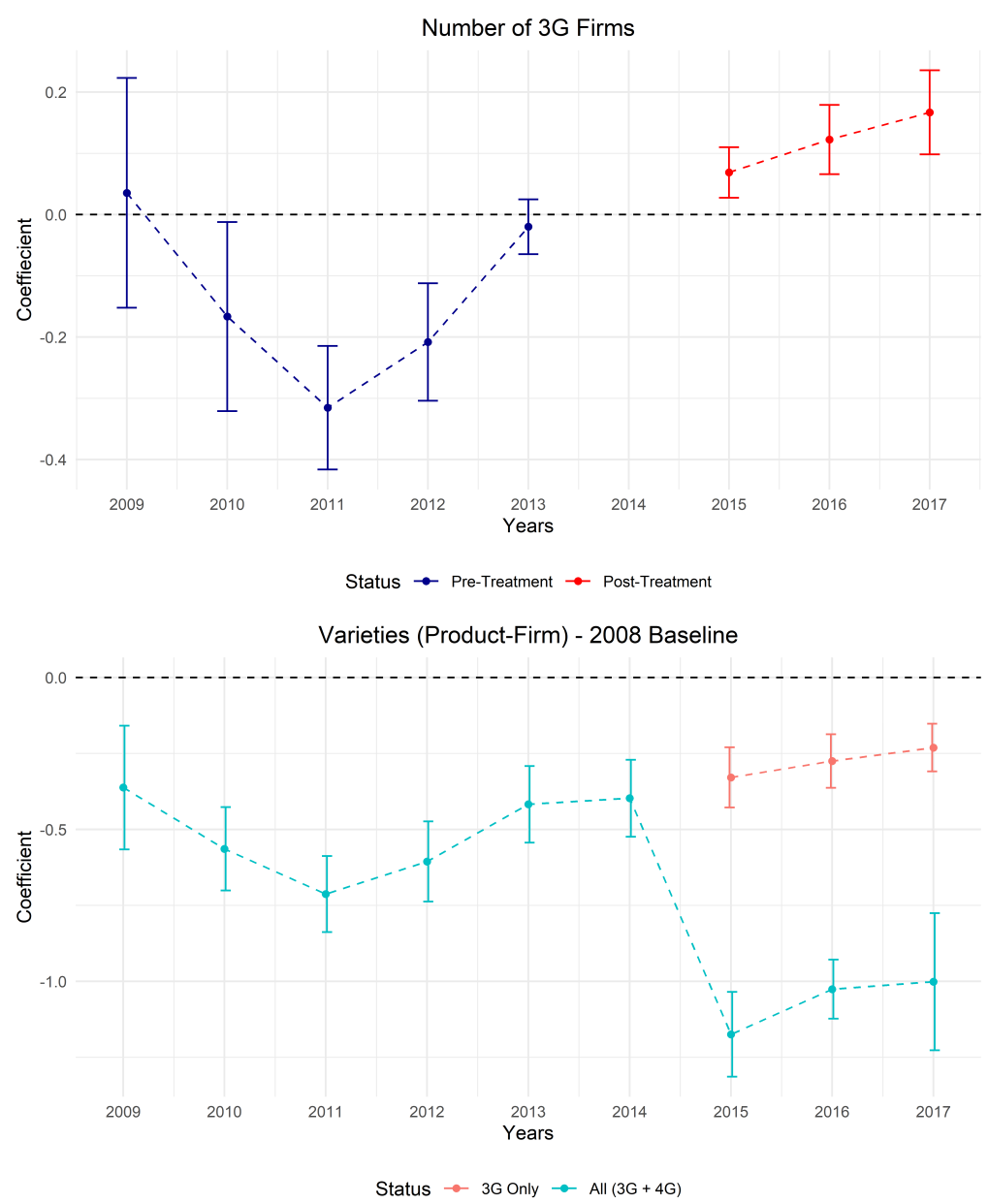

Mobile broadband data from ANATEL. Each coefficient represents the OLS coefficients of the ANATEL rules interacted with dummies for each year. All reduced-form regressions control for trend effects of statespecific factors, population size, and political fragmentation. Error bar indicates the $95 \%$ confidence interval. Robust standard errors are clustered at the meso-region level. The sample includes 385 micro-regions.

In fact, if we look at figure 6.1 the first plot shows exactly the same pre and post-treatment figure that I have exhibited before for labor market 
outcomes but now having the number of $3 \mathrm{G}$ firms as the dependent variable. Hence, the plot shows the vector $\hat{\omega}$ described in the equation 5-1 and the error bars represent the $95 \%$ confidence interval. As we can see for the years between 2009 - 2012, there is some evidence that local labor markets that had to wait more for $4 \mathrm{G}$ operator's compliance to ANATEL had gotten less $3 \mathrm{G}$ provision in previous years. It is important to note that the baseline here is the level of $3 \mathrm{G}$ operators in 2014 (the excluded dummy). For post-2014 effects, the effects are positive because the regions who will wait fewer years for $4 \mathrm{G}$ technologies had already reached maximum provision by firms of $3 \mathrm{G}$ services and hence cannot have any growth and coefficients capture only the remaining effects in local labor markets formed with municipalities with less than 30,000 inhabitants.

Figure 6.1, which has 2008 as the baseline, gives a more intuitive reasoning. Local labor markets that face longer waiting time due to ANATEL rule had less provision of $3 \mathrm{G}$ provision before 2014, as seen by the negative coefficients. After 2014, the number of varieties (technology x operator) of those with longer waiting is substantially lower due to $4 \mathrm{G}$. For $3 \mathrm{G}$ technologies, regulations seem to be less relevant over time as $3 \mathrm{G}$ operators face the incoming deadlines in sparsely populated municipalities.

Once we recognize there were diverging $3 \mathrm{G}$ trends, we should then ask if we should care about it. The answer to this is two-folded. First, there is indeed robust evidence of pre-trends in terms of $3 \mathrm{G}$ provision, however, there is no statistically significant evidence at all of pre-trends in terms of labor markets outcomes. Hence, this is very strong evidence that $3 \mathrm{G}$ provision had no previous significant effect in the labor market. Secondly, I control for trend effects of 3G availability (share of people covered by at least one operator) at baseline in the IV specification. In table 6.3, I exhibit the results. They are very similar to the origin specification but slightly less strong, except for the case of the impacts in the average skill level. Nonetheless, Figure 6.1 plots the coefficients of the effects of $4 \mathrm{G}$ operators on each of the relevant labor outcomes and its $95 \%$ confidence interval. There is a lot of overlap in the confidence interval between these two estimates.

While this may be counter-intuitive, there are remarkable differences in speed of 3G and 4G technologies. Fogg (2018) estimates that downloading speed of $4 \mathrm{G}$ technologies in Brazil is faster than fixed broadband on average, while that this is not the case for mobile broadband in general, which includes $3 \mathrm{G}$ connections. They cite two reasons for it: (i) implementing LTE antennas is cheaper than installing fiber cables for telecom operators, and (ii) smartphone manufacturers and designers prioritize using the tiny space of these devices for new features rather than better Wi-Fi antennas. 
Table 6.3: Effects of $4 \mathrm{G}$ (Controlling for $3 \mathrm{G}$ coverage trends)

\begin{tabular}{lcccc}
\hline \hline & \multicolumn{4}{c}{ Dependent variable: } \\
\cline { 2 - 5 } & $\log ($ Contracts $)$ & Routine & Manual & Skill Index \\
& $(1)$ & $(2)$ & $(3)$ & $(4)$ \\
\hline \# of 4G Operators & $-3.325^{* * *}$ & $-0.528^{* * *}$ & $-0.838^{* * *}$ & $0.170^{* * *}$ \\
& $(0.800)$ & $(0.162)$ & $(0.258)$ & $(0.060)$ \\
& & & & \\
\hline Original Specification & -3.925 & -0.579 & -0.951 & 0.166 \\
\hline Local Markets FE & $\mathrm{X}$ & $\mathrm{X}$ & $\mathrm{X}$ & $\mathrm{X}$ \\
Year FE & $\mathrm{X}$ & $\mathrm{X}$ & $\mathrm{X}$ & $\mathrm{X}$ \\
log(Pop 2010$) \times \mathrm{Y}$ & $\mathrm{X}$ & $\mathrm{X}$ & $\mathrm{X}$ & $\mathrm{X}$ \\
\# Munic $\times \mathrm{Y}$ & $\mathrm{X}$ & $\mathrm{X}$ & $\mathrm{X}$ & $\mathrm{X}$ \\
State Trends & $\mathrm{X}$ & $\mathrm{X}$ & $\mathrm{X}$ & $\mathrm{X}$ \\
Observations & 1,925 & 1,925 & 1,925 & 1,925 \\
Adjusted $\mathrm{R}^{2}$ & 0.998 & 0.975 & 0.962 & 0.979 \\
\hline \hline
\end{tabular}

All models control for local labor markets and years fixed effects. Regressions are weighted by the level of contracts in 2013. All columns are IV estimates. Robust standard errors are clustered at the meso-region level. Numbers between parenthesis are the coefficient standard deviations. In column (1), coefficients and standard deviations are multiplied by a hundred. $\log \left(\mathrm{Pop}_{2010}\right) \times \mathrm{Y}$ represents the trend-effects of the log-population of 2010 (yearly dummies interacted with this variable). \# Munic $\times \mathrm{Y}$ represents the trend-effects of the number of municipalities in local labor markets (yearly dummies interacted with this variable). * represents significance at the $10 \%$ level, ${ }^{* *}$ represents significance at the $5 \%$ level, and ${ }^{* * *}$ represents significance at the $1 \%$ level.

Figure 6.2: 4G Effects on local labor markets - Main results (controlling or not for trend-effects of $3 \mathrm{G}$ presence in 2013)

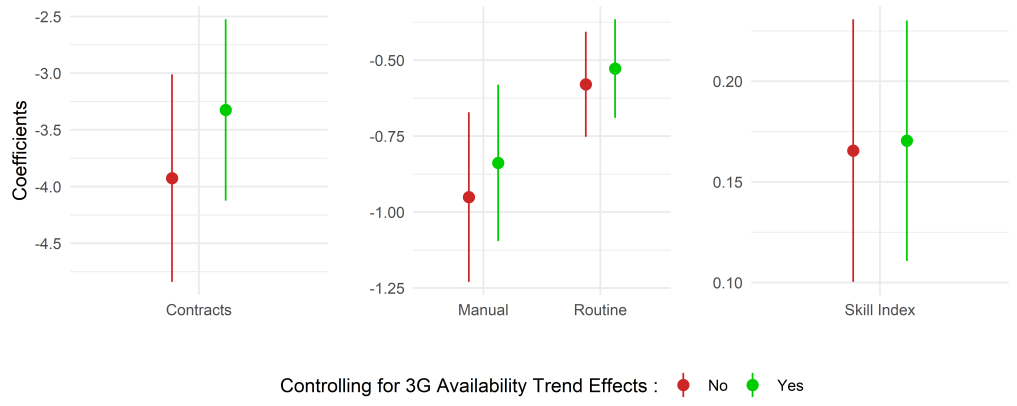

Mobile broadband data from ANATEL. Local labor market data from RAIS. Each coefficient represents the $I V$ estimates of the $4 G$ effects on labor market outcomes. All regressions control for trend effects of statespecific factors, population size, and political fragmentation. In green, there is an additional control: trend effects of $3 G$ levels at baseline. In red, there is not. Error bar indicates the 95\% confidence interval. Robust standard errors are clustered at the meso-region level. The sample includes 385 micro-regions. 


\section{4}

\section{Shifts in tasks and quality of RAIS-task-content matching}

An important characteristic of our sample of workers is that the big shifts that we observe in task-content along the decade, exhibited in figure 2.4 and figure 2.5, are contemporaneous to a small decrease in the quality of matching between RAIS and the tasks-content dataset. In figure 6.3, in the first years of the data, the share of workers matched with task-content measures is higher and gradually decreases, especially after 2012. This decrease is not big: at its maximum, the share of workers that were matched was $85.5 \%$ in 2010 and at its minimum in 2017 it has reached about $84.3 \%$. If this decrease of matching is homogenous among different local labor markets, we should not be concerned since all my regressions control for time-fixed effects.

Figure 6.3: Share of workers that is matched with the task-content dataset

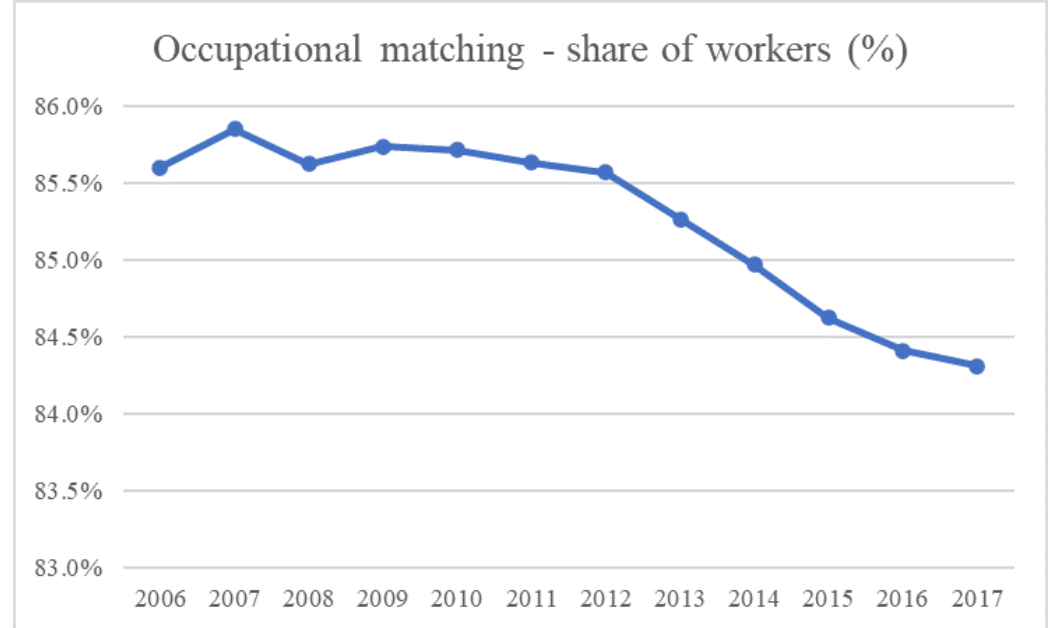

Nonetheless, we may still be concerned that this increased incompatibility may bias our estimates. Firstly, the documented shifts in task-content may not represent real shifts in the labor markets, then I may face significant measurement error. Secondly, if $4 \mathrm{G}$ presence is tightly correlated with poorer quality of matching, it could be the case that I attribute an effect for $4 \mathrm{G}$ presence in task content that is not actually real in the population. If, for example, 4G availability decreases the demand for occupations with high routine task-content among matched workers but increase the demand for unmatched occupation with same real routine task-content, the real taskcontent has not changed but regressions using the matched RAIS-task content sample will estimate that $4 \mathrm{G}$ presence reduced the demand for routine tasks.

I address these two concerns separately. For the first concern, in the appendix, I explore the fact that if documented shifts in task content were not real shifts in the full RAIS sample (matched and unmatched), then, 
contemporaneously to the fall of quality of matching, there should have been significant changes in differences between observable characteristics in matched and unmatched groups. There is no robust evidence of that. For the second concern, I check if I can identify any robust relationship between $4 \mathrm{G}$ presence and the quality of RAIS-task-content matching and I also re-run the original regressions but controlling now for previous trends in the share of workers matched and for the actual share of workers matched each year on each local labor market.

Table 6.4: Placebo test: effects of $4 \mathrm{G}$ in the share of matched workers

\begin{tabular}{|c|c|c|c|c|c|}
\hline & \multicolumn{5}{|c|}{ Dependent variable: } \\
\hline & \multicolumn{5}{|c|}{ Share of contracts matched with task-content (\%) } \\
\hline & \multicolumn{3}{|c|}{$O L S$} & \multicolumn{2}{|c|}{$I V$} \\
\hline & $(1)$ & $(2)$ & $(3)$ & $(4)$ & $(5)$ \\
\hline \# of $4 \mathrm{G}$ Operators & $\begin{array}{l}-0.126 \\
(0.084)\end{array}$ & $\begin{array}{l}-0.141 \\
(0.095)\end{array}$ & $\begin{array}{c}-0.176^{* *} \\
(0.073)\end{array}$ & $\begin{array}{l}-0.310 \\
(0.225)\end{array}$ & $\begin{array}{l}-0.378 \\
(0.235)\end{array}$ \\
\hline $\begin{array}{l}\text { Mean of Variable } \\
\text { F } 4 \mathrm{G}\end{array}$ & 85.48 & 85.48 & 85.48 & $\begin{array}{c}85.48 \\
203.59\end{array}$ & $\begin{array}{c}85.48 \\
178.95 \\
\end{array}$ \\
\hline Local Markets FE & $\mathrm{X}$ & $\mathrm{X}$ & $\mathrm{X}$ & $\mathrm{X}$ & $\mathrm{X}$ \\
\hline Year FE & $\mathrm{X}$ & $\mathrm{X}$ & $\mathrm{X}$ & $\mathrm{X}$ & $\mathrm{X}$ \\
\hline $\log \left(\operatorname{Pop}_{2010}\right) \times Y$ & & $\mathrm{X}$ & $\mathrm{X}$ & $\mathrm{X}$ & $\mathrm{X}$ \\
\hline$\#$ Munic $\times \mathrm{Y}$ & & $\mathrm{X}$ & $\mathrm{X}$ & $\mathrm{X}$ & $\mathrm{X}$ \\
\hline State Trends & & & $\mathrm{X}$ & & $\mathrm{X}$ \\
\hline Observations & 1,925 & 1,925 & 1,925 & 1,925 & 1,925 \\
\hline Adjusted $\mathrm{R}^{2}$ & 0.947 & 0.947 & 0.949 & 0.947 & 0.948 \\
\hline
\end{tabular}

All models control for local labor markets and years fixed effects. Regressions are weighted by the level of contracts in 2013. Columns (1) to (3) are OLS estimates, while Columns (4) to (5) are IV estimates. Robust standard errors are clustered at the mesoregion level. Coefficients and standard deviations are multiplied by a hundred. Numbers between parenthesis are the coefficient standard deviations. $\log \left(\mathrm{Pop}_{2010}\right) \times$ Y represents the trend-effects of the log-population of 2010 (yearly dummies interacted with this variable). \# Munic $\times$ Y represents the trend-effects of the number of municipalities in local labor markets (yearly dummies interacted with this variable). * represents significance at the $10 \%$ level, ${ }^{* *}$ represents significance at the $5 \%$ level, and ${ }^{* * *}$ represents significance at the $1 \%$ level.

If it was true that the results were driven by this worse compatibility among the merged datasets, we would notice negative effects on matching quality of $4 \mathrm{G}$ provision. In table 6.4 , I estimate equation $4-3$ with the share of matched workers as the $y_{m t}$ through OLS and IV methods and I find no robust evidence that $4 \mathrm{G}$ provision is correlated with lower compatibility between RAIS and task-content measures. While it is true that all coefficients are negative, they are not statistically significant, save column 3 . Hence, it 
does not seem that $4 \mathrm{G}$ provision is tightly connected with a worse quality of matching.

An alternative is adding as a control in our regressions the pre-trends of this occupational compatibility. As it can be seen by table 6.5, there is no remarkable difference between estimates. When directly controlling for the share of matched workers in each labor market by year, results in table 6.6 are slightly different and smaller in magnitude but not qualitatively divergent from the original specification. In figure 6.4, I exhibit coefficients of the dependent variable of number of $4 \mathrm{G}$ operators, controlling or not for the quality of matching and their 95\% confidence intervals. Similar to the situation where I control for baseline $3 \mathrm{G}$ levels, there is a lot of overlap in the confidence intervals between the coefficients of the two different specifications. Additionally, to all of these possible estimates, I also estimate the effects of $4 \mathrm{G}$ in total contracts (matched and unmatched with task-content) and effects are very similar to the specification controlling directly for compatibility, this is left for table A.5 in the appendix. Hence, we can be confident that our results are not driven by worsened quality of match between RAIS data and task-content measures.

Table 6.5: Effects of 4G (Controlling for compatibility trends)

\begin{tabular}{lcccc}
\hline \hline & \multicolumn{4}{c}{ Dependent variable: } \\
\cline { 2 - 5 } & $\log ($ Contracts $)$ & Routine & Manual & Skill Index \\
& $(1)$ & $(2)$ & $(3)$ & $(4)$ \\
\hline \# of 4G Operators & $-3.925^{* * *}$ & $-0.581^{* * *}$ & $-0.961^{* * *}$ & $0.165^{* *}$ \\
& $(0.910)$ & $(0.170)$ & $(0.280)$ & $(0.065)$ \\
\hline Original Specification & -3.925 & -0.579 & -0.951 & 0.166 \\
\hline Local Markets FE & $\mathrm{X}$ & $\mathrm{X}$ & $\mathrm{X}$ & $\mathrm{X}$ \\
Year FE & $\mathrm{X}$ & $\mathrm{X}$ & $\mathrm{X}$ & $\mathrm{X}$ \\
$\log ($ Pop 2010$) \times \mathrm{Y}$ & $\mathrm{X}$ & $\mathrm{X}$ & $\mathrm{X}$ & $\mathrm{X}$ \\
\# Munic $\times \mathrm{Y}$ & $\mathrm{X}$ & $\mathrm{X}$ & $\mathrm{X}$ & $\mathrm{X}$ \\
State Trends & $\mathrm{X}$ & $\mathrm{X}$ & $\mathrm{X}$ & $\mathrm{X}$ \\
Observations & 1,925 & 1,925 & 1,925 & 1,925 \\
Adjusted $\mathrm{R}^{2}$ & 0.998 & 0.975 & 0.962 & 0.979 \\
\hline \hline
\end{tabular}

All models control for local labor markets and years fixed effects. Regressions are weighted by the level of contracts in 2013. Regressions are weighted by the level of contracts in 2013. All columns are IV estimates. Robust standard errors are clustered at the meso-region level. Numbers between parenthesis are the coefficient standard deviations. In column (1), coefficients and standard deviations are multiplied by a hundred. $\log \left(\mathrm{Pop}_{2010}\right) \times \mathrm{Y}$ represents the trend-effects of the log-population of 2010 (yearly dummies interacted with this variable). \# Munic $\times$ Y represents the trend-effects of the number of municipalities in local labor markets (yearly dummies interacted with this variable). * represents significance at the $10 \%$ level, ** represents significance at the $5 \%$ level, and *** represents significance at the $1 \%$ level. 
Table 6.6: Effects of 4G (Controlling for compatibility)

\begin{tabular}{lcccc}
\hline \hline & \multicolumn{4}{c}{ Dependent variable: } \\
\cline { 2 - 5 } & $\log ($ Contracts $)$ & Routine & Manual & Skill Index \\
& $(1)$ & $(2)$ & $(3)$ & $(4)$ \\
\hline \# of 4G Operators & $-3.440^{* * *}$ & $-0.477^{* * *}$ & $-0.712^{* * *}$ & $0.130^{*}$ \\
& $(0.835)$ & $(0.163)$ & $(0.230)$ & $(0.068)$ \\
\hline Original Specification & -3.925 & -0.579 & -0.951 & 0.166 \\
\hline Local Markets FE & $\mathrm{X}$ & $\mathrm{X}$ & $\mathrm{X}$ & $\mathrm{X}$ \\
Year FE & $\mathrm{X}$ & $\mathrm{X}$ & $\mathrm{X}$ & $\mathrm{X}$ \\
$\log ($ Pop & & $\mathrm{X}$ & $\mathrm{X}$ & $\mathrm{X}$ \\
\# Munic $\times \mathrm{Y}$ & $\mathrm{X}$ & $\mathrm{X}$ & $\mathrm{X}$ & $\mathrm{X}$ \\
State Trends & $\mathrm{X}$ & $\mathrm{X}$ & $\mathrm{X}$ & $\mathrm{X}$ \\
Observations & 1,925 & 1,925 & 1,925 & 1,925 \\
Adjusted $\mathrm{R}^{2}$ & 0.998 & 0.977 & 0.966 & 0.981 \\
\hline \hline
\end{tabular}

All models control for local labor markets and years fixed effects. Regressions are weighted by the level of contracts in 2013. Regressions are weighted by the level of contracts in 2013. All columns are IV estimates. Robust standard errors are clustered at the meso-region level. Numbers between parenthesis are the coefficient standard deviations. In column (1), coefficients and standard deviations are multiplied by a hundred. $\log \left(\mathrm{Pop}_{2010}\right) \times \mathrm{Y}$ represents the trend-effects of the log-population of 2010 (yearly dummies interacted with this variable). \# Munic $\times \mathrm{Y}$ represents the trend-effects of the number of municipalities in local labor markets (yearly dummies interacted with this variable). ${ }^{*}$ represents significance at the $10 \%$ level, ${ }^{* *}$ represents significance at the $5 \%$ level, and ${ }^{* * *}$ represents significance at the $1 \%$ level. 
Figure 6.4: 4G Effects on local labor markets - Main results (controlling or not for share of workers matched with task-content data)
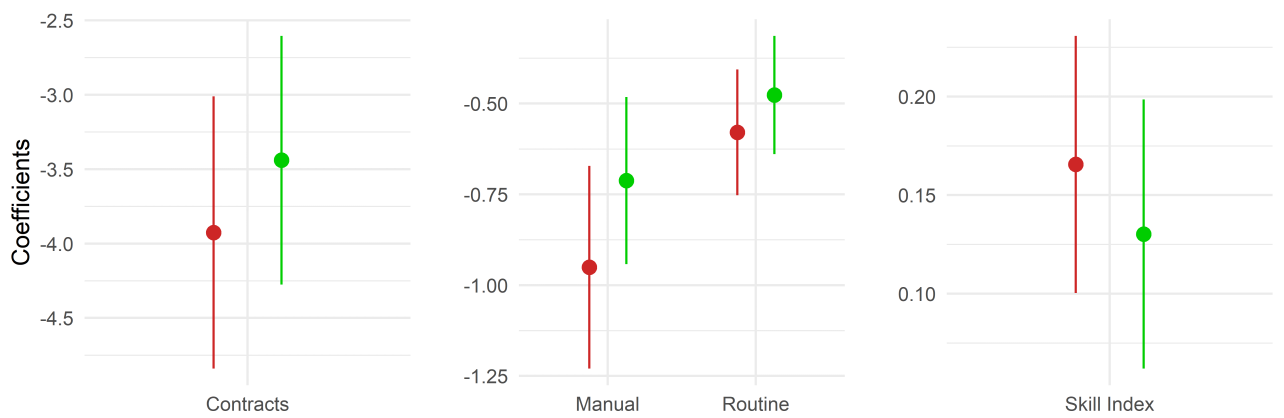

Controlling for Occupational Matching :

Mobile broadband data from ANATEL. Local labor market data from RAIS. Each coefficient represents the IV estimates of the $4 G$ effects on labor market outcomes. All regressions control for trend effects of state-specific factors, population size, and political fragmentation. In green, there is an additional control: the share of total workers that were matched by task-intensity. In red, there is not. Error bar indicates the 95\% confidence interval. Robust standard errors are clustered at the meso-region level. The sample includes 385 micro-regions. 


\section{7}

\section{Composition effects and potential mechanisms}

The shifts in the composition of skills and tasks of the workforce can be caused by several factors: it can be caused by shifts within educational levels (industries) or shifts between them. Moreover, it could be the case the mobile broadband connectivity has different impacts among different groups of the formal labor force. As an example, we could explain the effects of mobile connectivity on formal labor markets through two possible mechanisms. (i) mobile broadband increases the relative productivity and growth of the techintensive sector and, since these sectors tend to be less intense on low skilled labor and routine and manual tasks, there is shift in labor demand against these workers. (ii) there is no shift between industries, but some particular sectors are now more likely to adopt certain production technologies that are less intense in routine and manual tasks and in skilled work. It can also be the case that there is a combination of both. The same decomposition could be thought for educational groups: workers from all educational attainments could be doing less routine and manual tasks or there was an increase in the share of more educated workers, which tend to perform more abstract activities.

\section{1}

Effects within educational groups and increased demand for college graduates

We first take a look at the share of participation in the labor force of educational groups. In table 7.1, I consider the impact of those shocks among those who completed college (tertiary education, referred as college graduates), those who completed high school (secondary education, referred as high school graduates) and those who did not complete high school (dropouts or those who completed primary school or less, referred here as high school dropouts). In all regressions, I estimate IV estimates of the effects, and gradually control for state trends (columns 2, 5, 7) and previous schooling trends (variation of the share in primary education from 2008 to 2012). I find robust positive effects of mobile broadband expansion in the demand for college educated individuals and negative effects among high-school educated, but effects are not as precise. Moreover, there are positive coefficients among those that were high school 
dropouts or got less education than that, which could indicate some potential polarization in the labor market in terms of schooling, but these estimates are not statistically significantly different from zero.

Between 2008 and 2017, there has been a persistent drop of those with less than high-school and a robust increase of the participation of workers with completed high-school and completed college. Absent of the expansion of $4 \mathrm{G}$ mobile technologies, the rise of college educated participation in the labor force may have been slower. Between 2013 and 2017, there was 3 p.p. increase in the share of college educated worker. Considering the average expansion of 2 mobile broadband operators observed in the sample, the causal effect of internet expansion during that period was of 0.548 p.p. (about $18.2 \%$ of the expansion, $2 \mathrm{x}-0.274 / 3)$. Since these IV estimates are very precise, the lower bound of $4 \mathrm{G}$ importance, considering the $95 \%$ confidence interval, is about $16.9 \%$ of the expansion during the same period, but it could be as much as $19.6 \%$.

Therefore, it seems to be the case that part of the shifts in the composition of skills and routine tasks could be explained due to a shift in favor of the college educated workers. However. It can also be the cause that there was a shift within educational groups. We shall look for table 7.2 to see if that is the case. In that table, I exhibit, in each of the three lines of coefficients, the estimates of separate regressions of each educational group in the same column, according to the labor market outcome of each column. In fact, there seems to be important and relevant shifts within educational groups. At a first glance, we realize that the labor-saving effects was a generalized between all workers. In terms of point estimates, the drop of formal contracts among college educated workers was the lowest, while high school graduates observed the strongest displacement effects. The average increase of $4 \mathrm{G}$ firms observed between 2013 and 2017 of two firms lead to a drop of $10 \%$ of formal labor contracts among those with a high-school degree, $9.2 \%$ among those with incomplete high school and only $6 \%$ for those college educated.

In terms of tasks, there is an interesting heterogeneity. Increased nonmanual and non-routine shares may be driven primarily among high-school graduates, where we observe negative and statistically significant effects. The same could be said of the shift towards more skilled occupations. On the other hand, high school dropouts are doing fewer manual tasks but the effects on routine tasks are very imprecise and not statistically significant, although they do indicate a drop.

This is not observed among college educated workers, which did not seem to be affected in terms of the tasks they are doing nor the occupations they 
are working on. Based on point estimates, there seems to be some shifts in favor of non-routine tasks and skills among college-educated workers but the coefficients are very imprecise and not-statistically significantly different from zero.

If we take a further look at the effects in the composition of tasks in table 7.3, we see an unequivocal relationship between increased $4 \mathrm{G}$ connectivity and reduced demand for routine manual tasks driven by workers without a college degree. Interestingly, among those with high school education, most of this drop is converted into an increase in non-routine interactive tasks that are related with communication and human relations. For high school dropouts, however, there was also a substantial increase in routine cognitive tasks (estimates are not that precise, though, being significant only at the $10 \%$ level). Therefore, unlike the example of computerization in leading developed world, there has been an actual increase in routine cognitive tasks among those with no highschool. 


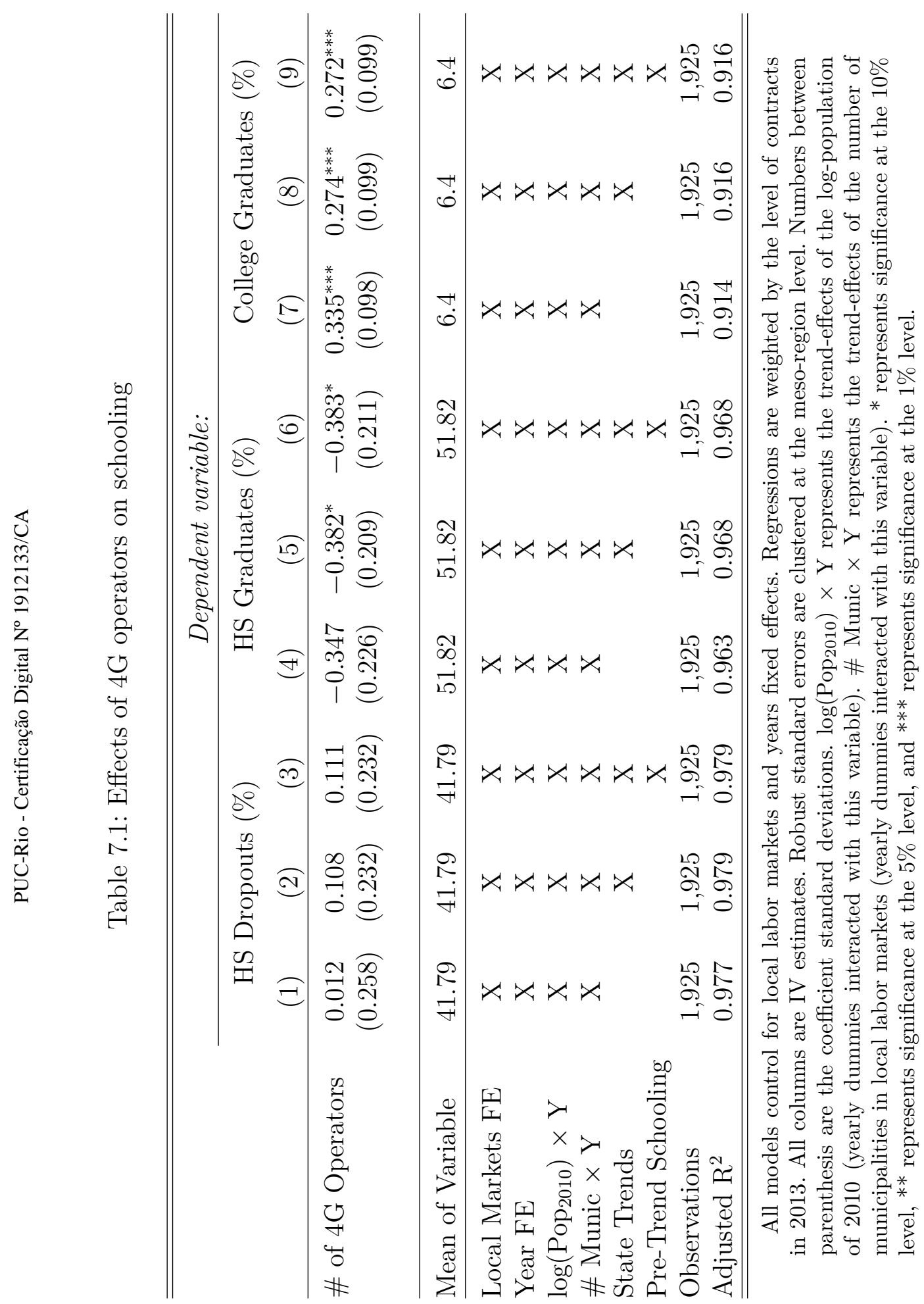


Table 7.2: Effects of 4G on labor market outcomes (by educational groups)

\begin{tabular}{|c|c|c|c|c|}
\hline & \multicolumn{4}{|c|}{ Dependent variable: } \\
\hline & $\log ($ Contracts $)$ & Routine & Manual & Skill Index \\
\hline Effects: \# of & & & & \\
\hline $4 \mathrm{G}$ operators on... & $(1)$ & $(2)$ & $(3)$ & $(4)$ \\
\hline HS Dropouts & $\begin{array}{c}-4.647^{* * *} \\
(1.271)\end{array}$ & $\begin{array}{l}-0.195 \\
(0.203)\end{array}$ & $\begin{array}{c}-0.838^{* * *} \\
(0.311)\end{array}$ & $\begin{array}{c}0.023 \\
(0.072)\end{array}$ \\
\hline HS Graduates & $\begin{array}{c}-5.052^{* * *} \\
(1.194)\end{array}$ & $\begin{array}{c}-0.609^{* * *} \\
(0.173)\end{array}$ & $\begin{array}{c}-1.063^{* * *} \\
(0.331)\end{array}$ & $\begin{array}{c}0.156^{* * *} \\
(0.056)\end{array}$ \\
\hline College Graduates & $\begin{array}{c}-3.224^{* *} \\
(1.314)\end{array}$ & $\begin{array}{c}-0.772 \\
(0.567)\end{array}$ & $\begin{array}{c}-0.114 \\
(0.669)\end{array}$ & $\begin{array}{c}0.210 \\
(0.235)\end{array}$ \\
\hline Original Specification & -3.925 & -0.579 & -0.951 & 0.166 \\
\hline $\begin{array}{l}\text { Mean of Variable } \\
\text { Uncompleted HS } \\
\text { Completed HS } \\
\text { Completed College }\end{array}$ & & $\begin{array}{c}56.6 \\
45.54 \\
-10.28\end{array}$ & $\begin{array}{c}4.32 \\
-24.51 \\
-78.64\end{array}$ & $\begin{array}{l}15.82 \\
20.16 \\
43.62\end{array}$ \\
\hline Local Markets FE & $\mathrm{X}$ & X & $\mathrm{X}$ & $\mathrm{X}$ \\
\hline Year FE & $\mathrm{X}$ & $\mathrm{X}$ & $\mathrm{X}$ & $\mathrm{X}$ \\
\hline $\log \left(\operatorname{Pop}_{2010}\right) \times Y$ & $\mathrm{X}$ & $\mathrm{X}$ & $\mathrm{X}$ & $\mathrm{X}$ \\
\hline$\#$ Munic $\times$ Y & $\mathrm{X}$ & $\mathrm{X}$ & $\mathrm{X}$ & $\mathrm{X}$ \\
\hline State Trends & $\mathrm{X}$ & $\mathrm{X}$ & $\mathrm{X}$ & $\mathrm{X}$ \\
\hline
\end{tabular}

All models control for local labor markets and years fixed effects. Regressions are weighted by the level of contracts in 2013. All columns are IV estimates. Robust standard errors are clustered at the meso-region level. Numbers between parenthesis are the coefficient standard deviations. Coefficients and standard deviations are multiplied by a hundred for column 1 . $\log \left(\mathrm{Pop}_{2010}\right) \times \mathrm{Y}$ represents the trend-effects of the log-population of 2010 (yearly dummies interacted with this variable). \# Munic $\times \mathrm{Y}$ represents the trend-effects of the number of municipalities in local labor markets (yearly dummies interacted with this variable). * represents significance at the $10 \%$ level, ${ }^{* *}$ represents significance at the $5 \%$ level, and $* * *$ represents significance at the $1 \%$ level. 
Table 7.3: Effects of $4 \mathrm{G}$ Operators on the share of tasks (\%)

\begin{tabular}{|c|c|c|c|c|c|}
\hline \multirow{5}{*}{$\begin{array}{l}\text { Effects: \# of } \\
4 \mathrm{G} \text { operators on... }\end{array}$} & \multicolumn{5}{|c|}{ Dependent variable: } \\
\hline & \multicolumn{3}{|c|}{ Non-Routine } & \multicolumn{2}{|c|}{ Routine } \\
\hline & Analytical & Interactive & Manual & Manual & Cognitive \\
\hline & & & & & \\
\hline & $(1)$ & $(2)$ & $(3)$ & $(4)$ & $(5)$ \\
\hline HS Dropouts & $\begin{array}{l}-0.059 \\
(0.048)\end{array}$ & $\begin{array}{l}0.183^{* *} \\
(0.070)\end{array}$ & $\begin{array}{l}-0.026 \\
(0.058)\end{array}$ & $\begin{array}{c}-0.393^{* * *} \\
(0.145)\end{array}$ & $\begin{array}{l}0.295^{*} \\
(0.175)\end{array}$ \\
\hline HS Graduates & $\begin{array}{c}0.071 \\
(0.043)\end{array}$ & $\begin{array}{c}0.299^{* * *} \\
(0.084)\end{array}$ & $\begin{array}{l}-0.066 \\
(0.052)\end{array}$ & $\begin{array}{c}-0.465^{* * *} \\
(0.139)\end{array}$ & $\begin{array}{c}0.161 \\
(0.120)\end{array}$ \\
\hline College Graduates & $\begin{array}{c}0.069 \\
(0.141)\end{array}$ & $\begin{array}{c}0.267 \\
(0.220)\end{array}$ & $\begin{array}{c}0.050 \\
(0.068)\end{array}$ & $\begin{array}{l}-0.107 \\
(0.275)\end{array}$ & $\begin{array}{l}-0.279 \\
(0.240)\end{array}$ \\
\hline Original Specification & 0.072 & 0.262 & -0.044 & -0.432 & 0.142 \\
\hline $\begin{array}{l}\text { Mean of Variable } \\
\text { HS Dropouts }(\%) \\
\text { HS Graduates }(\%) \\
\text { College Graduates (\%) }\end{array}$ & $\begin{array}{c}4.34 \\
5.65 \\
20.07 \\
\end{array}$ & $\begin{array}{c}9.77 \\
16.27 \\
34.33 \\
\end{array}$ & $\begin{array}{l}7.59 \\
5.31 \\
0.73\end{array}$ & $\begin{array}{c}44.57 \\
32.44 \\
9.95 \\
\end{array}$ & $\begin{array}{l}33.73 \\
40.33 \\
34.91 \\
\end{array}$ \\
\hline $\begin{array}{l}\text { Local Markets FE } \\
\text { Year FE } \\
\log \left(\text { Pop }_{2010}\right) \times \text { Y } \\
\# \text { Munic } \times \text { Y } \\
\text { State Trends }\end{array}$ & $\begin{array}{l}X \\
X \\
X \\
X \\
X\end{array}$ & $\begin{array}{l}X \\
X \\
X \\
X \\
X\end{array}$ & $\begin{array}{l}X \\
X \\
X \\
X \\
X\end{array}$ & $\begin{array}{l}X \\
X \\
X \\
X \\
X\end{array}$ & $\begin{array}{l}X \\
X \\
X \\
X \\
X\end{array}$ \\
\hline
\end{tabular}

All models control for local labor markets and years fixed effects. Regressions are weighted by the level of contracts in 2013. Columns (1) to (5) are IV estimates. Robust standard errors are clustered at the meso-region level. Numbers between parenthesis are the coefficient standard deviations. $\log \left(\mathrm{Pop}_{2010}\right) \times \mathrm{Y}$ represents the trend-effects of the log-population of 2010 (yearly dummies interacted with this variable). \# Munic $\times$ Y represents the trendeffects of the number of municipalities in local labor markets (yearly dummies interacted with this variable). * represents significance at the $10 \%$ level, $* *$ represents significance at the $5 \%$ level, and ${ }^{* * *}$ represents significance at the $1 \%$ level. 


\section{2}

\section{Heterogeneity from industrial tech-intensity}

We move forward to discuss the potential heterogeneous effects among different industries according to the tech-intensity of their production function. I use measures of computer usage intensity from Corseuil et al. (2018) and divide them on five group of industries. Those fifths of the technological intensity have the following descriptive statistics present below in table 7.4. Consistent with the routinization hypothesis, tech-intensive sectors are skewed towards workers with higher human capital and non-routine tasks. It is probably the case that routine tasks are already performed by computers, artificial intelligence and machines on those sectors.

Table 7.4: Descriptive statistics of industries by tech-intensity

\begin{tabular}{|c|c|c|c|c|c|c|c|c|}
\hline $\begin{array}{c}\text { Tech- } \\
\text { Intensity } \\
\text { Fifth }\end{array}$ & $\begin{array}{c}\text { Share of the } \\
\text { Workforce } \\
(\%)\end{array}$ & $\begin{array}{c}\text { College } \\
\text { Graduates } \\
(\%)\end{array}$ & Skill Index & Routine & Manual & $\begin{array}{c}\text { Routine } \\
\text { Cognitive (\%) }\end{array}$ & $\begin{array}{c}\text { Routine } \\
\text { Manual (\%) }\end{array}$ & $\begin{array}{c}\text { Non-routine } \\
\text { Cognitive (\%) }\end{array}$ \\
\hline 1 & 39.31 & 2.81 & 16.37 & 49.90 & -2.37 & 33.51 & 41.44 & 17.68 \\
\hline 2 & 21.46 & 4.77 & 20.17 & 44.34 & -28.55 & 40.87 & 31.30 & 23.41 \\
\hline 3 & 14.91 & 6.34 & 22.22 & 43.54 & -21.59 & 39.25 & 32.52 & 21.55 \\
\hline 4 & 14.93 & 10.66 & 21.45 & 41.85 & -30.69 & 41.52 & 29.40 & 23.82 \\
\hline 5 & 16.70 & 22.88 & 27.13 & 25.64 & -49.97 & 41.17 & 21.65 & 33.82 \\
\hline
\end{tabular}

RAIS data, task intensity measures from Funchal $\&$ Soares (2013) and tech-intensity data from Corseuil et al. (2018). The data from the universe of formal workers is matched with tech-intensity data through the industry code CNAE 1.0 and with task-intensity data through the occupational four-digits CBO.

As we can see from this table, less tech-intensive sectors concentrate a higher share of the workforce in Brazil, which is consistent to an economy that is not in the technological frontier of the world. Moreover, we can see that tech-intensive sectors tend to demand more workers in occupations in the upper percentiles of the skill distribution and more college graduates. Routine intensiveness is monotonically decreasing relative to tech-intensiveness. Manual tasks are way more prevalent in the bottom fifth of industries, while nonroutine cognitive tasks are positively correlated with tech-intensity.

In Brazil, however, it seems to be the case that routine cognitive tasks are more present in tech-intensive sectors than what we could expect from the developed countries. As seen from the distribution of tasks across the skill percentiles in figure 2.7, routine cognitive tasks tend to be very significant in the middle and lower part of the distribution and they are also still somewhat relevant even in top percentiles, unlike the United States. Sulzbach (2020) also notices a similar pattern. 
I then proceed to estimate the same regressions from the main IV specification but for each one of these fifths of tech-intensity distribution. Therefore, I ran the same regressions in the local labor market, restricting the analysis for each one of these groups. Figures 7.1 and 7.2 show the results for several relevant local labor market outcomes. The y-axis represents the coefficient size and its 95\% confidence interval and x-axis represent each one of these fifths. Dependent variables of these regressions have very different averages. For some of these variables, I adjust the size of the coefficients and standard errors according to the group averages, in order to provide a better sense of comparability between groups.

From figure 7.1 we can notice that, although there are differences in terms of point estimates of the reduction in formal employment contracts in data, this does not end up in statistically significant causal effects in terms of share of the total workforce. It is noticeable, however, that the second and third lowest quintiles (2 and 3 ) seem to be less sensitive to the $4 \mathrm{G}$ effect. This is a pattern that will prevail in other regressions. For example, the effects on the share of college educated workers are prevalent in the extremes of techintensiveness distribution, although results in the bottom of the distribution are not significant at the $5 \%$ level.

The shifts in composition towards skilled workers, however, are also not equal among different industries. High-tech sectors, fifths 4 and 5, seem to drive the effects of mobile broadband in terms of increased demand for more skilled occupations and less-routine work, although some of these results are not statistically significant at the $5 \%$ level (although most of them are for the $10 \%$ level). On the other hand, the shift of workforce composition away of manual tasks are concentrated in less-tech intensive sector. Those movements are consistent with what was observed with educational groups. Shifts against manual tasks were observed for high school graduates and dropouts, that are more prevalent on these low-tech industries. 
Figure 7.1: 4G effects on labor market outcomes by tech-intensity of industries
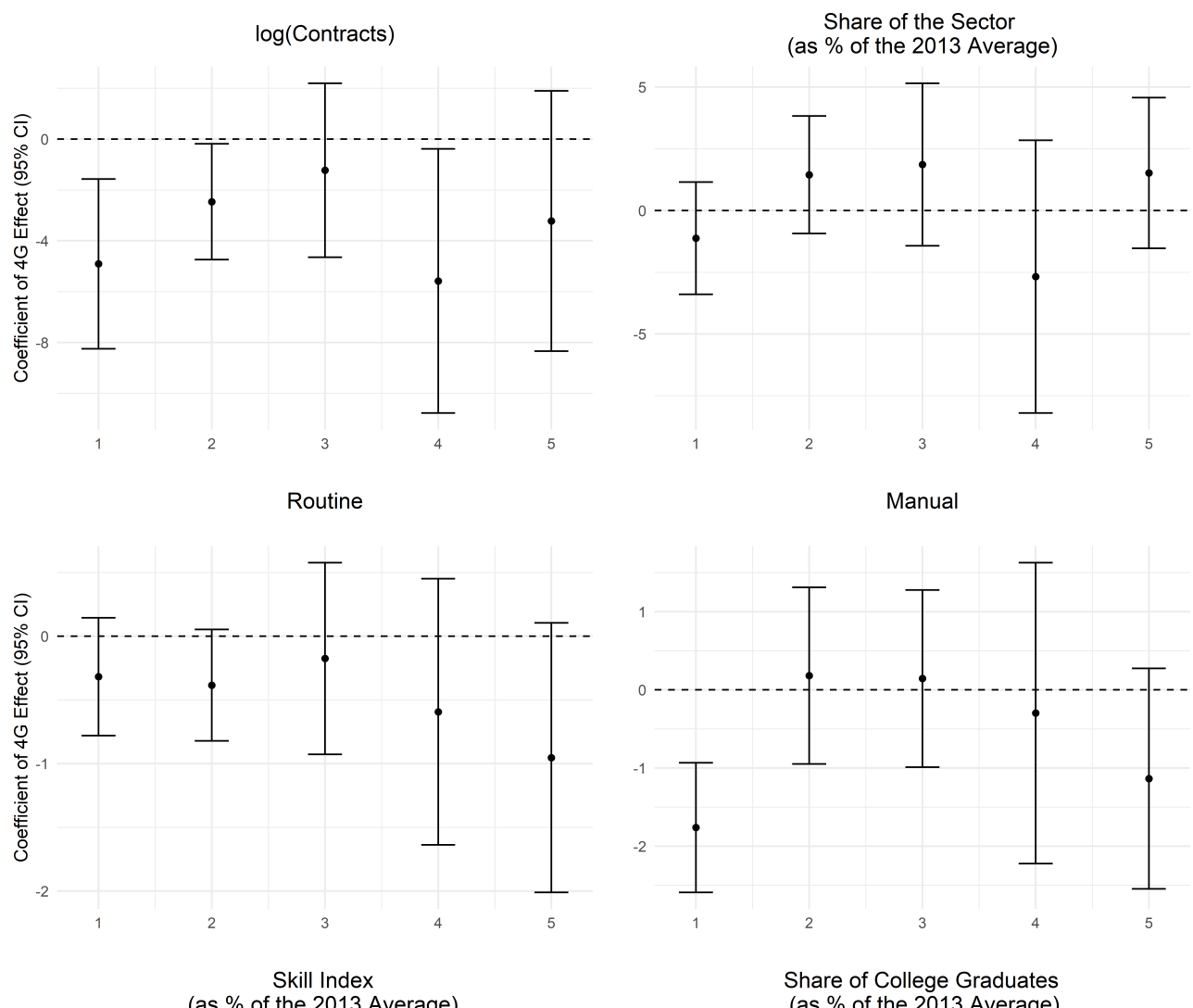

(as \% of the 2013 Average)
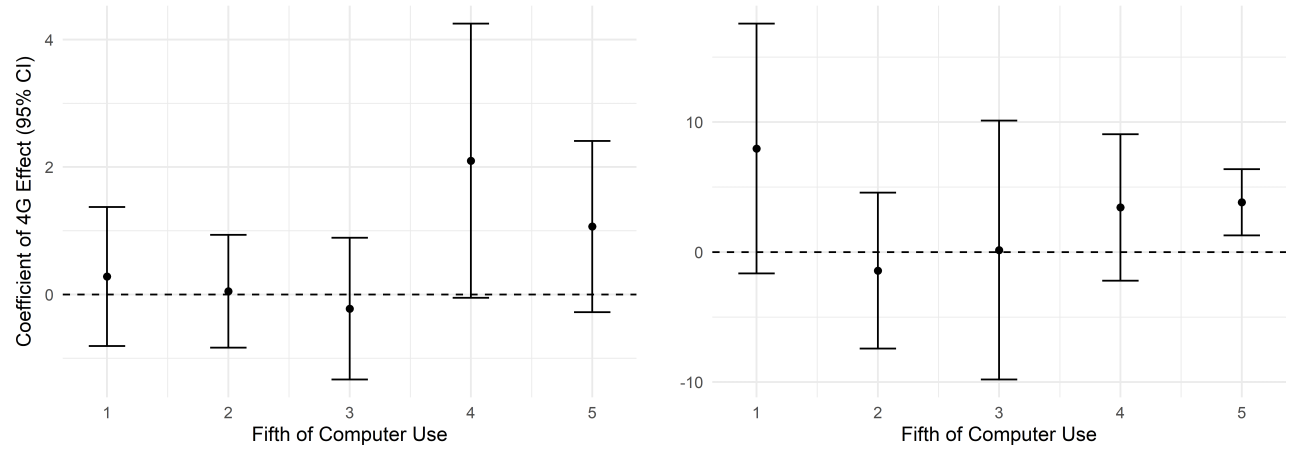

Formal employment data from RAIS, task-intensity from Funchal 8 Soares (2013), tech-intensity measure from Corseuil et al. (2018), and mobile broadband data from ANATEL. This figure plots the coefficients of IV estimates, controlling for state-trends and trend-specific effects of population size and number of municipalities. Standard errors are clustered at the meso-region level. Estimates of each tech-intensity fifth of the workforce: 1 represents the workers in the lowest fifth of sectors according to the tech-intensity and 5 represents the workers in the top fifth of sectors. 
Figure 7.2: 4G effects on the demand of tasks by tech-intensity of industries

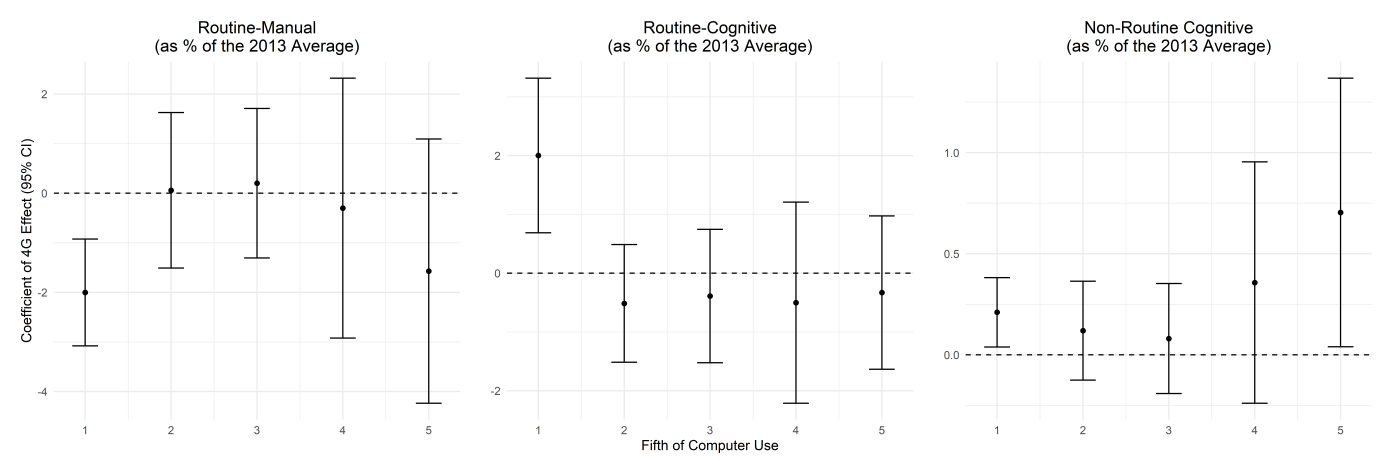

Formal employment data from RAIS, task-intensity from Funchal $\&$ Soares (2013), tech-intensity measure from Corseuil et al. (2018), and mobile broadband data from ANATEL. This figure plots the coefficients of IV estimates, controlling for state-trends and trend-specific effects of population size and number of municipalities. Standard errors are clustered at the meso-region level. Estimates of each tech-intensity fifth of the workforce: 1 represents the workers in the lowest fifth of sectors according to the tech-intensity and 5 represents the workers in the top fifth of sectors.

From figure 7.2 , we can have a better sense of the changes in the composition of tasks. Interestingly, we can see statistically significant effects for the lowest quintile and for the highest-quintile, but point estimates are stronger for the top quintiles (mobile broadband cause a $0.25 \%$ increase in non-routine cognitive in the bottom $20 \%$ of industries and a $0.75 \%$ increase the top 20\%). We see a similar pattern for routine manual tasks, with both industries showing a $2 \%$ reduction of routine manual tasks with the presence of one mobile operator, although results are not statistically significant for the top quantile. Interestingly, however, for the low-tech sector, there is also an increased shift towards routine cognitive tasks, the presence of one mobile operator increases the share of routine cognitive tasks in $2 \%$.

These heterogenous effects are consistent with a more nuanced version of the routinization hypothesis. The top quintiles of the distribution (4 and 5) seem to be associated with similar routinization processes that were seen in developed countries (Acemoglu \& Autor, 2011; Akerman et al., 2015), but the lowest quintile of tech-intensity seems to be experiencing older types of innovations, mirroring similar to the effects of computerization in lagging developed countries like Portugal (Fonseca et al., 2018), where reduction of routine manual tasks was intense but, if anything, routine cognitive tasks had only a slight decrease possibly due to increased demand of services (which has also increased in Brazil during that period) and low human and physical capital accumulation.

Increased $4 \mathrm{G}$ mobile presence could be interpreted as reduced cost for 
computer and computer-like solutions, and this reduction of costs will make different industries use different production technologies. These results are consistent with the sectors in the middle of the distribution not getting enough cost reductions from $4 \mathrm{G}$ internet to incorporate new technologies in their services. Nonetheless, it could be the case that low-tech sectors are now having opportunities to increase the presence of computer and computerlike solutions through mobile broadband and smartphone applications. These increased opportunities of computerization through mobile broadband were possibly also profitable for high-tech sectors, which have increased the demand for college graduates, skilled work and non-routine tasks (that are usually complemented with technological development). We need, however, more evidence of mechanisms to fully understand these phenomena.

\section{3}

\section{Effects on the distribution of skills}

Frequently, in developed country's computerization literature, technological shocks tend to be associated with job polarization. This is overwhelmingly related to the fact that the distribution of routine task intensity in the United States and some other developed nations have an inverted U-shape format concentrated in mid-skilled occupations. Therefore, routinization in the United States will necessarily pressure for job polarization. Among the earliest receivers of mobile broadband in Brazil, it is possible to see some similar patterns of job polarization, when compared these regions with the shifts in late receivers of mobile broadband technology.

This analysis is made reproducing the employment change of skill percentiles present in figure 2.6 for three different groups of local labor markets, that represent, each, employment-weighted thirds according to the level of years for compliance according to ANATEL's rule. Therefore, I divide these local labor markets into the Early Third, the Middle Third and the Late Third. Figure 7.3 shows that this groups experienced different timing of expansion of $4 \mathrm{G}$ technologies. Local labor markets that were part of the early group, as expected, receive earlier the broadband coverage (panel A) and experience more significant potential competition among operators (panel B).

In figure 7.4, I estimate the smoothed changes in all percentiles, normalizing them so that smoothed changes sum up to 0. Then I compare the Early and Middle Thirds with the Late one. In panel A, I show the smoothed changes for each group in absolute terms. The y-axis represents the change of employment for each hundredth, while the x-axis represents each employment weighted hundredths in the skill rank. If we find differences among changes 
Figure 7.3: Mobile broadband exposure by groups of local labor markets according to their years for compliance of mobile operators as defined by ANATEL

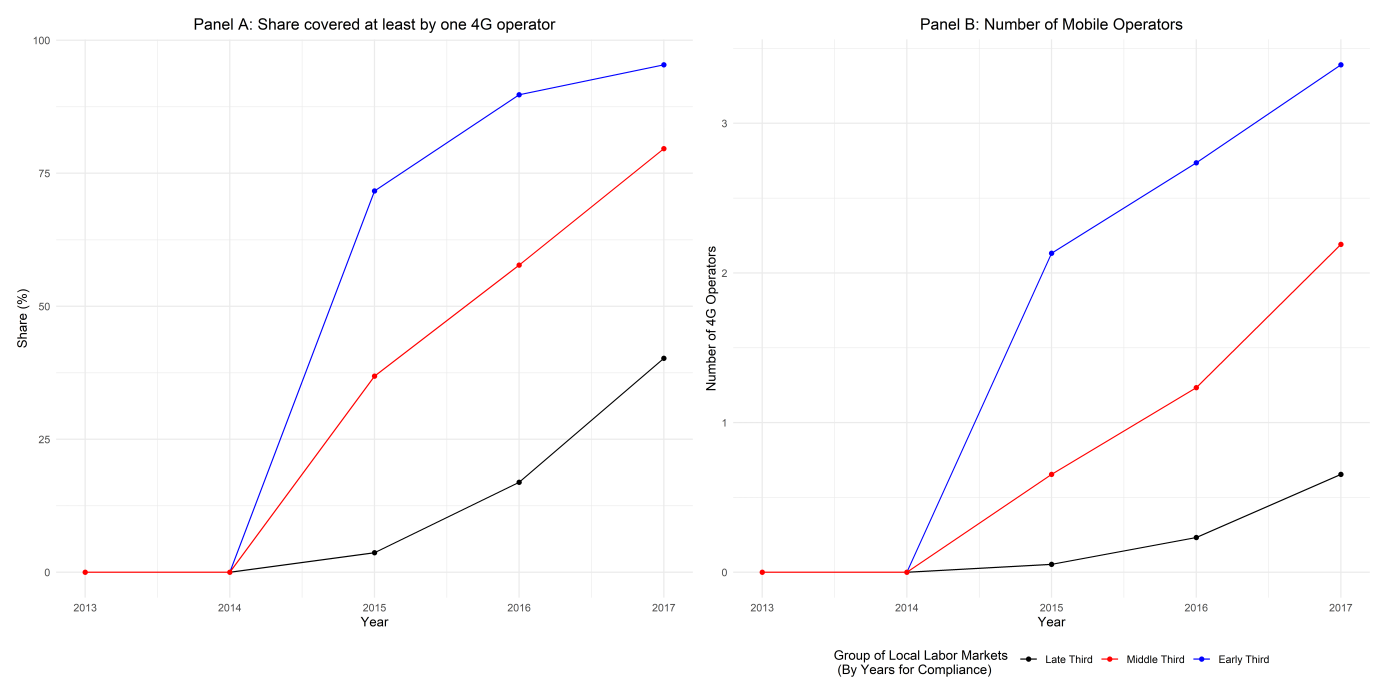

ANATEL Data. Employment weighted yearly average of the share of the population covered by at least one operator (in Panel A) and of the number of $4 G$ operators (in Panel B). Workers are divided in employment-weighted thirds of local labor market based on ANATEL's average years for compliance to provision commitments. Analysis restricted to the 385 local labor markets from the regression analysis.

in employment of percentiles for each of these groups, it could be the case that mobile broadband could be playing a role into that. In panel $\mathrm{B}$, these variation in employment shares is presented in relative terms, that is the differences between the two groups that were assigned by ANATEL to receive mobile broadband and the group that would receive later on. Panel B offers us some suggestive evidence of potential effects of mobile broadband in terms of polarization along the skill distribution. By making an analysis in relative terms, presenting the differences between early and middle thirds against the late third, I control for potential common trend effects. 
Figure 7.4: Smoothed employment changes in skill distribution by groups of local labor markets according to their years for compliance of mobile operators as defined by ANATEL (2013-2017)

Panel A: Smoothed changes in employment by skill percentile (2013-2017)

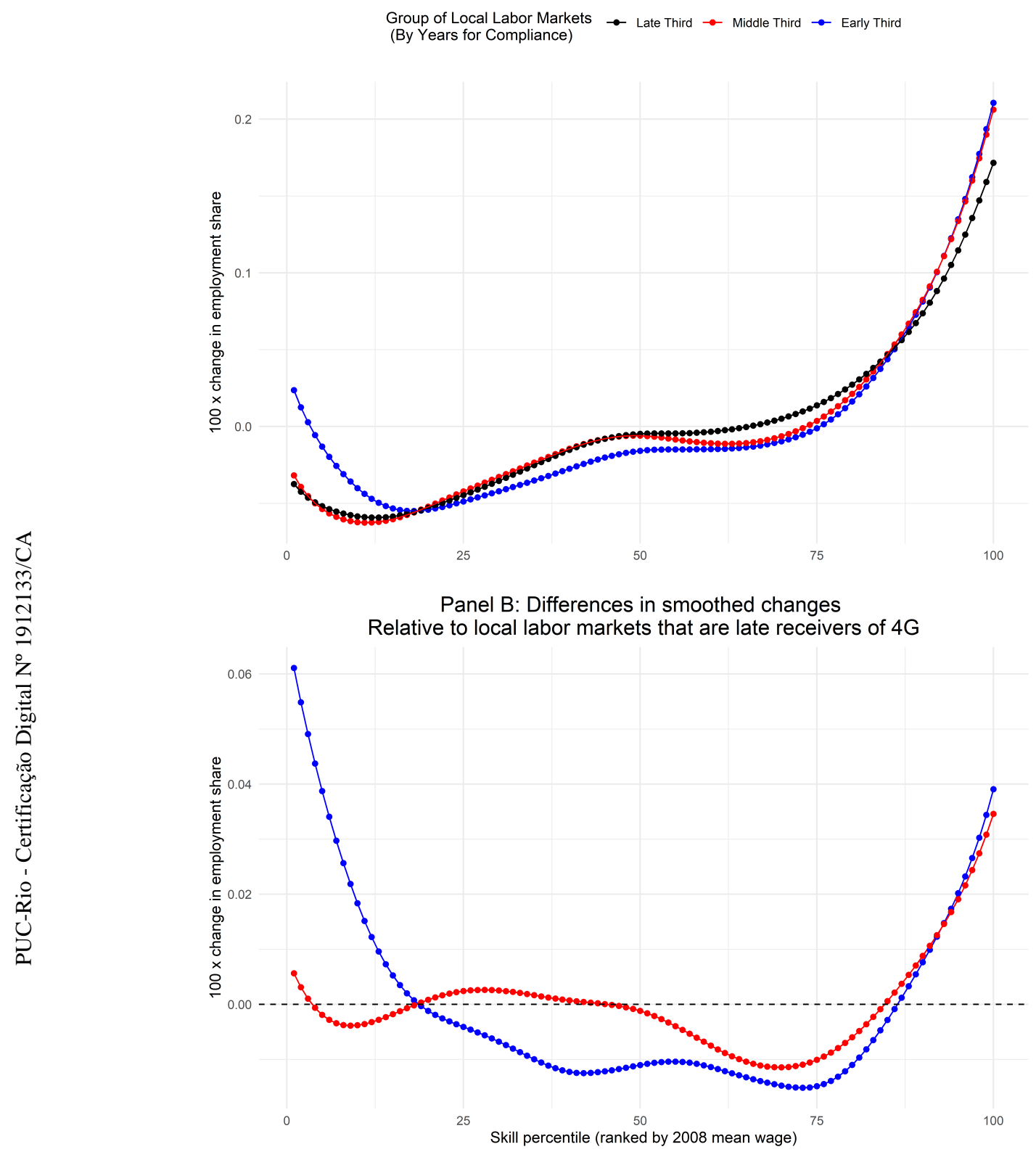

ANATEL and RAIS data. Panel A plots changes in employment-shares by hundredths of the 2008 skill distribution for three groups. Local labor markets are divided into employment-weighted thirds according to the average years for compliance of mobile operators to ANATEL's provision commitments. Ranking of occupations is fixed on the rank for the total 2008 sample as a normalization, since there could be variation on the ranking of occupations and the initial share of occupations for each sub-group. Percentiles are employment-weighted and variation in the $y$-axis is represent by the output of a locally weighted smoothing regression (using Stata command lowess, bandwidth 0.8 and 100 observations, following closely to Acemoglu and Autor (2011) methodology). Skill percentiles defined based on wages and the number of contracts for each occupation in 2008. An additional step is made centralizing mean variation in zero, since the relative variation must be zero. Panel (B) takes the difference between early and the middle third against the late third. 
Since mobile broadband is more prevalent in early and middle thirds, this is suggestive evidence that observed changes in the upper tail of the skill distribution seem to be more intense than what happens in local labor markets that take longer to get access of mobile broadband. This is consistent with routine-biased technological change. The top $25 \%$ of the skill rank is concentrated in occupations with decreased routine manual and cognitive tasks and very high share of non-routine abstract activities.

Effects in the rest of the distribution of skills seem to be negative or close to zero for the workers in the middle third of ANATEL's regulation (those who were not assigned as early receivers nor as late receivers of $4 \mathrm{G}$ technology). Interestingly, though, in markets that were early receivers of $4 \mathrm{G}$ technology there seems to be a relative increase in the demand for very low skilled work. These very low percentiles tend to have more cognitive and less manual tasks, when compared with other tasks in the bottom of the skill distribution. This could explain part of the increased participation of routine cognitive work in workers in low-tech industries and among less educated individuals. Therefore, we can see some suggestive evidence that early mobile broadband use is associated with job polarization pressures. While this is not the case for those local labor markets in the middle third, with additional data for periods where $4 \mathrm{G}$ technology has reached its maturity on this region, possibly the same pattern could emerge.

Although this analysis offers some suggestive evidence that broadband may be related with job polarization (and, with more confidence, in increased demand for the top of the distribution), this approach does not allow for controls of trend-effects of different states, population size and the number of municipalities, as it is used in our regression analysis. Moreover, it is not possible to establish confidence intervals and get a better sense of the causal effects on itself due to the lack of controls in this comparison. Therefore, this proposed comparison should be taken with a grain of salt.

\section{4}

\section{Mechanisms}

This dissertation's effects are reduced form effects. I find that connectivity has a causal effect on reducing the level of formal employment contracts, shifting the task composition towards skilled workers, and increasing the share of college graduates. These effects are high in magnitude and, therefore, they may be explained through many different mechanisms. Future research should address these potential channels through which broadband causes displacement and shifts in the composition of tasks. These could be explained through 
a wide-varying range of hypothetical factors:

1. Labor-saving technologies. These effects could be understood not only by the direct effects of mobile broadband technologies but also by the way that mobile broadband complement other productivityenhancing innovations. As reported in Dutz et al. (2018), ICT could raise firm-level productivity by improving the relationship with suppliers and customers or improving recruitment and training. Since connectivity in developing countries is also largely dependent on mobile phones, computerization-related or automation-related innovations, especially in low-tech sectors, could be deeply complemented with mobile broadband technologies. This would also explain the shift towards more high-skilled workers and non-routine tasks.

2. Changes in the consumer markets leading to alternative selling strategies and shifts in the composition of workers. An increase in connectivity from families across Brazil could have changed the optimal strategy of firms to reach out to consumers. Increased broadband connection raises the potential benefits of connecting firms to the web, selling products online, and adopting "big data" solutions. This, in turn, may lead firms to decrease their local presence, significantly reducing contracting of low-skill workers, while increasing their web presence, through the assistance of programmers, web designers, and web engineers.

3. New occupational choices and shifts in the labor supply. As already mentioned, increased mobile broadband could lead to the creation of new occupations, especially self-employment opportunities through jobs in the gig economy. Workers may shift from formal jobs to new opportunities such as becoming Uber drivers, working as deliverymen, or starting small firms to sell food or simple projects. This shift may be more concentrated among low-skilled routine-intensive workers, explaining what we see in data. Mobile broadband may have also reduced the entry costs of small firms, by making it easier to start a business and creating new opportunities for smaller firms to reach out to consumers.

4. Mobile broadband as a trade shock. Internet could have also been a driver of reduced export and import shocks in local economies. We know that mobile broadband expands access to foreign markets (Dutz et al., 2018; Fernandes et al., 2019). As a result, increased connectivity could have represented a trade shock for local economies. This dissertation's result could be a result of increased competition from foreign firms 
that drive labor-intensive firms out of the market, decreasing formal employment. Depending on the relative international task prices, if routine tasks are cheaper abroad, this trade shock could shift the workers' composition from routine tasks to non-routine tasks. On the other hand, some exporting firms could see increased opportunities. If these exporting firms tend to be less routine intensive and less labor-intensive, this could also be a potential explanatory factor.

5. Labor market efficiency. Bhuller et al. (2020) and Dutz et al. (2018) outline that the internet could increase the efficiency of labor markets, increasing the quality of employee-firms matching, reducing turnover, and increasing the average tenure. I have outlined some evidence that expanded mobile broadband has reduced gross turnover. This is seen in column 5 in Table 5.9, where we see reduced firings and hires bringing reduced gross turnover, but more evidence is needed.

6. Migration could be fostered in local economies. Reduced moving costs could also be a factor. As outlined by Dutz et al. (2018), mobile broadband could be a source of reduced industrial and regional moving costs This could lead to reduced formal employment if the internet allows people to move out of the most connected local economies. Porcher (2020) addresses the importance of information costs in migrating decisions. He considers that increased information costs may make migrants take poor decisions and go to places where they will have poorer welfare. Hence, the expansion of fixed broadband in Brazil has reduced out-migration in local economies. He notes, however, that this is based on a structural model that considers only the potential channel of broadband on information costs. Therefore, his counter-factual exercise considers the effects of the internet in migration if they did not affect local economies. It remains an open empirical question if mobile broadband has fostered out-migration in local economies. 


\section{8 \\ Conclusion}

In this dissertation, I explore the fast expansion of $4 \mathrm{G}$ services in Brazil to analyze the effects of mobile broadband in the labor demand, and, more specifically to the demand of tasks. Obtaining the causal effects of mobile broadband is not a simple task: entry of mobile operators is endogenous to the economic conditions of each municipality due to demand reasons. Therefore, even two-way fixed effects estimators may be biased, since there are unit-specific time-varying characteristics that may affect both labor market outcomes and the presence of $4 \mathrm{G}$ mobile operators. I use mobile operators' provision commitments with the Brazilian regulatory agency as an instrument for the mobile broadband expansion.

The mobile broadband expansion causes a strong reduction in formal employment contracts in Brazil. This is mainly driven by strong displacement effects, but mobile broadband is also associated with reduced gross turnover of the formal labor-force. Furthermore, these effects are not homogeneous among workers. Mobile broadband effects increase the demand for college graduates and skilled workers. These effects are consistent with routine-biased technological change. Mobile broadband causes a reduction in the demand for routine and manual tasks. Specifically, there is a significant reduction in routine manual tasks and an increased demand for non-routine interactive work.

Within shifts in the demand for tasks are concentrated in high-school graduates, although those with no or partial high-school education also experience a reduction in the demand for manual tasks. Mobile broadband differently affects industries across the tech-intensity distribution. Particularly, effects are concentrated in the extremes of the distribution. The effects in sectors with very strong computer use are very similar to the ones observed in leading developed countries Goos et al. (2014), with increased demand for nonroutine interactive tasks, skilled workers, and college graduates. Industries in the bottom of tech-intensity distribution present a more nuanced version of the routinization hypothesis, similar to what Fonseca et al. (2018) observe in Portugal: there is a decrease in routine manual tasks but not only non-routine tasks are more demanded. There is also an increase in routine cognitive tasks.

Moreover, I find suggestive evidence that mobile broadband can be 
associated with job polarization among workers in local labor markets that were early receivers of $4 \mathrm{G}$ technology in Brazil. For this group of workers, relative to late receivers, there is an increase in the share of percentiles in the top of the skill distribution and an increase in the bottom, concentrated in low-skilled occupations that are relatively less intensive in routine manual tasks.

This evidence shows that, while fostering mobile broadband technologies, policymakers in emerging economies ought to be careful about the potential redistributing and displacement effects. Mobile broadband is a labor-saving technology and its effects are concentrated routine manual tasks, while its main complementarities reside with skilled workers. Unfortunately, I'm not able to consider the effects of mobile broadband in the informal workforce. Exploring PNAD and other surveys could offer a new potential frontier for research. 


\section{Bibliography}

ACEMOGLU, D.; AUTOR, D.. Skills, tasks and technologies: Implications for employment and earnings. In: HANDBOOK OF LABOR ECONOMICS, volumen 4, p. 1043-1171. Elsevier, 2011.

ACEMOGLU, D.; RESTREPO, P.. Robots and Jobs: Evidence from US Labor Markets. Journal of Political Economy, 128(6):2188-2244, 2020.

AKERMAN, A.; GAARDER, I. ; MOGSTAD, M.. The skill complementarity of broadband internet. The Quarterly Journal of Economics, 130(4):17811824, 2015.

ATASOY, H.. The effects of broadband internet expansion on labor market outcomes. ILR Review, 66(2):315-345, 2013.

AUTOR, D. H.; KATZ, L. F. ; KEARNEY, M. S.. Trends in us wage inequality: Revising the revisionists. The Review of economics and statistics, 90(2):300-323, 2008.

AUTOR, D. H.; LEVY, F. ; MURNANE, R. J.. The skill content of recent technological change: An empirical exploration. The Quarterly journal of economics, 118(4):1279-1333, 2003.

AUTOR, D. H.; PRICE, B.. The changing task composition of the us labor market: An update of autor, levy, and murnane (2003). mimeo, 2013.

AUTOR, D. H.; DORN, D.. The growth of low-skill service jobs and the polarization of the us labor market. American Economic Review, 103(5):1553-97, 2013.

BAHIA, K.; CASTELLS, P.; CRUZ, G.; MASAKI, T.; PEDRÓS, X.; PFUTZE, T.; RODRÍGUEZ-CASTELÁN, C. ; WINKLER, H.. The welfare effects of mobile broadband internet: Evidence from nigeria. Technical report, The World Bank, 2020.

BESSONE, P.; CAMPANTE, F.; FERRAZ, C. ; SOUZA, P.. Internet access, social media, and the behavior of politicians: Evidence from brazil. Working Paper, 2020. 
BHULleR, M.; KOSTOL, A. R. ; VIGTEL, T. C.. How Broadband Internet Affects Labor Market Matching. IZA Discussion Papers 12895, Institute of Labor Economics (IZA), Jan. 2020.

BLACK, S. E.; SPITZ-OENER, A.. Explaining women's success: technological change and the skill content of women's work. The Review of Economics and Statistics, 92(1):187-194, 2010.

BULLA, A.. Essays on wage inequality in developing countries. PhD thesis, Universitat Autònoma de Barcelona,, 2014.

BÖHM, M. J.. The price of polarization: Estimating task prices under routine-biased technical change. Quantitative Economics, 11(2):761-799, 2020.

CHUN, N.; TANG, H.. Do Information and Communication Technologies Empower Female Workers? Firm-Level Evidence from Viet Nam. ADB Economics Working Paper Series 545, Asian Development Bank, May 2018.

CORSEUIL, C. H.; POOLE, J. P. ; ALMEIDA, R. K.. The impact of digital technologies on worker tasks: Do labor policies matter? Technical Report 234, IPEA, 2018.

COSTA, F.; GARRED, J. ; PESSOA, J. P.. Winners and losers from a commodities-for-manufactures trade boom. Journal of International Economics, 102:50-69, 2016.

DIX-CARNEIRO, R.; KOVAK, B. K.. Trade liberalization and the skill premium: A local labor markets approach. American Economic Review, 105(5):551-57, 2015.

DIX-CARNEIRO, R.; SOARES, R. R. ; ULYSSEA, G.. Economic shocks and crime: Evidence from the brazilian trade liberalization. American Economic Journal: Applied Economics, 10(4):158-95, 2018.

DUTZ, M. A.; ALMEIDA, R. K. ; PACKARD, T. G.. The jobs of tomorrow: technology, productivity, and prosperity in Latin America and the Caribbean. The World Bank, 2018.

FERNANDES, A. M.; MATTOO, A.; NGUYEN, H. ; SCHIFFBAUER, M.. The internet and Chinese exports in the pre-ali baba era. Journal of Development Economics, 138(C):57-76, 2019.

FOGG, I.. The state of wifi vs mobile network experience as $5 \mathrm{~g}$ arrives. In: TECHNICAL REPORT. OpenSignal, 2018. 
FONSECA, T.; LIMA, F. ; PEREIRA, S. C.. Job polarization, technological change and routinization: Evidence for portugal. Labour Economics, 51:317-339, 2018.

FUNCHAL, B.; SOARES, J.. Understanding demand for skills after technological trade liberalization. Vitória: Fucape, 2013.

GOLDSMITH-PINKHAM, P.; SORKIN, I. ; SWIFT, H.. Bartik instruments: What, when, why, and how. American Economic Review, 110(8):25862624, 2020.

GONZAGA, G.; GUANZIROLI, T.. Returns to experience across tasks: evidence from brazil. Applied Economics Letters, 26(20):1718-1723, 2019.

GOODMAN-BACON, A.. Difference-in-differences with variation in treatment timing. Working Paper 25018, National Bureau of Economic Research, September 2018.

GOOS, M.; MANNING, A. ; SALOMONS, A.. Explaining job polarization: Routine-biased technological change and offshoring. American economic review, 104(8):2509-26, 2014.

GORDON, R. J.. The demise of us economic growth: restatement, rebuttal, and reflections. Technical report, National Bureau of Economic Research, 2014.

GRANJA, J.. Regulation and service provision in dynamic oligopoly: Evidence from mobile telecommunications. Job Market Paper, 2021.

HJORT, J.; POULSEN, J.. The arrival of fast internet and employment in africa. American Economic Review, 109(3):1032-79, 2019.

KATZ, L. F.; MURPHY, K. M.. Changes in relative wages, 1963-1987: supply and demand factors. The quarterly journal of economics, 107(1):3578, 1992.

MALONEY, W. F.; MOLINA, C.. Are automation and trade polarizing developing country labor markets, too? World Bank Policy Research Working Paper, (7922), 2016.

PAUNOV, C.; ROLLO, V.. Has the internet fostered inclusive innovation in the developing world? World Development, 78:587-609, 2016.

POLIQUIN, C. W.. The wage and inequality impacts of broadband internet. Technical report, Job Market Paper, University of California, Los Angeles, 2020. 
PORCHER, C.. Migration with costly information. Technical report, Working Paper, Princeton, 2020.

RIVA, F. L. R.. Computerization, occupational tasks and the labor market: evidence from a natural experiment in brazil, 2016.

SPITZ-OENER, A.. Technical change, job tasks, and rising educational demands: Looking outside the wage structure. Journal of labor economics, 24(2):235-270, 2006.

SULZBACH, V. N.. Essays on job polarization in the brazilian labor market. PhD thesis, Universidade Federal do Rio Grande do Sul, 2020.

SUN, L.; ABRAHAM, S.. Estimating Dynamic Treatment Effects in Event Studies with Heterogeneous Treatment Effects. Papers 1804.05785, arXiv.org, Apr. 2018.

VIOLLAZ, M.; WINKLER, H. J.. Does the Internet Reduce Gender Gaps?

: The Case of Jordan. Policy Research Working Paper Series 9183, The World Bank, Mar. 2020.

ZUO, G. W.. Wired and hired: Employment effects of subsidized broadband internet for low-income americans. American Economic Journal: Economic Policy, 2019. 


\section{Appendix}

\section{A.1 \\ Occupational matching}

Reduced quality of matching between RAIS data and task-content measures can bring problems to the identification strategy. Observable shifts in task-content may not represent real shifts. For example, if a group of identified workers in a routine-intense occupation were actually moving to similar routine-intense occupations that are not identified, observed shifts in task content will not be representative of actual shifts. Nonetheless, if that was the case, when the quality of matching decreases, then we should expect that there would be a "break" in differences in observable characteristics starting in 2013, since the tasks composition of these matched and unmatched groups would change. Alternatively, if observable characteristics among them moved in parallel trends, there would be little indication that the quality of matching is the main factor moving differences in task-composition. Hence, one indication that shifts in observable task content shifts are not totally representative of real shifts in task content is if observed differences among unmatched and matched started to significantly increase or reduce the share of matched workers starting from 2013.

Evidence, if anything, is mixed. There are some changes in differences among the two groups for some observable characteristics but not all of them. In figures A.1, A.2, A.3, and A.4, I exhibit plots of average wages, share of employed in December 31st, the (separation + hiring)/ contracts ratio (an approximation of turnover), and the share of temporary contracts, respectively. Non-matched workers tend have higher salaries, higher employment in the end of the year, reduced turnover, and less temporary contracts. Visually, the two groups seem to move in parallel trends even after the fall in quality in 2013, but employment and turnover differences tend to decrease a little. However, differences in wages between the two groups is stable after 2013, while the differences in temporary contracts is very stable across all years, averaging out 2 p.p. Hence, it is not clear that there is convergence or divergence among these two groups and that the matched RAIS-task content data is not 
providing a trustworthy picture of share of tasks.

Figure A.1: Average wage by sample groups (RAIS subsample matched with task-content vs RAIS subsample unmatched)

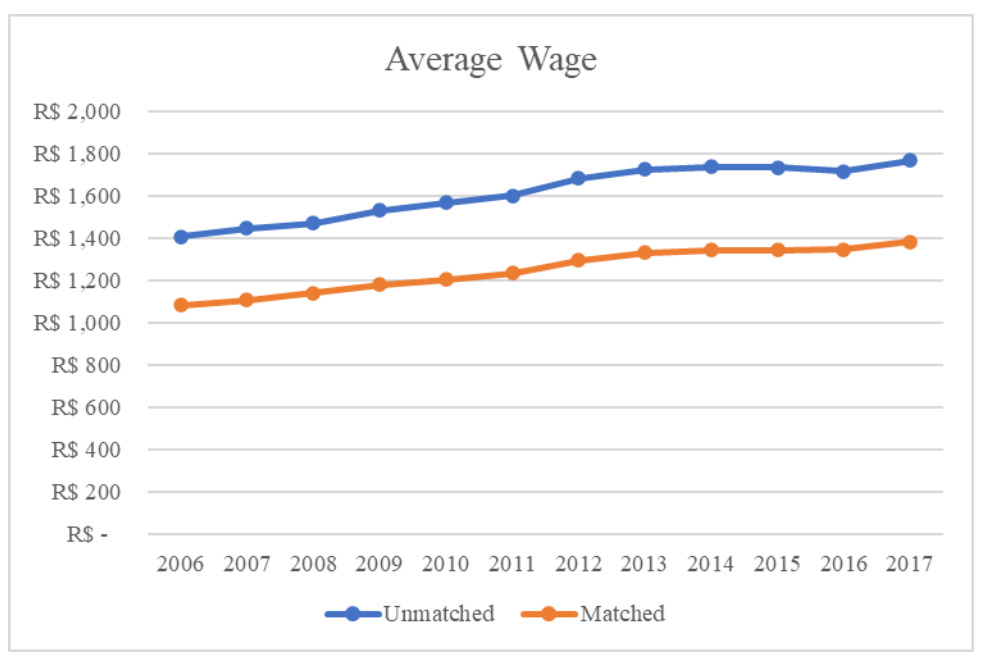

Figure A.2: Share of employment in December, $31^{\text {st }}$ (RAIS subsample matched with task-content vs RAIS subsample unmatched)

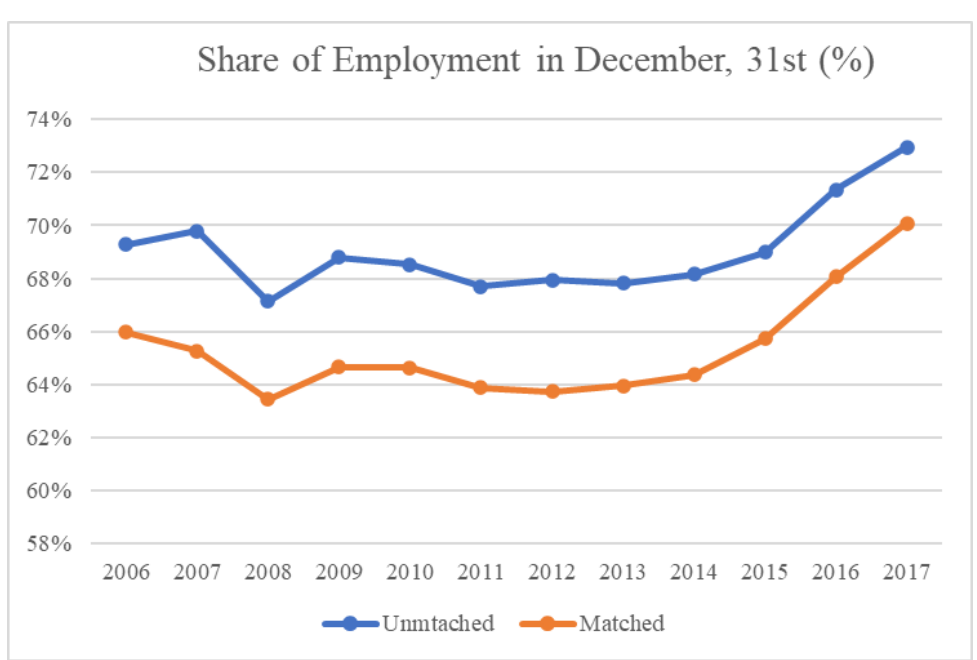


Figure A.3: (Separation + Hires)-Contracts Ratio (RAIS subsample matched with task-content vs RAIS subsample unmatched)

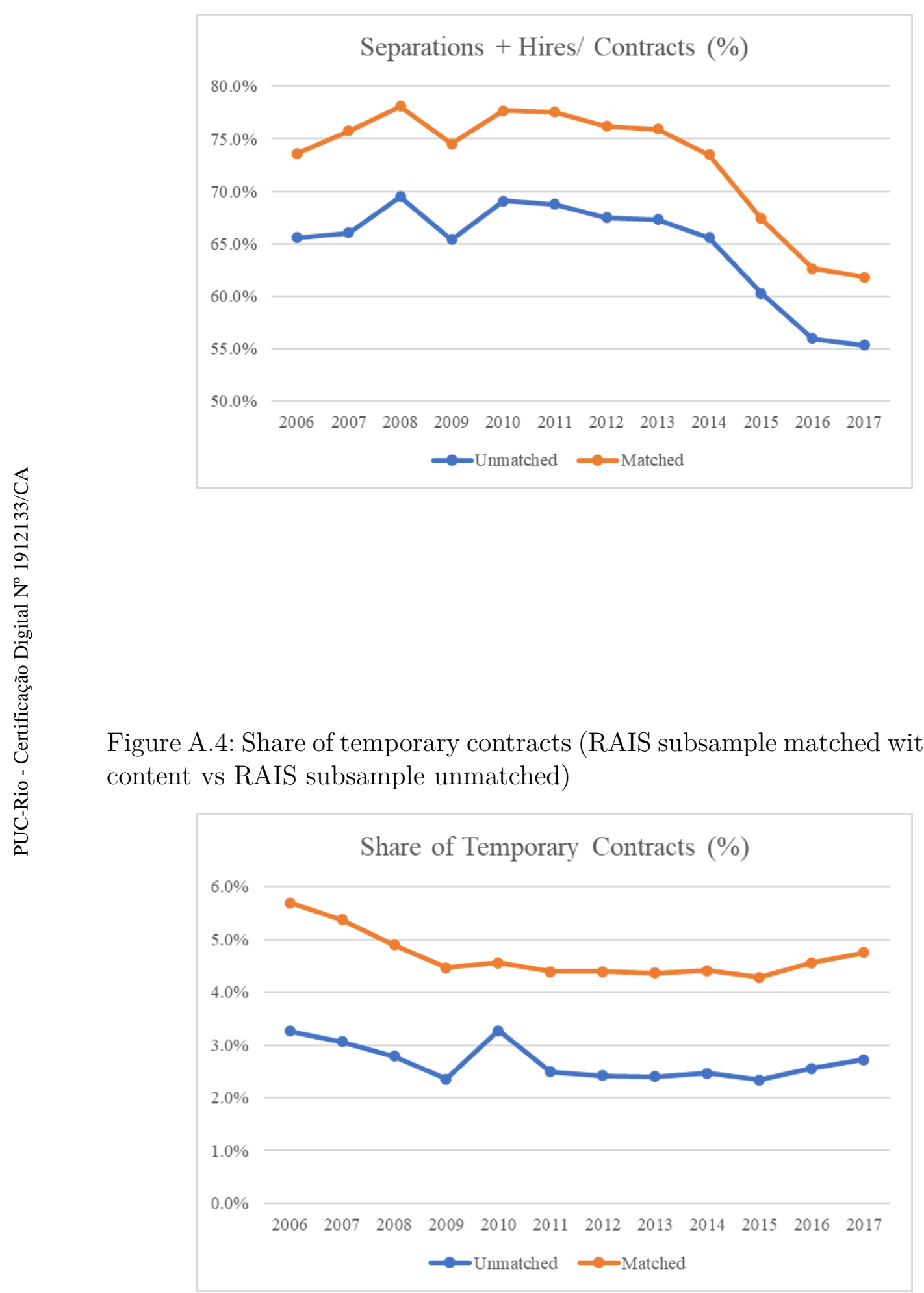




\section{A. 2}

First-Stage: other outcomes

Table A.1: Effects of ANATEL Rules on 4G connectivity

\begin{tabular}{|c|c|c|c|c|c|}
\hline & \multicolumn{5}{|c|}{ Dependent variable: } \\
\hline & \multicolumn{3}{|c|}{ Share of People Covered by $4 \mathrm{G}(\%)$} & \multicolumn{2}{|c|}{ 4G Access per Capita } \\
\hline & $(1)$ & $(2)$ & $(3)$ & $(4)$ & $(5)$ \\
\hline $\mathrm{YfC} \times 2014$ & & & & $\begin{array}{l}-0.263 \\
(0.521)\end{array}$ & $\begin{array}{l}-0.290 \\
(1.262)\end{array}$ \\
\hline YfC $\times 2015$ & $\begin{array}{c}-23.284^{* * *} \\
(1.027)\end{array}$ & $\begin{array}{c}-22.181^{* * *} \\
(2.735)\end{array}$ & $\begin{array}{c}-21.152^{* * *} \\
(2.551)\end{array}$ & $\begin{array}{c}-1.158^{* * *} \\
(0.439)\end{array}$ & $\begin{array}{l}-1.540 \\
(1.065)\end{array}$ \\
\hline YfC × 2016 & $\begin{array}{c}-24.139^{* * *} \\
(1.240)\end{array}$ & $\begin{array}{c}-19.745^{* * *} \\
(2.838)\end{array}$ & $\begin{array}{c}-17.216^{* * *} \\
(2.522)\end{array}$ & $\begin{array}{c}-3.305^{* * *} \\
(0.433)\end{array}$ & $\begin{array}{c}-4.745^{* * *} \\
(1.053)\end{array}$ \\
\hline $\mathrm{YfC} \times 2017$ & $\begin{array}{c}-18.688^{* * *} \\
(1.462)\end{array}$ & $\begin{array}{c}-14.532^{* * *} \\
(3.157)\end{array}$ & $\begin{array}{c}-14.237^{* * *} \\
(2.801)\end{array}$ & $\begin{array}{c}-5.573^{* * *} \\
(0.847)\end{array}$ & $\begin{array}{c}-8.640^{* * *} \\
(2.049)\end{array}$ \\
\hline Unit-Specific FE & $\mathrm{X}$ & $\mathrm{X}$ & $\mathrm{X}$ & $\mathrm{X}$ & $\mathrm{X}$ \\
\hline Year FE & $\mathrm{X}$ & $\mathrm{X}$ & $\mathrm{X}$ & $\mathrm{X}$ & $\mathrm{X}$ \\
\hline $\log \left(\operatorname{Pop}_{2010}\right) \times Y$ & & $\mathrm{X}$ & $\mathrm{X}$ & & $\mathrm{X}$ \\
\hline$\#$ Munic $\times \mathrm{Y}$ & & $\mathrm{X}$ & $\mathrm{X}$ & & $\mathrm{X}$ \\
\hline State Trends & & & $\mathrm{X}$ & & $\mathrm{X}$ \\
\hline Observations & 1,925 & 1,925 & 1,925 & 200 & 200 \\
\hline Adjusted $\mathrm{R}^{2}$ & 0.866 & 0.870 & 0.896 & 0.964 & 0.965 \\
\hline
\end{tabular}

All models control for local labor markets and years fixed effects. Regressions are weighted by the level of contracts in 2013. All columns are OLS estimates. Robust standard errors, clustered at the meso-region level for columns (1) to (3). Coefficients and standard deviations are multiplied by a hundred. Numbers between parenthesis are the coefficient standard deviations. $\log \left(\mathrm{Pop}_{2010}\right) \times \mathrm{Y}$ represents the trend-effects of the log-population of 2010 (yearly dummies interacted with this variable). \# Munic $\times$ Y represents the trend-effects of the number of municipalities in local labor markets (yearly dummies interacted with this variable). ${ }^{*}$ represents significance at the $10 \%$ level, ${ }^{* *}$ represents significance at the $5 \%$ level, and $* * *$ represents significance at the $1 \%$ level. 


\section{A.3 \\ Extra robustness checks}

Table A.2: Effects of $4 \mathrm{G}$ (Controlling for previous routine trends)

\begin{tabular}{lcccc}
\hline \hline & \multicolumn{4}{c}{ Dependent variable: } \\
\cline { 2 - 5 } & $\log ($ Contracts $)$ & Routine & Manual & Skill Index \\
& $(1)$ & $(2)$ & $(3)$ & $(4)$ \\
\hline \# of 4G Operators & $-3.886^{* * *}$ & $-0.570^{* * *}$ & $-0.955^{* * *}$ & $0.161^{* *}$ \\
& $(0.909)$ & $(0.165)$ & $(0.280)$ & $(0.062)$ \\
\hline Original Specification & -3.925 & -0.579 & -0.951 & 0.166 \\
\hline Local Markets FE & $\mathrm{X}$ & $\mathrm{X}$ & $\mathrm{X}$ & $\mathrm{X}$ \\
Year FE & $\mathrm{X}$ & $\mathrm{X}$ & $\mathrm{X}$ & $\mathrm{X}$ \\
log(Pop & $\mathrm{X}$ & $\mathrm{X}$ & $\mathrm{X}$ & $\mathrm{X}$ \\
\# Munic $\times \mathrm{Y}$ & $\mathrm{X}$ & $\mathrm{X}$ & $\mathrm{X}$ & $\mathrm{X}$ \\
State Trends & $\mathrm{X}$ & $\mathrm{X}$ & $\mathrm{X}$ & $\mathrm{X}$ \\
Observations & 1,925 & 1,925 & 1,925 & 1,925 \\
Adjusted $\mathrm{R}^{2}$ & 0.998 & 0.975 & 0.961 & 0.980 \\
\hline \hline
\end{tabular}

All models control for local labor markets and years fixed effects. Regressions are weighted by the level of contracts in 2013. All columns are IV estimates. Robust standard errors are clustered at the meso-region level. Numbers between parenthesis are the coefficient standard deviations. In column (1), coefficients and standard deviations are multiplied by a hundred. $\log \left(\mathrm{Pop}_{2010}\right) \times$ Y represents the trend-effects of the log-population of 2010 (yearly dummies interacted with this variable). \# Munic $\times$ Y represents the trend-effects of the number of municipalities in local labor markets (yearly dummies interacted with this variable). * represents significance at the $10 \%$ level, $* *$ represents significance at the $5 \%$ level, and *** represents significance at the $1 \%$ level. 
Table A.3: Effects of 4G (Controlling for previous manual trends)

\begin{tabular}{lcccc}
\hline \hline & \multicolumn{4}{c}{ Dependent variable: } \\
\cline { 2 - 5 } & $\log ($ Contracts $)$ & Routine & Manual & Skill Index \\
& $(1)$ & $(2)$ & $(3)$ & $(4)$ \\
\hline \# of 4G Operators & $-3.918^{* * *}$ & $-0.586^{* * *}$ & $-0.904^{* * *}$ & $0.169^{* *}$ \\
& $(0.920)$ & $(0.173)$ & $(0.273)$ & $(0.067)$ \\
\hline Original Specification & -3.925 & -0.579 & -0.951 & 0.166 \\
\hline Local Markets FE & $\mathrm{X}$ & $\mathrm{X}$ & $\mathrm{X}$ & $\mathrm{X}$ \\
Year FE & $\mathrm{X}$ & $\mathrm{X}$ & $\mathrm{X}$ & $\mathrm{X}$ \\
log(Pop 2010$) \times \mathrm{Y}$ & $\mathrm{X}$ & $\mathrm{X}$ & $\mathrm{X}$ & $\mathrm{X}$ \\
\# Munic $\times \mathrm{Y}$ & $\mathrm{X}$ & $\mathrm{X}$ & $\mathrm{X}$ & $\mathrm{X}$ \\
State Trends & $\mathrm{X}$ & $\mathrm{X}$ & $\mathrm{X}$ & $\mathrm{X}$ \\
Observations & 1,925 & 1,925 & 1,925 & 1,925 \\
Adjusted $\mathrm{R}^{2}$ & 0.998 & 0.975 & 0.962 & 0.979 \\
\hline \hline
\end{tabular}

All models control for local labor markets and years fixed effects. Regressions are weighted by the level of contracts in 2013. All columns are IV estimates. Robust standard errors are clustered at the meso-region level. Numbers between parenthesis are the coefficient standard deviations. In column (1), coefficients and standard deviations are multiplied by a hundred. $\log \left(\mathrm{Pop}_{2010}\right) \times$ Y represents the trend-effects of the log-population of 2010 (yearly dummies interacted with this variable). \# Munic $\times \mathrm{Y}$ represents the trend-effects of the number of municipalities in local labor markets (yearly dummies interacted with this variable). * represents significance at the $10 \%$ level, ${ }^{* *}$ represents significance at the $5 \%$ level, and $* * *$ represents significance at the $1 \%$ level. 


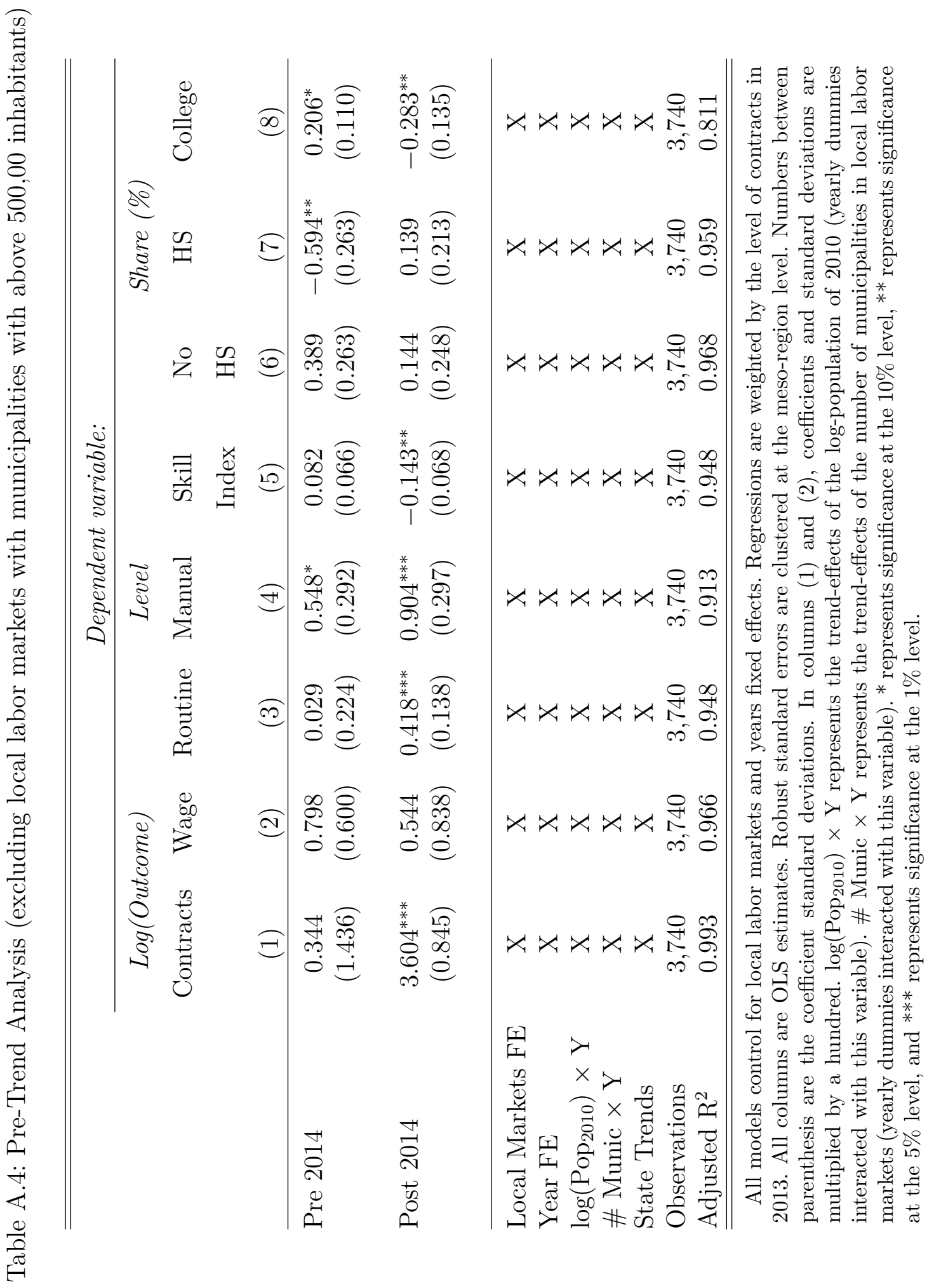


Figure A.5: Pre-trend analysis of reduced-form effects of ANATEL's average years for compliance on local labor market outcomes. (95\% Confidence Interval)
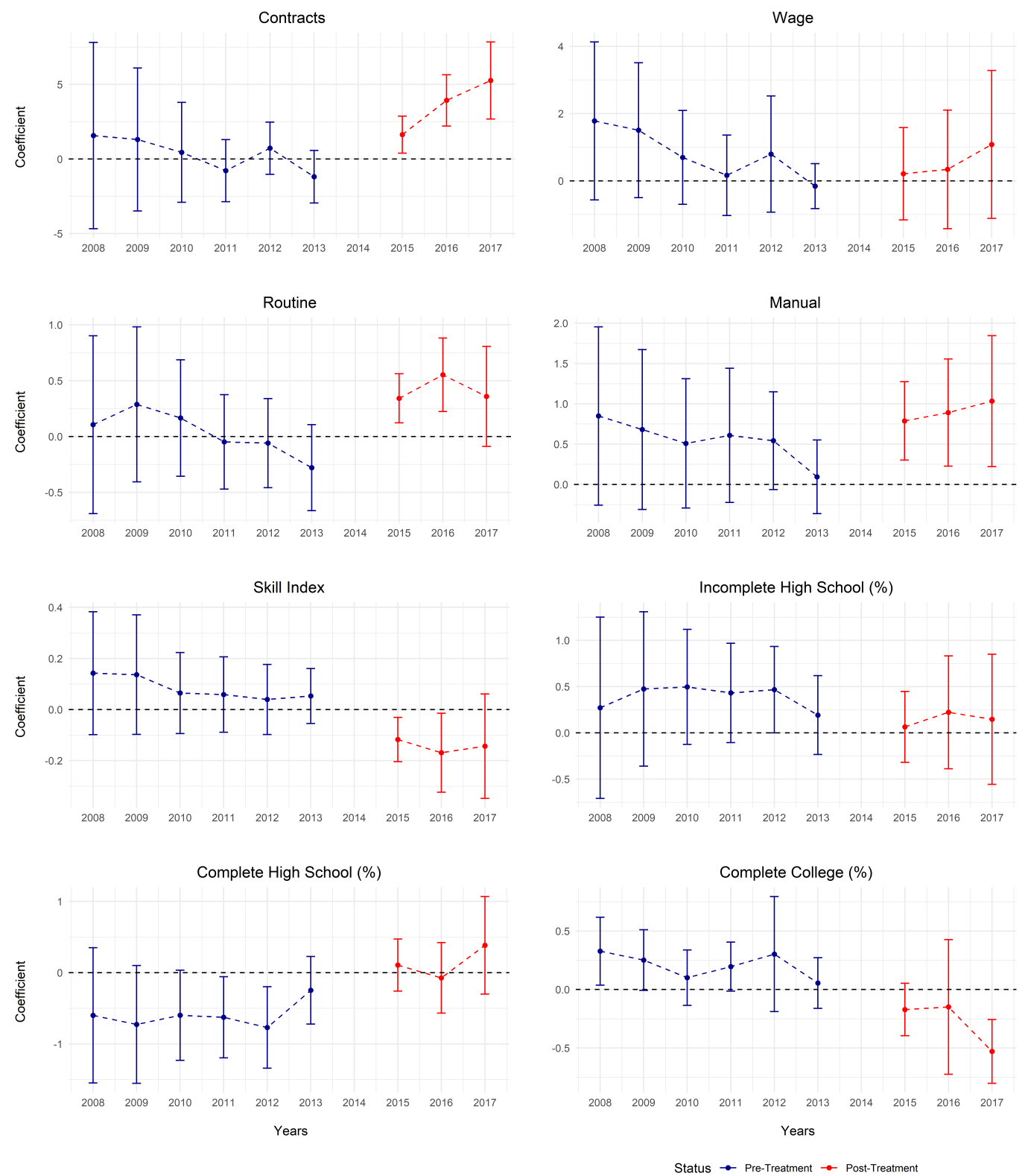

Source: Local labor market data from RAIS. Each coefficient represents the OLS coefficients of the ANATEL rules interacted with dummies for each year. All reduced-form regressions control for trend effects of state-specific factors, population size, and political fragmentation. Error bar indicates the $95 \%$ confidence interval. Robust standard errors are clustered at the meso-region level. The sample includes 375 microregions. 
Table A.5: Effects of 4G Operators on contracts (Including non-compatible)

\begin{tabular}{|c|c|c|c|c|c|}
\hline & \multicolumn{5}{|c|}{ Dependent variable: } \\
\hline & \multicolumn{5}{|c|}{$\log ($ Contracts $)$} \\
\hline & \multicolumn{3}{|c|}{$O L S$} & \multicolumn{2}{|c|}{$I V$} \\
\hline & $(1)$ & $(2)$ & $(3)$ & $(4)$ & $(5)$ \\
\hline \# of $4 \mathrm{G}$ Operators & $\begin{array}{c}-1.257^{* * *} \\
(0.362)\end{array}$ & $\begin{array}{c}-1.660^{* * *} \\
(0.510)\end{array}$ & $\begin{array}{c}-1.453^{* * *} \\
(0.477)\end{array}$ & $\begin{array}{c}-3.136^{* * *} \\
(0.853)\end{array}$ & $\begin{array}{c}-3.410^{* * *} \\
(0.841)\end{array}$ \\
\hline $\mathrm{F} 4 \mathrm{G}$ & & & & 203.59 & 178.95 \\
\hline Local Markets FE & $\mathrm{X}$ & $\mathrm{X}$ & $\mathrm{X}$ & $\mathrm{X}$ & $\mathrm{X}$ \\
\hline Year FE & $\mathrm{X}$ & $\mathrm{X}$ & $\mathrm{X}$ & $\mathrm{X}$ & $\mathrm{X}$ \\
\hline $\log \left(\operatorname{Pop}_{2010}\right) \times Y$ & & $\mathrm{X}$ & $\mathrm{X}$ & $\mathrm{X}$ & $\mathrm{X}$ \\
\hline$\#$ Munic $\times$ Y & & $\mathrm{X}$ & $\mathrm{X}$ & $\mathrm{X}$ & $\mathrm{X}$ \\
\hline State Trends & & & $\mathrm{X}$ & & $\mathrm{X}$ \\
\hline Observations & 1,925 & 1,925 & 1,925 & 1,925 & 1,925 \\
\hline Adjusted $\mathrm{R}^{2}$ & 0.998 & 0.998 & 0.999 & 0.998 & 0.999 \\
\hline
\end{tabular}

All models control for local labor markets and years fixed effects. Regressions are weighted by the level of contracts in 2013. Columns (1) to (3) are OLS estimates, while Columns (4) to (5) are IV estimates. Robust standard errors are clustered at the mesoregion level. Coefficients and standard deviations are multiplied by a hundred. Numbers between parenthesis are the coefficient standard deviations. $\log \left(\mathrm{Pop}_{2010}\right) \times$ Y represents the trend-effects of the log-population of 2010 (yearly dummies interacted with this variable). \# Munic $\times \mathrm{Y}$ represents the trend-effects of the number of municipalities in local labor markets (yearly dummies interacted with this variable). ${ }^{*}$ represents significance at the $10 \%$ level, ${ }^{* *}$ represents significance at the $5 \%$ level, and ${ }^{* * *}$ represents significance at the $1 \%$ level. 